\title{
On Knowledge Creation and Learning at the Intersection of Product Development and Engineering Education
}

\section{Peter Hallberg}



Linköping Studies in Science and Technology. Dissertation No. 2121

\title{
ON KNOWLEDGE CREATION AND \\ LEARNING AT THE INTERSECTION OF \\ PRODUCT DEVELOPMENT AND \\ ENGINEERING EDUCATION
}

\author{
Peter Hallberg
}


$(\mathrm{cc})$ EY-No 1 This work is licensed under a Creative Commons AttributionNonCommercial 4.0 International License.

https://creativecommons.org/licenses/by-nc/4.0/

Copyright (C) Peter Hallberg, 2021

On Knowledge Creation and Learning at the Intersection of Product Development and Engineering Education

ISBN: 978-91-7929-708-4

ISSN: 0345-7524

Distributed by:

Division of Machine Design

Department of Management and Engineering

Linköping University

SE-581 83 Linköping, Sweden

Printed in Sweden by LiU-Tryck, Linköping, 2021

Cover image: Göran Billeson, 2014

About the cover - It takes some thirty-plus keywords to cover all three fields of knowledge represented in this dissertation, how many can you find? Behind these keywords, in this case literally, we find one expression of their application. The picture was taken during the final event of the introductory CAD course described in paper [II], a course partly designed to provide engineering identity to freshman students through active learning. In addition to corresponding to a number of standards of the CDIO educational framework, the course also comes with a fair amount of joyful learning. 


\section{Abstract}

Today's demands on higher engineering education given the rapid transformation of society are, to say the least, multifaceted. Rapidly increased complexity of technology as well as adaptation to sustainability requirements are causing major transformations and mergers of whole domains of technology that strongly impact current and future engineering workforces within these domains, in particular, the need for new competencies. To adapt to industry demands for engineering competence that fits new constellations of technology domains, providers of advanced engineering training - i.e., engineering faculties - need to inventory their toolbox for ways to support knowledge creation processes.

Product development theory is a central part of many types of academic engineering programs. However, as the product development process itself is a process of knowledge creation, it also has strong relations to theories of learning. This thesis explores the idea that some of the tools of engineering that are also taught at engineering faculties and therefore are familiar to their members can beneficially be applied to the development and management of engineering curricula. This thesis explores the domains of product development theory, engineering education and learning analytics in search of overlapping approaches to knowledge creation.

The outcome of this search, which are also the result of this thesis, is a set of proposed tools, measures, and approaches for the development, management, content, and arrangement of engineering curriculum. The main contributions focus on the use of physical artifacts and their contribution to engineering educational frameworks, such as the Conceiving - Designing Implementing - Operating (CDIO) initiative. For this purpose, the thesis picks up on a previously developed concept of low-cost demonstrators for the establishment of a formalized learning and enabling platform that promotes implementation and execution of the CDIO framework. Furthermore, by adopting a similar approach to product development and learning theory, additional tools are identified and developed for curriculum adaptation, enhancement, and management. In particular, by examining the curriculum from previously unexplored perspectives followed by establishment of novel measurements, this thesis demonstrates how curriculum developers and program managers can increase their insights into the outcomes of their decisions. 


\section{Sammanfattning}

Idag präglas de flesta teknikområden av snabbt ökande komplexitet, hög innovationsgrad, och därtill nya eller skärpta krav på miljömässig hållbarhet. Inte sällan leder ny teknik, eller nya sätt att använda befintlig teknik till att hela teknikområden slås samman, vilket snabbt skapar förändrade behov av kompetens hos de ingenjörer - både nuvarande och framtida - som ska driva utvecklingen vidare. Den här utvecklingen påverkar både krav och förväntningar på dagens ingenjörsutbildning, och för att öka förmågan att snabbt anpassa och tillgodose industrins behov behövs nya verktyg för att effektivt tillhandahålla utbildning av både nya och befintliga ingenjörer.

Produktutvecklingsteori är en central del inom flera akademiska ingenjörsprogram, och eftersom produktutvecklingsprocessen i sig är att betrakta som en process för skapande av kunskap, finns här även starka kopplingar till teorier om lärande. Den här avhandlingen synliggör att vissa av de verktyg och metoder som ingenjörer använder för att utveckla produkter, också kan användas för att skapa, utveckla, administrera och förbättra de förutsättningar under vilka kunskap hos blivande ingenjörer skapas, det vill säga utbildningens organisation och genomförande. Avhandlingen söker överbrygga tre olika teoretiska områden produktutveckling, teorier kring ingenjörsutbildning, och metoder för att analysera lärande - i syfte att söka efter överlappande metoder för att skapa ny kunskap.

Inom ramen för avhandlingen presenteras en uppsättning metoder och verktyg för utveckling och administration av tekniska utbildningsprogram, dess innehåll och arrangemang. De viktigaste resultaten fokuserar på användningen av fysiska artefakter och deras bidrag till ramverk för ingenjörsutbildning, såsom CDIO. För detta ändamål bygger avhandlingen vidare på ett tidigare utvecklat koncept för så kallade lågkostnadsdemonstratorer, i syfte att skapa en formaliserad plattform för lärande vilken även främjar implementering och genomförande av CDIO-ramverket. Genom att använda ett liknande tillvägagångssätt, det vill säga att kombinera produktutvecklings-teori med teorier om lärande, identifierar och utvecklar avhandlingen ytterligare verktyg som kan användas för anpassning, förbättring och administration av ingenjörsprogram. Genom att undersöka ingenjörsutbildningar från tidigare outforskade perspektiv och därtill applicera nya typer av mätetal, visar avhandlingen även hur läroplansutvecklare och programansvariga kan erhålla fördjupad förståelse av effekterna av sina beslut. 


\section{Acknowledgements}

The work with this thesis has been both joyful and challenging, and many people have supported me along the way. There are, however, a few special thanks that needs to be expressed:

To professor Johan Ölvander, my main supervisor, for . . . well, everything. Your experience and ability to guide with patience and encouragement has been of uttermost value.

To my co-supervisors Jonas Detterfelt and Kerstin Johansen, for constructive criticism, valuable input, and careful proofreading in the writing process.

To the Department of Management and Engineering, where this thesis was carried out, for facilitating the research, both economically and practically.

To former and current employees at the Division of Machine Design, and especially Johan Hedbrant, for being such a wandering encyclopedia and general source of inspiration and particularly for introducing me to the world of psychometrics and coping measures.

To Stig Algstrand, who first hired me in 2002, and my first supervisor professor, Petter Krus, who gave me the opportunity to pursue a doctoral degree.

To all amanuensis that implicitly have supported my research while easing the workload in my courses. Sometimes, some of you had to step up and take responsibility that was not initially asked for. For that I am not only thankful, but also proud, as I have seen many of you grow with the task - Teodor Johnsson, Maria Andersson, Nils Björklund, Klas Walldén, Carl Karlsson, to name a few. Also, Fabian Lagerstedt and Daniel Krainer - your work on the CEP, the craftmanship and understanding of my intentions were simply key to realize the physical parts of the concept - and Johan Wellander - without your stunning Excel magic required for managing the data of the 2017 case studies, I would probably still be struggling with cells refusing to compute. Also, and not to forget, your work on the PowerApps applications that not only greatly enhanced classroom turn taking in my courses, but also made its way into my research.

To editors and anonymous reviewers, for engaging productively with my work, in particular regarding paper $[\mathrm{VI}]$ and the development of the construct of curriculum nativeness.

To Mr. Smith et al. (of The Cure) for providing what came to be the soundtrack of this thesis (Disintegration).

To my sister, my mother and my late father for always being there. Dad, I really miss you.

Finally, I would like to thank my wife Mathilda and our children, August, Eugen, and Arthur, for the continuous encouragement and support which you have given me and for the many perfectly valid reasons to not be at work. Without you, life would make much less sense and not be anywhere nearly as enjoyable. I love you so much.

Linköping, December 2020. 


\section{Appended papers}

This dissertation is based on the following seven papers, which are appended in chronological order and referred to by their Roman numerals. All papers are printed in their original state with the exception of minor errata and changes in text and figure layout to maintain consistency throughout the thesis.

[I] Hallberg, P, Krus, P, Austrin, L., "Low cost demonstrator as a Mean for Rapid product realization with an Electric Motorcycle Application” ASME 2005 International Design Engineering Technical Conferences \& Computers and Information in Engineering Conference, Long Beach, California, USA, September 24-28, 2005.

[II] Hallberg, P, Ölvander, J., "Hands On Assessment During Computer Aided Design Education" 2012 ASME International Mechanical Engineering Congress and Exposition, Houston, Texas, USA, November 9-15, 2012.

[III] Hallberg, P, "CDIO Enabling Platform as a Catalyst for Course Integration" Proceedings of the 12th International CDIO Conference, Turku University of Applied Sciences, Turku, Finland, June 12-16, 2016.

[IV] Hallberg, P, "Curriculum Adaptation in Eras of Transformation by Utilizing o CDIO Enabling Platform" Proceedings of the 14th International CDIO Conference, Kanazawa Institute of Technology, Kanazawa, Japan, June 28-July 2, 2018

[V] Hallberg, P, Ölvander, J, "Means and Measures for the Benefit of the Persistent Freshman" 7:e Utvecklingskonferensen för Sveriges ingenjörsutbildningar, Luleå tekniska universitet, 27 november - 28 november 2019

[VI] Hallberg, P, Ölvander, J, "Curriculum Nativeness - Measures and Impacts on the Performance of Engineering Students" European Journal of Engineering Education, 2020. Accepted for publication 26 October 2020.

[VII] Hallberg, P, Ölvander, J, "Could Coping Capability be a Measure for Predicting the Performance of Freshman Engineering Students?” Submitted for journal publication. Under review. 


\section{Additional publications}

The following papers and publications are not part of the thesis, but constitute an important part of the background.

[VIII] Hallberg, P., Krus, P., Johansson, B., "Redesigning Mature Products for Sustainability" NordDesign 2006, Reykjavik, Iceland, August 16 - 18, 2006.

[IX] Hallberg, P., Nåbo, M., Krus, P., Skyllermark, S., Atterfors, O., "Modular Design of Sustainable Light Vehicles for Third World Emerging Markets" EVER'2007 International Conference on Ecological Vehicles and Renewable Energies, Monaco, March 29-April 1, 2007.

[X] Hallberg, P., Andersson, H., Nåbo, M., Krus, P., "Modular sustainable light multipurpose vehicle" EET-2008 European Ele-Drive Conference and International Advanced Mobility Forum, Geneva, Switzerland, March 11-13, 2008.

\section{Author contributions}

In papers [I] to [IV] and papers [VIII] to [X], Peter Hallberg is the main author and contributor and responsible for presenting the work and communicating the research findings at scientific conferences, seminars, etc. The co-authors who are listed in papers [I] to [IV] and papers [VIII] to $[\mathrm{X}]$ provided support and feedback on the manuscripts as subject matter experts. In papers [VI] and [VII], Hallberg was responsible for setting up the initial design of the studies, administrating the surveys, processing the data, and conducting analysis and interpretations. For papers [VI] and [VII], Johan Ölvander contributed with analysis and interpretation of the data.

Generally, the research presented in this thesis should be considered as a continuation of the author's licentiate thesis, which was published in 2013 by Linköping University Electronic Press with the title "Low-Cost Demonstrators: Enhancing Product Development with the Use of Physical Representations". In the Swedish academic system, the structure of the licentiate thesis is similar to the structure of the $\mathrm{PhD}$ thesis, and the $\mathrm{PhD}$ candidate is encouraged to write it halfway through his or her studies. It is a summary of the $\mathrm{PhD}$ candidate's work that aims to provide a set of initial answers to the project's research questions. In this light, it should be noted that some elements of this $\mathrm{PhD}$ thesis are based on, and in turn taken from, the licentiate thesis. These include sections of texts and figures that were deemed unnecessary to rephrase and change. The use of text from the licentiate thesis is noted in the beginning of each chapter. 


\section{Abbreviations}

$\begin{array}{ll}\text { CAD } & \text { Computer Aided Design } \\ \text { CAE } & \text { Computer Aided Engineering } \\ \text { CDIO } & \text { Conceive Design Implement Operate } \\ \text { CEP } & \text { CDIO Enabling Platform } \\ \text { EDM } & \text { Educational Data Mining } \\ \text { EE } & \text { Engineering Education } \\ \text { EER } & \text { Engineering Education Research } \\ \text { ESE } & \text { Engineering Self-Efficacy } \\ \text { ESE-D } & \text { Design self-efficacy dimension of ESE } \\ \text { ESE-E } & \text { Experimental self-efficacy dimension of ESE } \\ \text { ESE-G } & \text { General self-efficacy dimension of ESE } \\ \text { ESE-T } & \text { Tinkering self-efficacy dimension of ESE } \\ \text { LCD } & \text { Low-Cost Demonstrator } \\ \text { PD } & \text { Product Development } \\ \text { SE } & \text { Self-Efficacy or General Self Efficacy } \\ \text { SOC } & \text { Sense of Coherence } \\ \text { SOC-C } & \text { Comprehensibility dimension of SOC } \\ \text { SOC-MA } & \text { Manageability dimension of SOC } \\ \text { SOC-ME } & \text { Meaningfulness dimension of SOC }\end{array}$




\section{Contents}

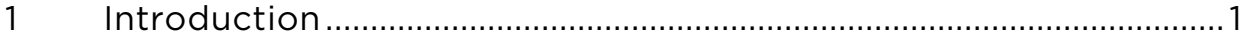

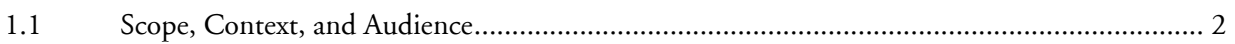

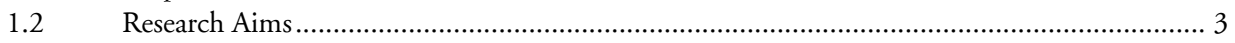

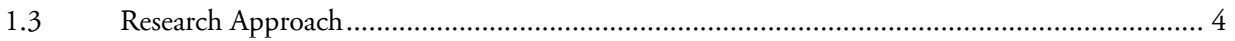

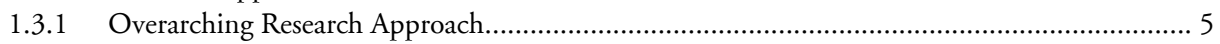

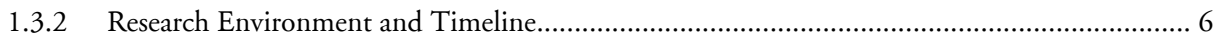

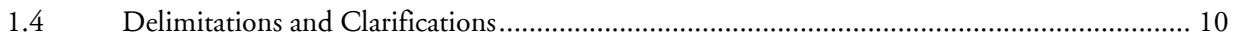

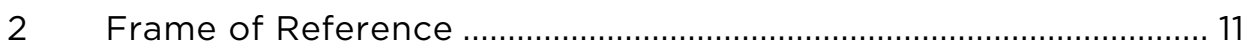

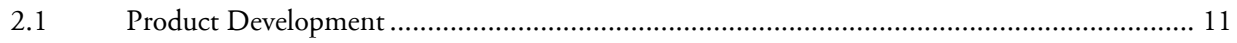

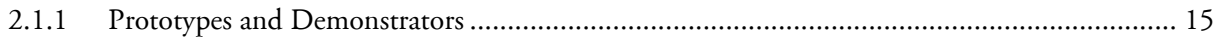

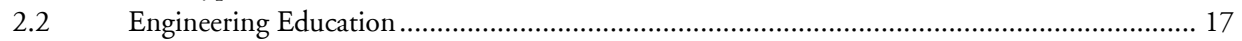

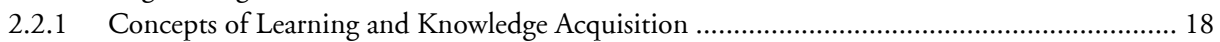

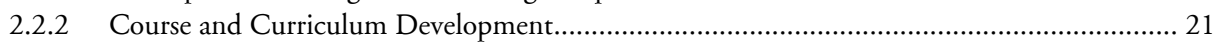

2.2.3 Engineering Educational Frameworks and Practices .............................................................. 25

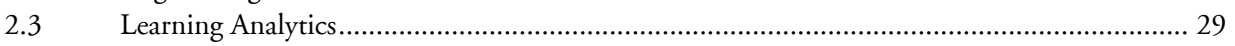

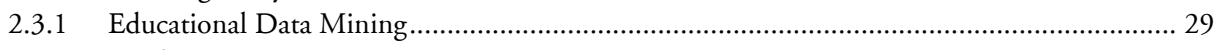

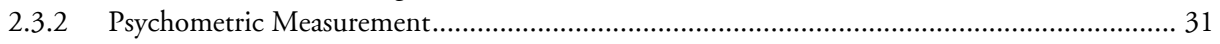

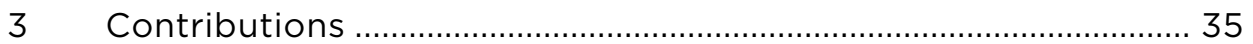

3.1 Knowledge Creating and Learning Processes Supported by Physical Demonstrators ............... 35

3.2 A Physical Platform Approach for Enabling and Implementing Educational Frameworks...... 40

3.3 Measures and Metrics for Supporting Development and Management of EE ........................ 44

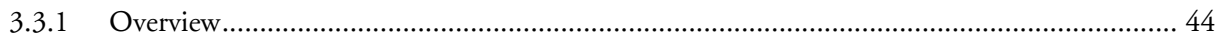

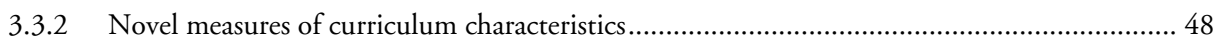

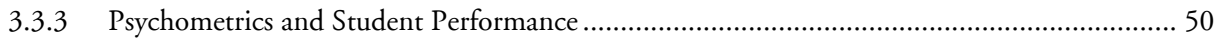

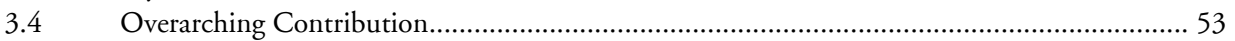

3.4.1 Alignments of Theories of Knowledge Creation and Learning .............................................. 53

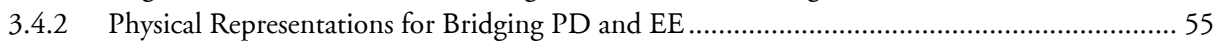

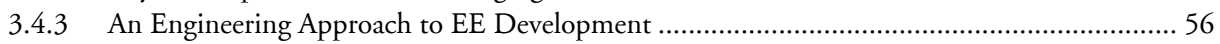

3.4.4 Aspects of Curriculum Nativeness and Engineering Identity ……....................................... 58

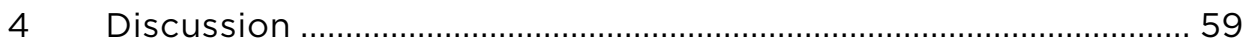

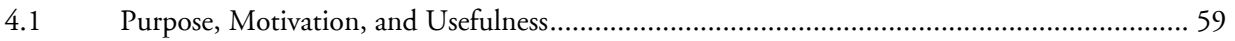

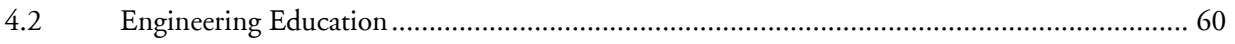

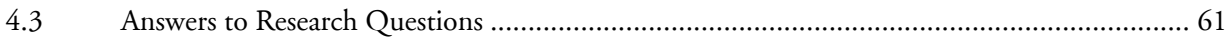

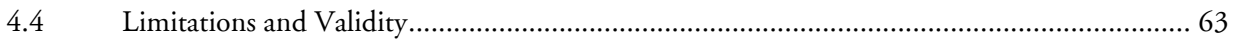

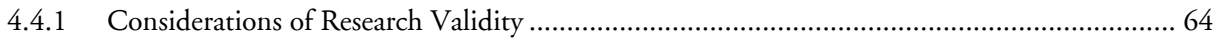

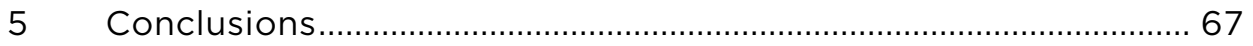

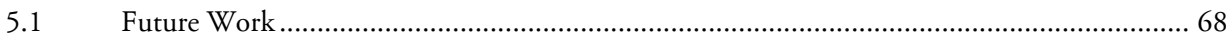

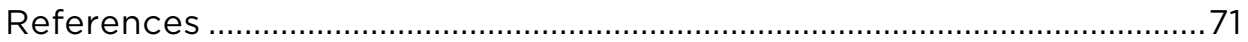





\section{1 \\ Introduction}

Seen from above, one can say that this thesis is justified by two highly interconnected and manmade phenomena - engineering and the transformation of society. The term engineering probably goes back to about $2550 \mathrm{BCE}$ with the first engineer known by name and achievement - Imhotep - builder of the Step Pyramid at Șaqqārah, Egypt (Short, 2009). One can only speculate about Imhotep's perception of the times he lived in. Some 4300 years later, skipping great engineering eras of the Romans, the renaissance, and others, the first industrial revolution took off in Great Britain. Imhotep's colleagues during the $18^{\text {th }}$ and $19^{\text {th }}$ century - great names such as Watt, Cartwright, Hargreaves and Margret E. Knight - were able to reflect over the engineering capabilities of the Egyptian civilization and the ones that followed with a sense of restraining inertia while witnessing the dramatic effect of their own contributions to the field of engineering, and the impact they had on the transformation of society.

Today, no fewer than three industrial revolutions later, we can without speculation conclude that both societal and technological phase of development supersedes everything our engineering pathfinders ever experienced. Refinements of engineering tools have improved dramatically, resulting in enhanced quality, cost-effectiveness, innovation, etc. Among those tools, we find one of the subjects for this thesis - product development (PD) methodology. In addition, contemporary engineering practices have become highly knowledge intensive, demanding that engineers possess the necessary competencies, which in turn highlights another central theme for this thesis - engineering education (EE).

Civil engineering (as opposed to military engineering) emerged as a separate discipline in the $18^{\text {th }}$ century, when the first professional societies and schools of engineering were founded (Smith, 2020). Thus, the development of organized EE is a part of the human progress within the different fields of technology since the $18^{\text {th }}$ century when the first industrial revolution started. In fact, the timespan of all industrial revolutions that followed the first covers the history of organized EE (Jørgensen, 2007). Consequently, EE (among them higher engineering education institutions) must keep up with the developments created by the engineers they train. In practice, EE must adjust to the demands from industry. This interplay of supply and demand 
between institutions and industry has not always been without difficulties, and some have led to major reorganizations in engineering training such as the CDIO initiative - a widespread engineering educational framework that this thesis in part addresses (CDIO Initiative, 2020). Although CDIO was initiated as the result of a mismatch between the way engineering was taught and what industry wanted during the 1990s, this condition can be seen from a more holistic perspective.

In the post-war western world, providers of higher engineering education have predominantly been part of an academic tradition, and there has always been a need for EE institutions to adapt to industry's demands. However, has this task always been the same in terms of feasibility? Of course, this question is as much rhetorical as answerable in the negative. Most faculty members can confirm that their organization is often characterized by stringency, rigidity, tradition, and benevolent reluctance to adapt to industry's needs. The development of technology has gradually resulted in interdisciplinarity and merging of domains. A hundred years ago, there were a handful of fields commonly taught at engineering institutions - e.g., mechanical and civil engineering. Things like biomechanical, mechatronic, or systems engineering were naturally unheard of since these fields had not yet emerged. Today, the list of such disciplines is steadily growing as a result of increased complexity and innovation, and the pace is increasing. This growth implies EE providers need to sharpen their tools and add new tools so they can effectively adapt to these new needs.

For a trained engineer, this reasoning is thrilling news: We have a problem, so let's go fix it. And somewhere here we are homing in on the main purpose of this thesis. As a faculty member engineer, how can I address and manage the challenges I face when developing the engineering curriculum from an engineer's perspective? Moreover, most of the research presented in this thesis has been conducted at Linköping University in a cross-disciplinary research institution also responsible for annually teaching about 9000 engineering students. Indeed, a technical institution involved in both research and education is a suitable setting for raising and exploring adequate questions related to challenges faced both by the industry and the academic institutions who are set to supply the necessary workforce for these businesses to function. The overarching aim of this thesis is to address some of these questions. The following sections provide background, environment descriptions, intentions, as well as research aims.

\subsection{Scope, Context, and Audience}

The area of this dissertation could be defined by referring to different sub-topics within fields of PD, EE, and Learning Analytics (LA), which is also illustrated in Figure 1-1. PD theory generally covers many types of products, both tangible and intangible. Given the research environment described in 1.3.1, the scope of this thesis, within this knowledge area, focuses on development of physical products, which are also subjects for several sub-areas: physical demonstrators, digital prototyping, and computer aided design (and engineering). To further break down the other two knowledge areas, EE primarily targets aspects related to course and curriculum design as well as program management. Much of the work in this area of the thesis relates to existing educational frameworks and practices. Primarily, this thesis focuses on the $\mathrm{CDIO}$ Initiative, an engineering educational framework founded on the premise that $\mathrm{EE}$ and real-world demands on engineers have drifted apart. CDIO principles also encompass much of the learning theory that this dissertation elaborates on - e.g. experiential, active, and integrative learning methods as well as problem-based learning (PBL). Finally, by intersecting the knowledge area of LA, this thesis also connects means of engineering and PD to the functionalities of faculty and engineering program management. In practice, the thesis relates 
to the following areas: educational data mining, social cognitive theory, and psychometrics, and how they support the development of engineering education.

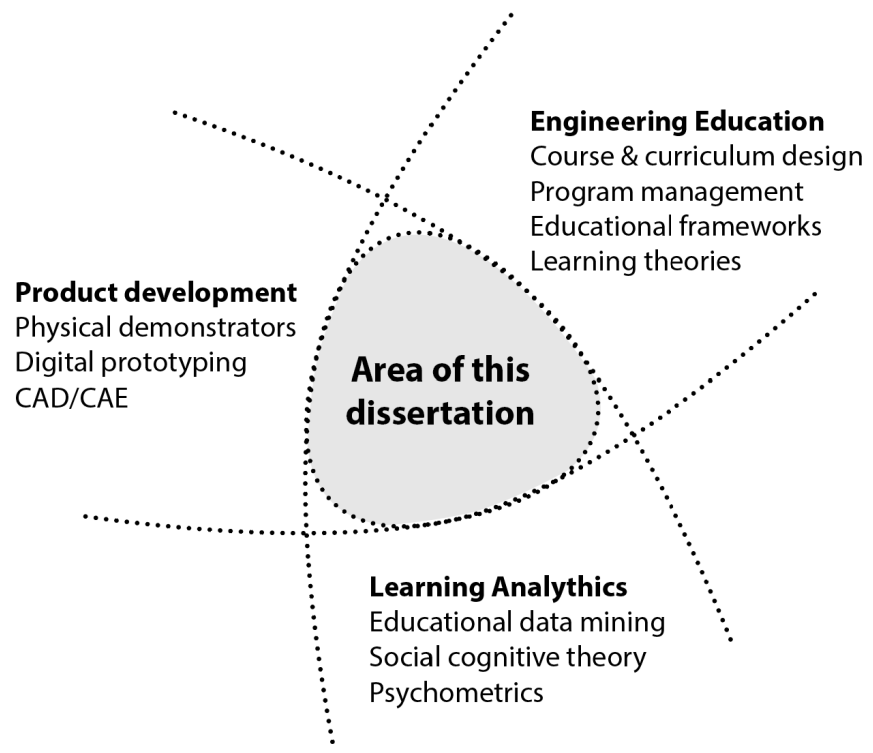

Figure 1-1 Illustration of the area of this dissertation and related primary research fields with sub-areas.

In addition to the above clarification of the thesis' scope, it is also appropriate to briefly make a statement about the context where the research has unfolded and the audience this thesis is directed to. This work targets higher engineering education mainly viewed from a Swedish academic perspective. According to The World Bank, higher education, also known as tertiary education in some countries, refers to "all post-secondary education, including both public and private universities, colleges, technical training institutes, and vocational schools" (2020). However, when referring to higher engineering education, this thesis is referring to organized education leading to an academic degree. Thus, the primary focus is on the educational activities taking place at universities rather than alternative post-secondary learning environments. This focus also suggests the audience for this thesis - primarily members of faculty at universities active in the development, execution, and management of engineering curricula and degree programs.

\subsection{Research Aims}

The research leading to this dissertation has been driven by an endeavor to improve engineering education. Key to understanding the research aims is the observation that EE knowledge creation (in general and within individuals in an educational setting) has a strong resemblance to product development processes. Fundamentally, both of these phenomena aim to generate information and knowledge, albeit for different purposes. In EE, the purpose as well as the outcome of the process is to provide students the required knowledge and skills. For PD, tools and methods are used by team members to gain the necessary knowledge of the developed product so that the PD process will be successful. Also, given the perspectives declared for in the previous section, the EE settings that this thesis target are the ones that to some extent deal 
with development of products, with an emphasis on physical products. Consequently, it is close at hand to pick up the theories and approaches of product development mainly used within the field of mechanical engineering for the purpose of further analysis and synthesis based on resemblances to more general theories of learning.

With reference to this line of thinking, a first principal and overarching research question can be formulated:

[RQ1] What are the relations between product development processes and learning processes in higher engineering education?

Moreover, product development research has been shown, even in era of digitalization, that the use of physical artifacts such as prototypes and demonstrators can ease the development process. Hence, the second research question is formalized:

[RQ2] How can physical representations and artifacts support the creation of new knowledge in both an educational and product development setting?

If further broken down, it is inevitable to reflect on implementation aspects of the physical representations given that they prove beneficial for knowledge creation and learning processes. In the case with the EE settings given by the research environment of this thesis, implementation questions are explored using in place and used CDIO learning frameworks. From this, a third research question is formulated:

[RQ3] How can a physical platform be formalized to support the development of knowledgecreating processes and engineering curriculum execution in a CDIO setting?

Finally, as the thesis attempts to bridge product development and engineering education, a central aspect of product development is the use of metrics and measures to predict the performance of the process and the properties of a product before it reaches the market. Consequently, to apply the same line of thinking in engineering education, the fourth and last research question of the thesis is formulated:

[RQ4] What metrics could be defined to support curriculum development and to monitor student performance?

The four research questions above form the basis of this thesis and will be further examined in relation to the appended papers.

\subsection{Research Approach}

This section details the research approach of this dissertation, the research environment, and a timeline of the research activities performed. The section also provides an overview of the papers written and the applied methodological approaches.

Before elaborating on methodological aspects, the terms used in this dissertation need to be clarified. This thesis focuses on applied research. Applied research "aims at finding a solution for an immediate problem facing a society, or an industrial/business organization, whereas fundamental research is mainly concerned with generalizations and with the formulation of a theory" (Kothari, 2008). The vast majority of the conducted research could be described as case-based research. According to Yin (2014), a case study investigates a contemporary phenomenon in its real-world context, especially when the boundaries between phenomenon and context are not clearly evident. An exploratory case study aims to formulate productive 
research questions regarding a phenomenon, whereas a descriptive case study aims to describe the phenomena (Yin, 2014). A prescriptive counterpart to a descriptive research approach, in context of this thesis, should be seen as active intervention in the studied environment (i.e., the EE environment) followed by observation and analysis. Therefore, the word 'prescriptive' is used with reference to its formal meaning of "saying exactly what must happen, especially by giving an instruction or making a rule" (Cambridge English Dictionary, 2020). Therefore, the conducted research has been characterized by research that alternates between descriptive and prescriptive approaches by means of both qualitative and quantitative tools such as observations, interviews, survey studies, and statistical data analysis. Quantitative methods rely on the collection and analysis of numerical data to describe, predict, or control variables and phenomena of interest (Mills et al., 2009), whereas qualitative research uses non-numerical approaches with the purpose of providing "in-depth, intricate and detailed understanding of meanings, actions, non-observable as well as observable phenomena, attitudes, intentions and behaviors" (Cohen et al., 2017).

Furthermore, some circumstances that have characterized this research connects with so-called action research, which aims to address social and professional challenges in an iterative cycle of action and reflection (Hammond et al., 2012). Action research is a concept that became important in the field of educational research with the work of Carr et al., who describe the approach as "a form of self-reflective enquiry undertaken by participants in social situations in order to improve the rationality and justice of their own practices, their understanding of these practices, and the situations in which the practices are carried out" (2003). In the context of this thesis, part of the research could be labeled action-based given that most research aims to directly target and question the researcher's actions. Moreover, the research has been carried out without separating or distancing from the activity (e.g., teaching, supervising, etc.), which is the subject of the research. This is an approach that typically characterizes action-based research and becomes particularly evident in papers [III] and [IV].

\subsubsection{Overarching Research Approach}

In practice, the majority of the research represented in this dissertation shows strong resemblance to some of the approaches applied within industrial research. One such approach is the so-called industry-as-a-laboratory method, first proposed by Potts (1993) and further described by Muller (2013). The industry-as-a-laboratory methodology uses the actual industrial setting as a test environment. In short, a researcher investigating a new (engineering) method formulates a hypothesis about the application of the new method and then applies it in an industrial setting. The results of this experiment are then observed and used to evaluate the hypothesis, and the process continues in an iterative manner.

Figure 1-2 illustrates an adaptation of Muller's approach to Potts' work so as to mirror the practical research approach for this dissertation. The industrial setting is here replaced by the EE environment, where the continuous operations are viewed (in this case) from a program/faculty management perspective. The approach could thereafter be described as follows, with numerical references to elements of Figure 1-2. Challenging and applicable problem within the EE environment are identified and inspires the researcher to search for solutions (1). The researcher then turns to the engineering education research (EER) community/literature for reference to process the identified problems (2), followed by an establishment of hypothesis (3). The hypothesis is then evaluated and further developed with respect to ERR (4). Next, the researcher once again turns to EER to develop means for testing the hypothesis (2) before being applied on selected subjects within what Muller calls the 
"Application playground" (5), which in this case resemble the elements of the EE environment - e.g., learning operations, courses, programs, group of students, and internal organizations. The effects from the testing are thereafter observed, for example, by means of measurements, surveys, and data collection (6), followed by evaluation and analysis with respect to ERR (4). Based on the outcome of the evaluations, the researcher once again turns to EER (2) to either reformulate the hypothesis (3) or modify and apply updated methods on the application playground (5).

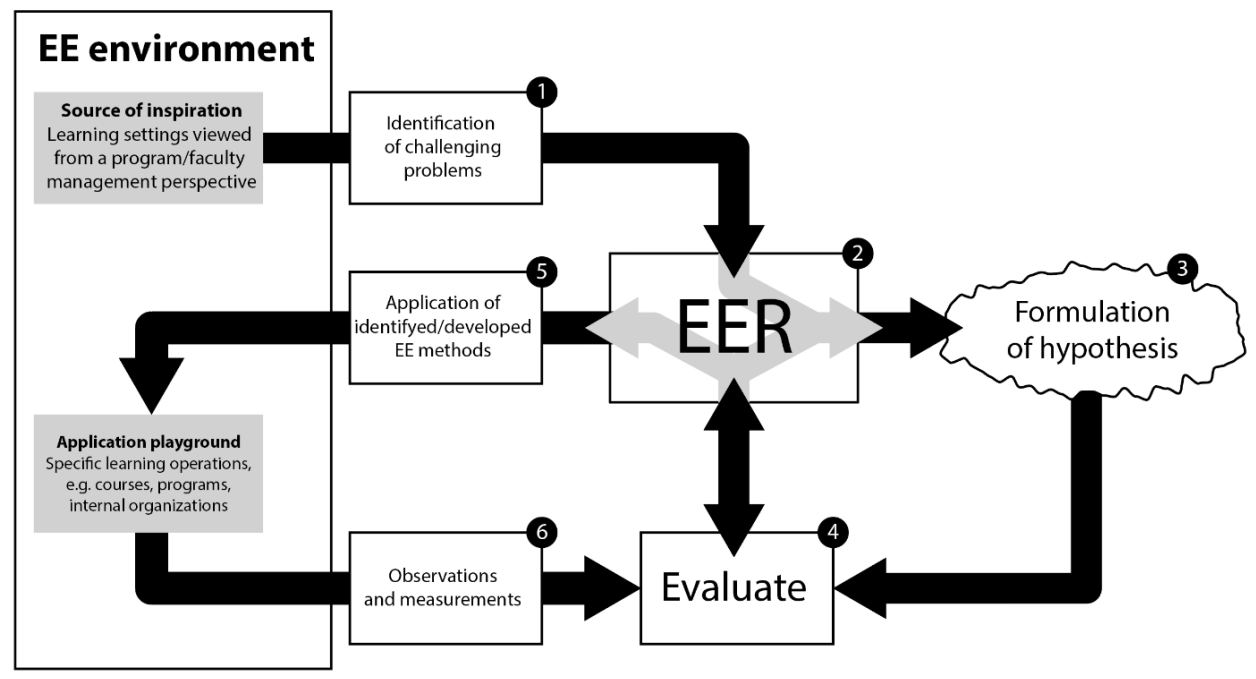

Figure 1-2 Illustration of an adoption of the industry-as-a-laboratory approach (Potts, 1993 and Muller, 2013) to conduct research targeting ongoing operations in an EE environment.

\subsubsection{Research Environment and Timeline}

The activities leading to this thesis could be described in three phases - partly separated and partly overlapping - regarding knowledge domains. Table 1-1 provides an illustrative overview of the time spanned by the following three phases.

\section{First phase}

The journey to this dissertation took off in the early 2000s while I was serving as a junior lecturer at Linköping University, mainly teaching and supervising CAD, CAE, and product development. During this first phase, the progress was characterized by exploratory and descriptive research based on case analysis oriented around and based on observations made from various final year student projects at the department of mechanical engineering. It was exploratory in the sense that formation of the research aims was performed gradually, based on (descriptive) observations within the EE environment together with input from the industrial partners. With reference to Borrego et al. (2009) - whose contribution intends to illustrate the "ways in which educational research methods have been and could be used in engineering education" - this approach aligns with some of the examples Borrego labels as exploratory. However, while Borrego places exploratory studies in a "mixed methods" category, where exploratory research designs usually precede quantitative means, the first phase of this dissertation leans heavily toward being just exploratory and descriptive merely in a nonquantitative sense. 
Table 1-1 Time line detailing the major activities and events significant for this dissertation. White diamonds indicate paper submission, black diamonds indicate acceptance. The three main research phases are indicated by the grey background fields, for which the bottom part of the table respectively declares for the research area of focus, addressed research questions, applied methodological research paradigms and approaches.

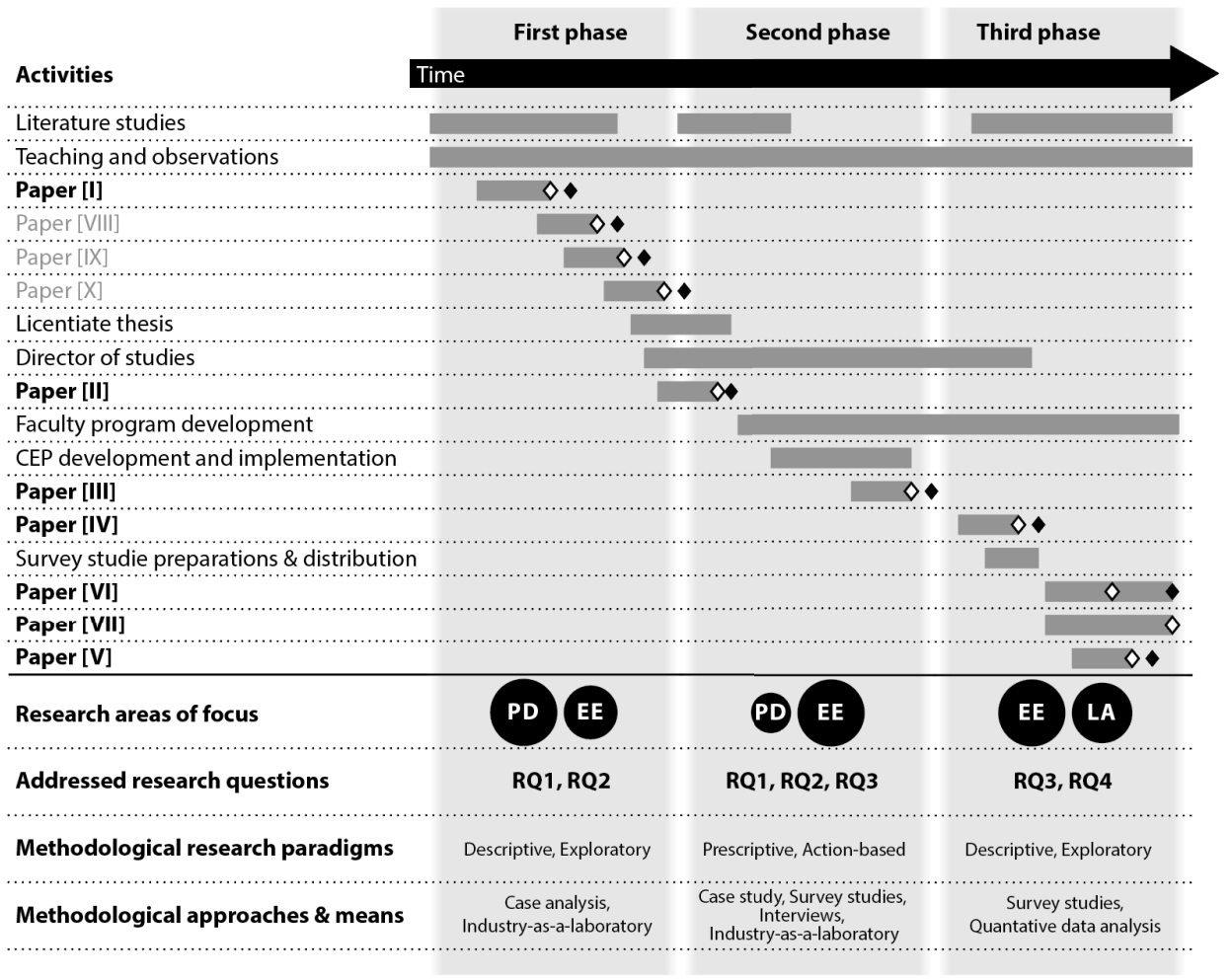

Methodologically, the research activities aligned with the industry-as-a-laboratory approach described in the previous section. Over the years, these projects received substantial influence and support from the industrial partners that were involved (mainly Saab Aerospace), which awoke the interest for physical demonstrators and in particular the concept that eventually was labeled low-cost demonstrators and formed the basis of papers [I], [VIII], [IX], and [X], as well as the licentiate dissertation in 2012. These papers and the licentiate thesis mainly focus on the recognized benefits of using low-cost demonstrators as a catalyst during knowledge-creating processes in both industrial and academic settings. Consequently, the first and second research question is in focus. Moreover, in relation to this dissertation, the research areas in focus during this phase were both product development and engineering education with a slight predominance of the former.

\section{Second phase}

The advent of paper [II] (which was also appended to the licentiate thesis) and the process of writing the licentiate thesis marked the beginning of the second phase, which turned the focus more towards engineering education but still approaching it from a product development perspective. From the licentiate, the research was conducted while serving as a director of studies at the division of Machine Design, and later also while serving on the Machine Design 
educational board as a member of the program committee for the Mechanical Engineering bachelor program. This allowed for in-depth understanding of the functioning and properties of an engineering faculty and the development and management of programs and curricula, which resulted in shifting the research towards these areas. Paper [II] picked up on the experiences from working with low cost demonstrators in the final year student projects and applied them at the opposite end of the curricula - i.e., first year courses. As a result, the research in practice shifted towards didactic aspects of the engineering domain, exemplified in paper [II], when demonstrating the significant effects of introducing physical artifacts and active learning in EE settings. Following the momentum of this shift in research focus, an opportunity emerged to reflect on the role of learning styles commonly used within EE. During the first half of the 2010s, while conducting faculty management services, I had a very useable overview of the activities that contribute to the effectiveness and quality of a higher engineering program. This, together with my interest in the CDIO framework, resulted in contributions that sought to apply previous experiences with physical artifact in EE on the curriculum design level. The outcomes of these efforts are mainly represented by papers [III] and [IV]. The main methodological approaches adopted during this second phase were case studies, survey, and interview studies. Given the that the CDIO Enabling Platform (presented in paper [III]) and the argument of its extended use (presented in paper [IV]) came to be following observations of deficiencies (and possibilities) within the EE environment, the resulting research could be described as action based. The EE literature provides related examples where outspoken action research is deployed with the aim of improving the educational process. For example, Jørgensen et al. (2007) presents a study where engineering students developed Continuous Improvement (CI) and innovation capabilities by action research and methods from experiential learning. Moreover, papers [III] and [IV] constitute research that is primarily prescriptive in nature as these papers deal with attempts of actively influencing the EE environment. Again, altogether, the research outcomes of this phase relate primarily to research questions one, two, and three. Both the first and second phase aligns well with the industry-as-a-laboratory approach described in the previous section.

\section{Third phase}

The third phase of research activities followed from accepting the chair of the program committee responsible for the Mechanical Engineering bachelor program at Linköping University, resulting in an intensified work with program management issues. Consequently, curriculum/program development/management matters play a significant role in papers [V], $[\mathrm{VI}]$, and [VII] and therefore is the field of EE primarily in focus. However, as much of the research activities represented by these papers also elaborate on potential tools and means for measuring properties of the study objects - e.g., students and their progress and curriculum and course characteristics - this phase also focuses on learning analytics (LA). Moreover, these contributions came about from more than just an urge to investigate properties of the existing research environment from an engineer's point of view. Indeed, there were also fundamental and overarching questions about engineering identity and to what extent a curriculum can provide the measures for a better understanding of students' perception of engineering. The origin of these questions was a direct result from both collegial and committee discussions regarding the composition of the above-mentioned bachelor program. The investigation and assessment of tools and methods available for supporting these discussions resulted in the large survey study that was prepared in late 2016 and conducted for the study year 2017/2018. The survey study is mainly the basis for paper [VII], with paper [VI] as a parallel outcome from the preparation work. Targeting the third and fourth research question of this thesis, the research activities of the third phase could best be described as exploratory, particularly considering the 
elaborations on native (course or curriculum) content in paper [VII] with the adjunct attempt of establishing a construct of curriculum nativeness. They could also be characterized as descriptive as the main approach was based on observations using quantitative evaluations. Hence, as opposed to the first phase, this phase fully corresponds with the mixed method/exploratory research paradigm declared for in the aforementioned study of Borrego et al. (2009):

Exploratory designs begin with a primary qualitative phase, then the findings are validated or otherwise informed by quantitative results. This approach is usually employed to develop a standardized (quantitative) instrument in a relatively unstudied area. The qualitative phase identifies important factors, while the quantitative phase applies them to a larger and/or more diverse sample. (Creswell and Plano Clark, 2007)

\section{Methodological Considerations}

As previously stated, the research reported in this dissertation was conducted while serving as a teacher at the faculty of science and engineering at Linköping University, a technical institution responsible for developing and providing EE at basic and advanced level. Given that I had a strong relation to the academy and the fact that the research targets the academy itself, it should inherently be classified as applied research.

Moreover, this thesis can be characterized as a mixture of qualitative and quantitative research. From a qualitative perspective, the aim has been to gain understanding of underlying processes, routines, natures, and traditions of the Swedish higher engineering education system to answer the research questions. However, along the way quantitative research was addressed, which becomes particularly evident in papers [VI] and [VII].

Two objects can be pointed out as main subjects of the research constituted by this dissertation: 1) the individual engineering student (or sometime group of students) and 2) the system of higher EE in the Swedish context, with reference to its regulations, admission systems, course plans, and curricula compositions as well as their executions, industry relevance mechanisms, etc. The aim has been to view both of these objects as interdependent entities of which we can still interchangeably focus on one and then the other (moving the other from foreground to background).

Epistemologically, the conducted research could be characterized as positivistic-inductive. I have avoided inferring hypotheses from observations that are not themselves interpreted in light of observations, consequently expressing the view that everything will ultimately have to be 'answerable' to the observations. Observations, comparisons, and validations of the knowledgecreating (learning) processes taking place at the faculty and at related companies (i.e., future workplaces of our students) has been performed both from an empirical and theoretical perspective.

Moreover, a part of the conducted research could be categorized as falsifiable where, for example, the empirical findings from the statistical studies of paper [VI] were assessed with the intention of developing falsifiable models of student performance with respect to curriculum composition. 


\subsection{Delimitations and Clarifications}

The title of this thesis reflects the content, aim, and purpose of the research. However, the thesis includes a set of abstractions out of which at least one calls for additional clarification.

One can approach the concept of knowledge from different perspectives. A dedicated and puritanical epistemologist would say, while citing Plato, that knowledge must be justified, true, and believed and then perhaps initiate a philosophical problematization of the concept. However, this thesis adopts a view that knowledge is created - i.e., knowledge creation - and therefore primarily contextual and refers to the broad palette of information-generating events taking place within both EE settings and industry following product development activities. Events perceived and valued by the individuals and organizations in these settings may result in both explicit knowledge (such as the theoretical understanding of a subject) and implicit knowledge (such as practical skills or expertise). Accordingly, references to knowledge creation processes within non-academic settings should primarily be interpreted as an EE setting counterpart and vice versa - i.e., the learning processes under which higher engineering students or the practicing engineers acquire new knowledge, skills, familiarity, awareness, or understanding of someone or something. 


\section{2 \\ Frame of Reference}

This chapter briefly summarizes the theoretical frameworks for this research and defines key concepts used in the thesis and the appended papers. The overarching purpose is to support the discussion of the claimed contributions in chapter 3. Some of this material is taken from the licentiate thesis "Low-Cost Demonstrators: Enhancing Product Development with the Use of Physical Representations" (Hallberg, 2013) of which this thesis in part should be seen as a continuation. The outline of this chapter follows the three main areas of knowledge seen in Figure 1-1: product development, engineering education, and learning analytics.

\subsection{Product Development}

Product development theory deals with creation of products with new or different characteristics that offer new or additional benefits to a customer (Ullman, 2017). Ulrich et al. (2015) states that product development is a "set of activities beginning with the perception of a market opportunity and ending in the production, sale, and delivery of a product". Products can be classified as either tangible (i.e., physical objects) or intangible (i.e., 'objects' that only can be perceived indirectly, such as services). However, business models may be based on products characterized by a combination of both tangible and intangible properties, such as product-service systems (Beuren et al., 2013). Furthermore, product development efforts could either aim for creation of new innovative products based on new technology or new combinations of existing technologies or aim to refine existing products by updating, redesigning, or replacing some of the components or technologies that make up the product, which is more often the case.

The literature provides ways of defining the term product development from a meta-perspective. Cross (2008) distinguishes descriptive models of product development from prescriptive models: descriptive models describe the sequences in a design process. A schematic view of a simple and purely descriptive four-stage model of the design process can be seen in Figure 2-1. Other descriptive models are all more or less variations of this 'generic' principle, characterized by four phases: exploration of the design space; generation of plausible solutions; iterative evaluation of 


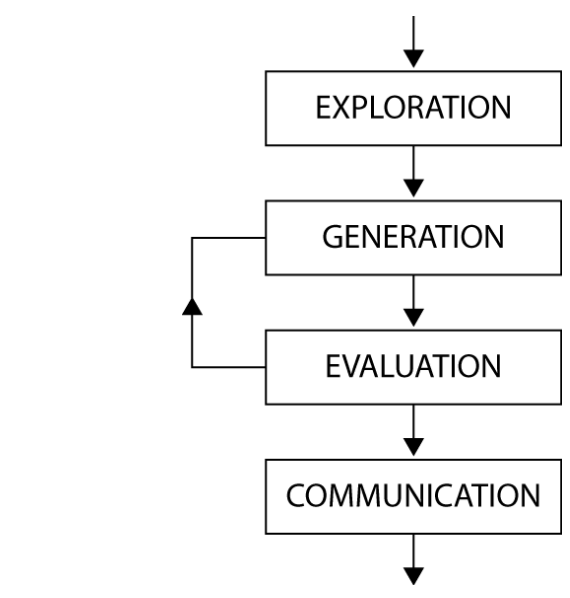

Figure 2-1 A purely descriptive, 4-stage model of the design process (Cross, 2008).

these solutions; and communication with the customer or manufacturer. The process is said to be heuristic as previous experience is used to improve and evolve the design of the product.

Every design process relies on activities, elements, methods, or techniques whose functioning is to support the generation stage, adding to the knowledge of the developing product throughout the design process. Examples of such creative problem-solving techniques are brainstorming (Putman et al., 2009), TRIZ (Terninko et al., 1998), and SWOT analysis (Gürel et al., 2017).

According to Ulrich et al. (2015), the development of a product comprises a number of activities, "starting with the perception of a market opportunity and ending in the production, sale, and delivery of a product". These activities need to be organized and controlled to attain a satisfactory design process. Several design process models have been described by acknowledged authors. One of the earliest was provided and used for educational purposes by American educator Morris Asimow in the 1960s (Asimow, 1962). Others, more contemporary authors, - such as Ulrich et al. (2015), Pugh (1990), Ullman (2017), Hubka et al. (1992), Roozenburg et al. (1995), and Pahl et al. (2013) - are frequently cited. A common denominator for these prescriptive design processes is the grouping of events into different phases. For example, Pahl et al. states that a general design process is constituted by the following four phases.

- Clarification of the task: The design problem is analyzed and information about it is collected. Requirements and constraints are established and listed in a requirements specification.

- Conceptual design: Essential problems are identified; function structures are established, and concept variants are elaborated and evaluated to determine the principle solution.

- Embodiment design: Preliminary layouts are established. Technical and economic considerations are considered to evaluate and reject and/or combine the preliminary layouts to produce a definitive layout. 
- Detail design: Production documents are produced implying an entire specification of arrangement, dimensions, materials, and tolerances of all the parts in the product.

A generic product development process of Ulrich et al. is illustrated in Figure 2-2. This model depicts a sequence of activities that "an enterprise employs to conceive, design, and commercialize a product” (Ulrich et al., 2015). The actual development takes place between the first and the sixth phase - i.e., after the initial planning phase and before production rampup.

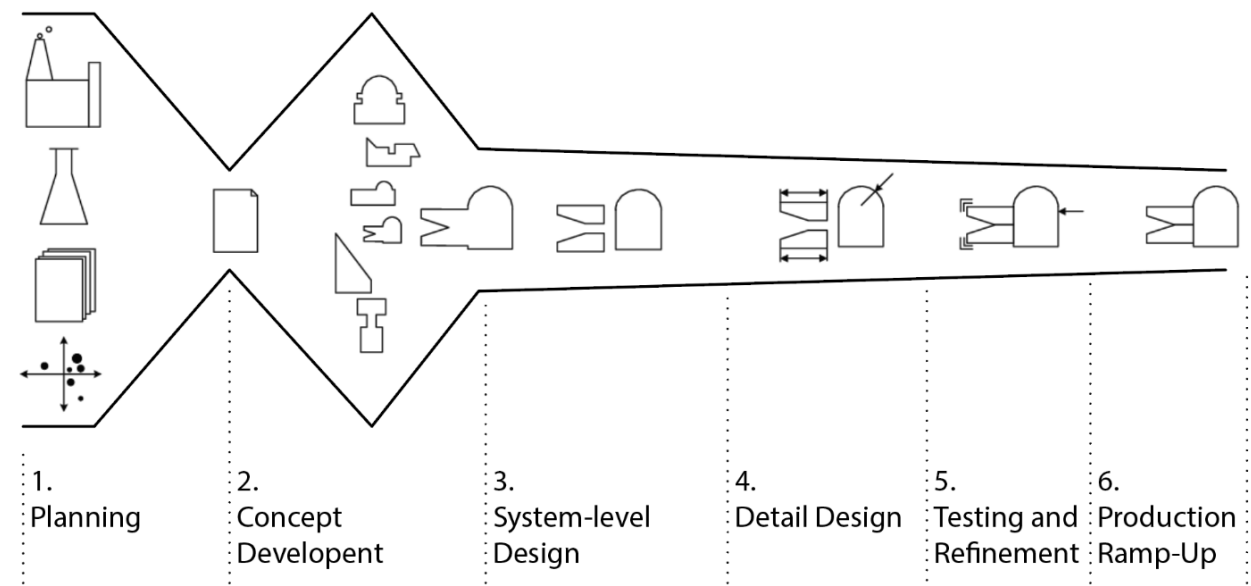

Figure 2-2 A generic product development process (Ulrich et al., 2015)

Of special interest for this work are the multi-disciplinarity aspects of engineering activities, such as knowledge creation from development of products. The literature provides several welldefined design processes that also consider that activities inevitably interact with each other. For example, the Integrated Product Development model, first proposed by Andreasen et al. (1986), emphasizes the relations between market, design, and production domains (Figure 2-3). This idealization of the design process strives to unify the activities in these domains for each phase of the design process.

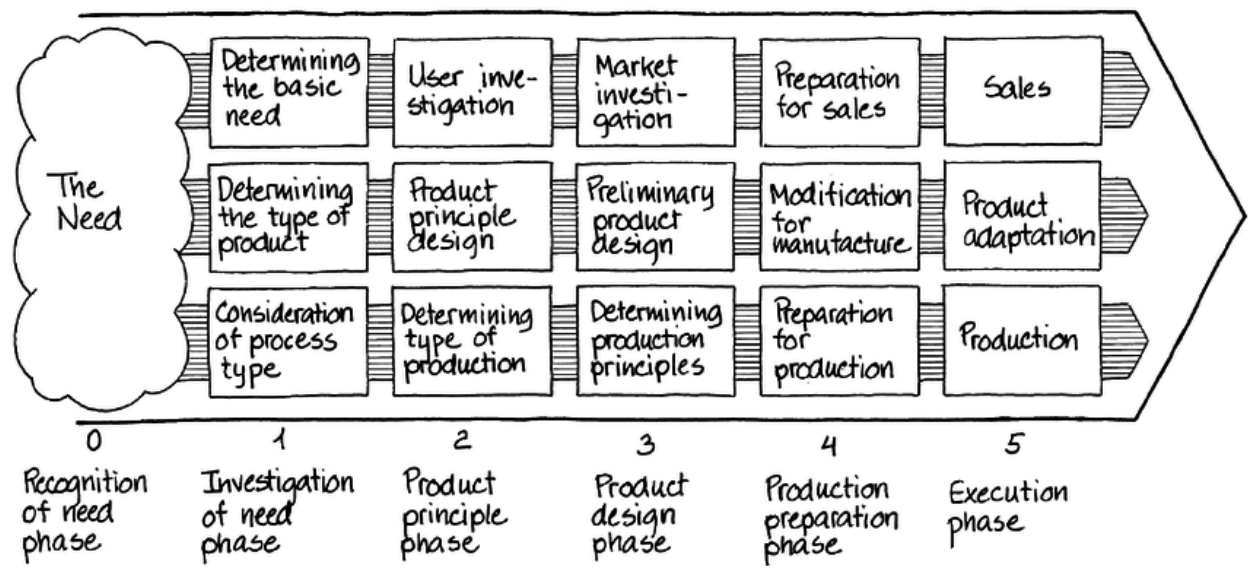

Figure 2-3 The Integrated Product Development model by Myrup Andreasen, M. \& Hein, L. (1986) 


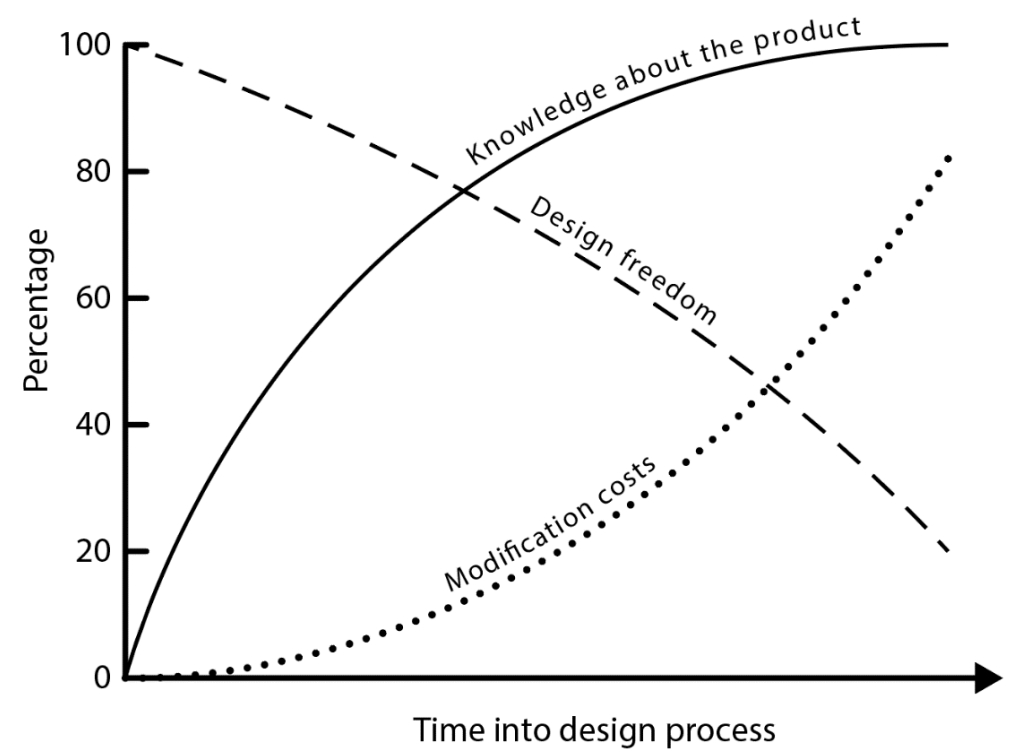

Figure 2-4 The design paradox illustrated by the build-up of knowledge of the product (solid line), design freedom (dashed line) and modification costs (dotted line), of an ideal design process.

Furthermore, most product development projects are bound by contradicting relations between budget and information, infamously known as the design paradox. Figure 2-4 illustrates this paradox with three curves. Ideally, the project starts with absolute design freedom (dashed line) as no decisions about the design have been made. Consequently, there is no knowledge of the product (solid line). Immediately following project start, decisions are made that increase the knowledge of the product but limit the design freedom. The limitation is, of course, due to the decisions themselves, but the limitation is also implicit because of the resulting cost of modifications (dotted line). Modification costs usually increase the further the design process progresses as adjustments of a more mature product naturally affect previously made decisions. Fundamental parts of the design paradox must be emphasized given the aims of this thesis, in particular the way that the paradox paints the design process as a continuous creation and buildup of knowledge.

The literature also provides justifying arguments for refinement of a product development process, arguments partly applicable for the research focus of this thesis and therefore the enhancement of EE knowledge creation processes. In an industrial context, increased cost effectiveness is the obvious and most often referred to reason why anyone adopts or seeks refinements of an existing product development process. Recent years have also seen sustainability and environmental considerations become subjects for design process enhancements. Ulrich et al. (2015) provides a summary of the basic characteristics of a successful refinement of the design process:

- Product quality: How good is the product resulting from the development effort? Does it satisfy customer needs? Is it robust and reliable?

- Product cost: What is the manufacturing cost for the product being developed? 
- Development time: How quickly did the team complete the product development effort? Development time determines how responsive the firm can be to competitive forces and to technological developments.

- Development cost: How much was spent on developing the product? Development cost is usually a significant fraction of the investment required to achieve the profits.

- Development capability: Are the design teams better able to develop future products because of their experience with product development project? Development capability is an asset the firm can use to develop products more effectively and economically.

\subsubsection{Prototypes and Demonstrators}

Throughout the engineering design literature, the concept of physical prototyping is commonly presented as part of the later stages of the design process. Some well-cited works within the field of product development, such as Pahl et al. (2013), actually say very little about prototyping, yet refer to prototyping as a very costly and time-consuming activity. At the same time, prototyping is considered potentially beneficial throughout the design process, not only preceding product launch. Prototyping as a mean for sub-system evaluation, somewhat related to the concept of demonstrating, is also emphasized:

However, it is possible to test parts of the proposed plant or equipment by building partial prototypes within existing plant or equipment or by using specific test facilities. (Pahl et al., 2013)

Ullman refers to prototyping and prototypes as representations of design information that describe an evolving product (Ullman, 2017). Seen as a set of deliverables, the prototype fulfills two purposes: "[T] hey are the embodiment of information that describes the product and they are a means to communicate that information to others". Ullman also specifies four categories of prototypes:

- Proof-of-concept or proof-of-function prototypes focus on developing the function of the product with respect to the list of requirements. They are viewed as learning tools, where exact geometry, materials, and manufacturing processes are of less importance.

- Proof-of-product prototypes are developed to refine components and assemblies where geometry, materials, and manufacturing processes are as important as function.

- Proof-of-process prototypes are used to verify both the geometry and the manufacturing process. Exact materials and manufacturing processes are used to manufacture samples of the product.

- Proof-of-production prototypes are used to verify the entire production process. They are also called preproduction prototypes, products manufactured just prior to launch.

Ulrich et al. define a prototype as "an approximation of the product along one or more dimensions of interest", which may include anything from sketches and mathematical models to fully functional preproduction versions of the product (2015). The process of developing these approximations is called prototyping. Furthermore, Ulrich et al. classify prototypes as either physical or analytical. Physical prototypes are typically tangible artifacts built as approximations of the forthcoming product. Aspects of interest are built into this artifact for testing and experimentation. Purely analytical prototypes are intangible and typically consist of 
computer simulation models, spreadsheet models, or 3D-CAD models, where interesting aspects of the product are analyzed.

The second dimension is the degree to which the prototype is comprehensive as opposed to focused. A comprehensive prototype corresponds closely to the everyday use of the word prototype and usually implements most of the attributes of the product it represents. Such comprehensive prototypes, for example, are given to customers to identify any remaining design flaws before production and launch. Focused prototypes explore one or a few attributes of a product. For example, a foam model could be used to explore the esthetics of a product, while an experimental circuit board could be used to investigate electronic performance. Ulrich et al. speak about "looks-like" prototypes and "works-like" prototypes, both to be considered focused, which are often built separately to answer critical questions much earlier than a comprehensive prototype.

Ulrich et al. also plot the two dimensions, physical-analytical and comprehensive-focused, along two separate axes. Figure 2-5 is a generalization of the same diagram. Notably, a focused prototype can be either physical or analytical, whereas a fully comprehensive prototype usually cannot be considered analytical.

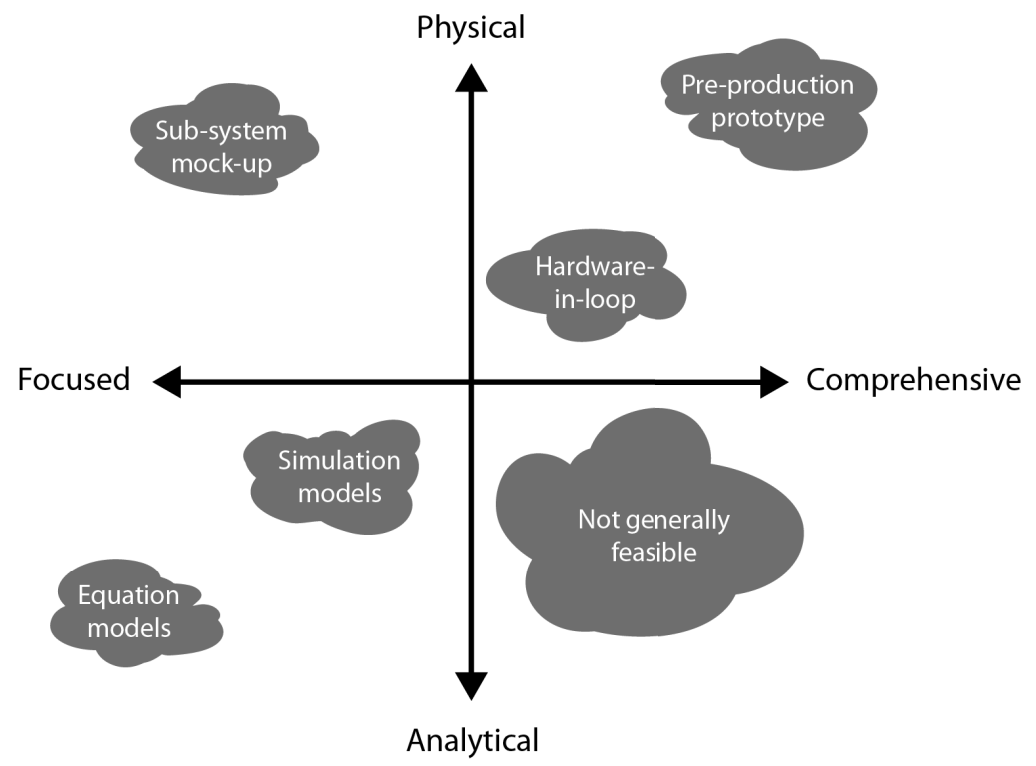

Figure 2-5 Types of prototypes according to Ulrich et al., 2015. The diagram is a generalization of an example.

Paper [I] as well as related papers [VIII], [IX], and [X] all deal with the concept of so-called low-cost demonstrators. In this context, the term demonstrator refers to the kind of prototypes usually found in the aerospace industry. A typical example and often referred to in a Swedish context is the Saab 210, a scaled-down testbed that preceded the Saab 35 Draken, which was built to explore the double delta-wing concept and made its maiden flight in 1952 (Jouannet, 2012). A more recent example is the Dassault Systemes nEUROn project, a platform for development of engineering and cooperation skills among the participating companies (nEUROn, 2020). The purpose of these aircraft (both pictured in Figure 2-6), which also is significant for demonstrators, was not to represent a forthcoming product as a whole but rather 
to act as a platform for evaluation of key aspects of the projects that otherwise would impose unacceptable uncertainties throughout the project.
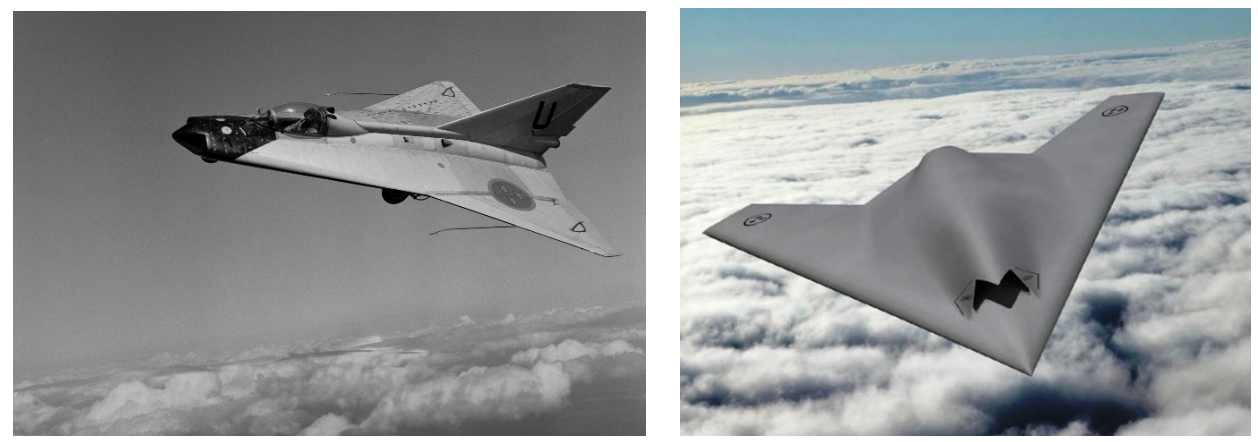

Figure 2-6 Two aerospace demonstrators, the Saab 210 (left) and the Dassault nEUROn (right)

Prototypes do not necessarily have to take a physical form. Terms like digital prototype, digital mock-up, or virtual prototype refers to virtual representations of a physical product under development using CAD and CAE systems. Ulrich et al. (2015) declare the advantages of using such prototyping techniques referring to the following abilities:

- easily visualize the three-dimensional form of the design;

- create photo-realistic images for assessment of product appearance;

- automatically compute physical properties such as mass and volume; and

- perform computer-based analyses, such as stress distribution and thermal flow finiteelement analysis, CFD analysis.

Ulrich et al. (2015) also emphasize "the efficiency arising from the creation of one and only one canonical description of the design, from which other, more focused descriptions, such as cross-sectional views and fabrication drawings, can be created". Recent trends are pointing toward virtual representations that stretch beyond product launch - i.e., so-called digital twins that allow for "a real mapping of all components in the product life cycle using physical data, virtual data and interaction data between them" (Tao et al., 2018).

The aforementioned concepts and terms of product development theory are fundamental for the forthcoming discussions, specifically with regard to prototyping and integrating PD, and help bridge product development and engineering education, which is the subject for the next section.

\subsection{Engineering Education}

As a research field, Engineering Education Research (EER) is relatively young, both in the North America and Europe. In the US context, the advent of EER could be traced back to the 1980s. According to Jesiek et al. (2009), concerns over US industrial, scientific, and technological capacity, industrial and economic competitiveness, and defense capabilities resulted in the so-called "Neal Report" (National Science Board (US), 1987). The report, which summarized an almost decade-long debate regarding these matters in the US, suggested 
government actions. Eventually, funding was provided by the US National Science Foundation (NSF) that stimulated "support in the late 1980s for education-related research by NSF's Division of Undergraduate Education" (Jesiek et al., 2009). Following additional reports suggesting intensified research on EE, the relaunch of ASEE's Journal of Engineering Education $(J E E)$ in 1993 also lead to a focus on EE, catalyzing discussion and debate. Currently, the JEE is considered one of the leading journals in EER.

In Europe, much of the contemporary EER is centered around the European Society for Engineering Education - SEFI (SEFI, 2020), which also hosts the European Journal of Engineering Education. According to de Graaff (2016), the origin of European EER goes back to the 1960 s following a drastic increase in students enrolling in higher education. This increase in students required adjustments to teaching methods to meet a shift in demands from students, the academy, and industry. In recent years, EER has been internationally revitalized (Borrego et al., 2011), and engineers are more often conducting their own educational research (de Graaff, 2016).

The focus of EER was outlined in a special report in the Journal of Engineering Education (American Society for Engineering Education, 2006). The report points out and elaborates on the following five areas:

- Engineering Epistemologies: Research on what constitutes engineering thinking and knowledge within social contexts now and into the future.

- Engineering Learning Mechanisms: Research on engineering learners' developing knowledge and competencies in context.

- Engineering Learning Systems: Research on the instructional culture, institutional infrastructure, and epistemology of engineering educators.

- Engineering Diversity and Inclusiveness: Research on how diverse human talents contribute solutions to the social and global challenges and relevance of our profession.

- Engineering Assessment: Research on and the development of assessment methods, instruments, and metrics to inform engineering education practice and learning.

Seemingly there are differences between north American and European EER in terms of methodological approaches, where research in the US tends to focus more on quantitative studies and European EER more on qualitative studies (Wallin, 2015). Furthermore, Borrego et al. (2013) conclude that "Northern and Central European educational approaches focus on authentic, complex problems, while U.S. approaches emphasize empirical evidence".

\subsubsection{Concepts of Learning and Knowledge Acquisition}

A common theme for this thesis is the processes under which a person obtains new knowledge or skills. There are many models that explain these processes from a cognitive perspective as well as concrete and practical perspectives. Central to knowledge creation and learning processes both within industry $\mathrm{PD}$ settings and $\mathrm{EE}$ academic environments is knowledge acquisition from experiences. Two separate but yet interconnected concepts are of special interest here - experiential learning and active learning. Kolb's theories (2014) are fundamental when discussing learning or creation of knowledge by interacting with the surrounding environment. Kolb defines experiential learning as the process whereby knowledge (as well as skills, attitudes, beliefs, emotions, etc.) is created through the transformation of experiences. 
Kolb's model is composed of four sequentially arranged elements: 1) concrete experience; 2) observation of and reflections on that experience; 3) formation of abstract concepts based on the reflection; and 4) testing of these new concepts in terms of active experimentation. The process then starts over with the concrete experience, followed by observations of the testing, etc. Kolb calls this the learning cycle, which in its basic form is illustrated in Figure 2-7. This spiral of learning can begin with any one of the four elements, but typically begins with a concrete experience.

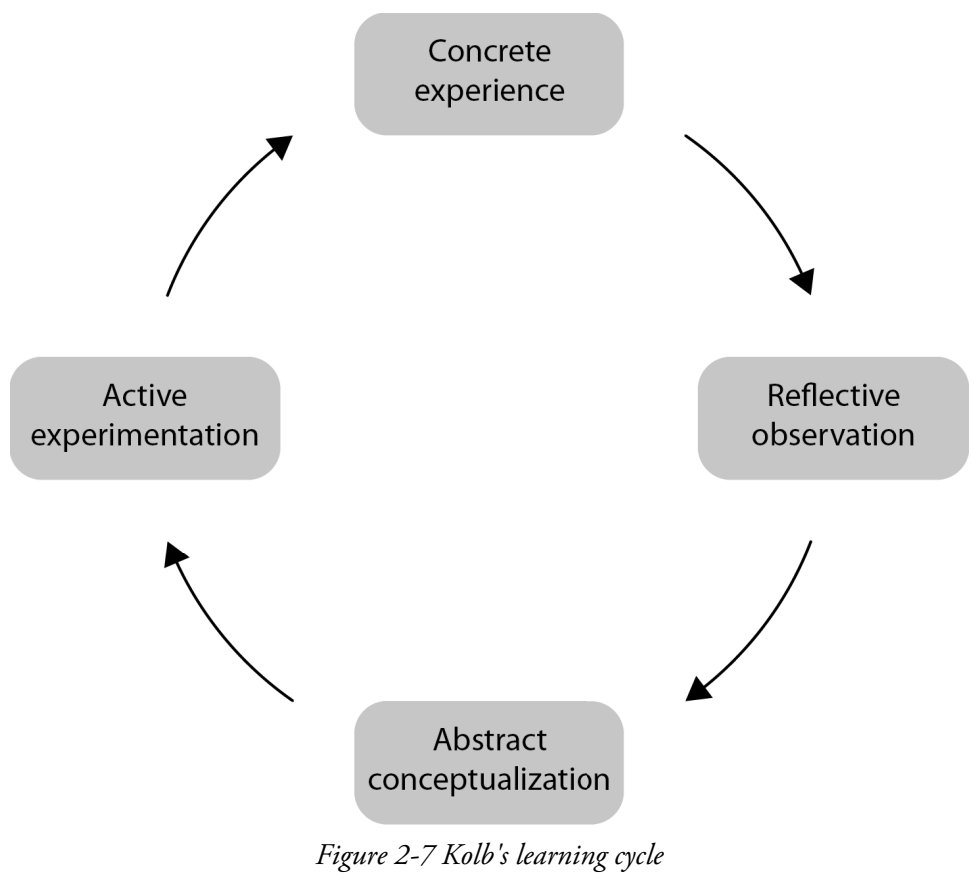

Kolb's concept of learning is commonly referred to within EER and there are a number of wellcited contributions that use the model for enhanced understanding of different aspects of EE. For example, Chan (2012) demonstrates an experiential learning project through Kolb's learning theory using a qualitative research method, and Cagiltay (2008) examines the relationship between students' learning styles and their performance in EE using Kolb's learning style inventory.

According to Bonwell et al. (1991), the concept of active learning is "a method of learning in which students are actively or experientially involved in the learning process and where there are different levels of active learning, depending on student involvement". Active learning modules are typically designed to engage students in the learning process using laboratory exercises, case exercises, projects, etc. Active learning is often contrasted with classic learning styles such as lecture-based teaching with little or no interaction with the learners. Within EER, the use of active learning modules, where students are actively or experientially involved in the learning process rather than passively learning, is a well-established and recognized method to increase student performance. Freeman et al. (2014) concluded that student performance increased by just under half the standard deviation with this type of learning compared with lecturing and that students in traditional lecture courses are 1.5 times more likely to fail than students in courses promoting interactive engagement. Bonwell, Freeman, and others explicitly 
refer to the term active learning when discussing learning styles based on student interaction, collaboration, cooperation, and problem-based learning.

There are obvious and strong relations between Kolb's experiential learning theories and the concept of active learning, whereas many expressions of active learning can be directly mapped onto the phases of Kolb's learning cycle. Figure 2-8 illustrates examples of means of learning grouped in the quadrants of the learning cycle, ordered from the circle center (where the means are characterized by more passive learning) towards the boundary (where the means are characterized by more active engagement).

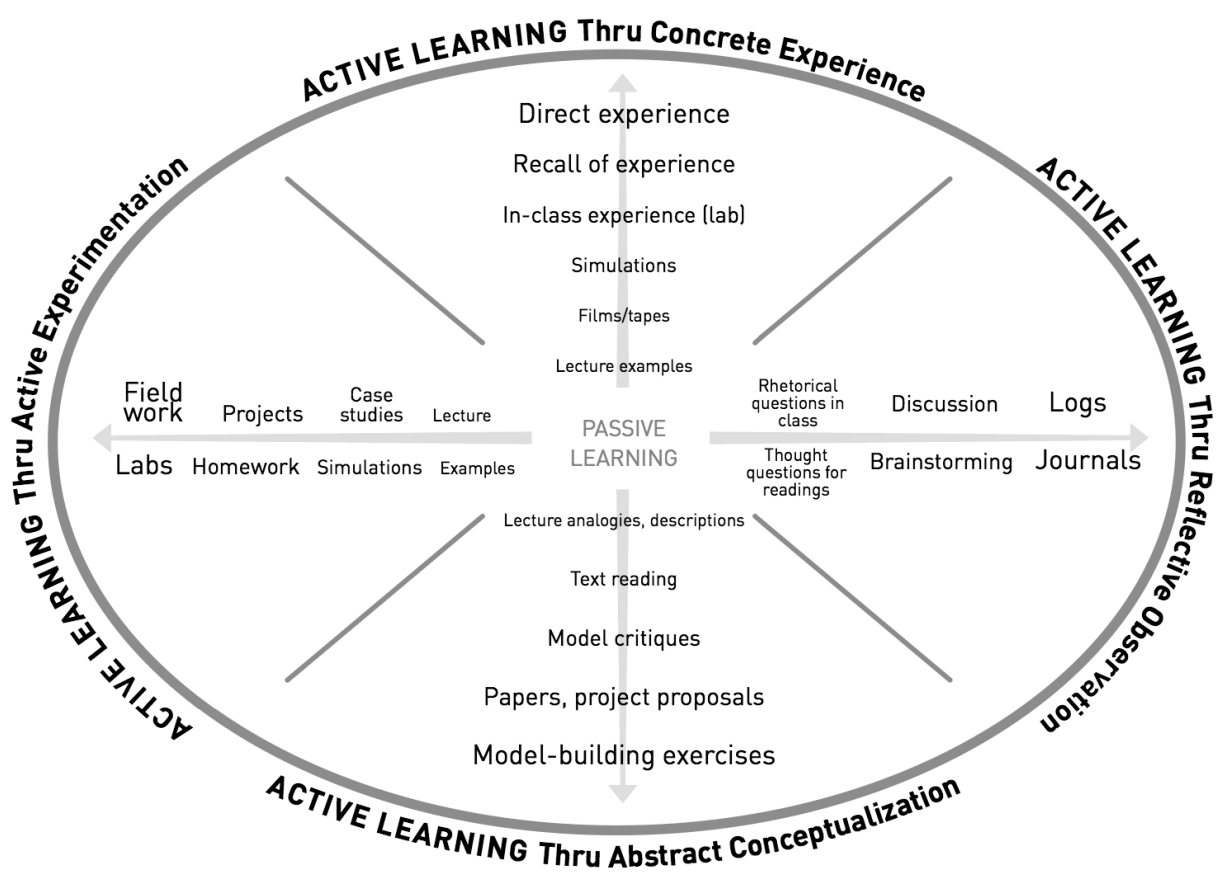

Figure 2-8 Examples of common forms of active learning mapped directly to the four elements of Kolb's learning cycle by which knowledge acquisition occurs (Illustration adopted from BYU Faculty Center, 2003)

Moreover, discussions on learning within EE settings often deal with the actual learning environment addressing contextual perspectives on the processes of learning and knowledge acquisition. Säljö (2013) explains how the ways of learning, in the sense of creating new knowledge, are strongly connected to the actual context where the learning activity takes place. Furthermore, by referring to a sociocultural perspective on learning theory (Vygotsky, 1997), commonly used to describe processes of knowledge creation catalyzed by interaction between people, one can look at attributes that promote active learning, such as the physical artefacts that are subjects for papers $[\mathrm{I}],[\mathrm{II}],[\mathrm{III}]$, and [IV], as "learning platforms" for creating new information - i.e., project team members (students or engineers) learning by interacting with each other while working on different areas of the platform. This reasoning is closely related to $\mathrm{EE}$ when conducted in the form of projects or collaborative laboratory exercises, particularly such as the one described in paper [II], which discusses the connection between the low-cost demonstrator approach and hands-on activities within a computer aided design course. 
Similar reasoning - where context and environment is highlighted as a driver and catalyst for knowledge creation - can also be found where industrial settings are in focus. Aspects of context have been shown to be important as MIT research associate Schrage (1999) concludes that extensive interaction with the physical world fosters creativity and learning during product development (e.g., several companies have realized that playful exploration is the best way to learn). Examples are given where companies secretly spend years and huge amounts of money on developing a single (thought-to-be promising) prototype but upon launch the product has become obsolete or requirements may have changed or were not correctly understood. Instead, Schrage argues for plenty of low-risk models that continuously communicate the ideas that evolve, both pushing them at the audience (i.e., stakeholders, designers, customers, etc.) as well as the other way around by pulling ideas from the market to shape the requirements. Interestingly, Schrage argues for simplicity rather than high fidelity and diversity rather than uniformity.

\subsubsection{Course and Curriculum Development}

According to van den Akker (2007), citing Taba (1962), the Latin word 'curriculum' is related to the verb currere (i.e., running) and refers to a course or track to be followed. van den Akker concludes that "in the context of education, where learning is the central activity, the most obvious interpretation of the word curriculum is to view it as a course, trajectory, or 'plan for learning'". The word syllabus is often used in the same context as curriculum, but often comprises a narrower scope. Unless otherwise stated, this thesis consistently uses the word 'curriculum' to refer to a composition of courses that correspond to an academic degree.

An important theoretical concept related to both course and curriculum development is constructive alignment. Biggs (1996) builds this theory on a marriage between constructivist learning theory and instructional design literature. Constructivism comprises a family of theories that emphasize the "centrality of the learner's activities in creating meaning", whereas instructional designers emphasize "alignment between the objectives of a course or unit and the targets for assessing student performance” (Biggs, 1996). These and related ideas have had a very strong impact on teaching and assessment in higher EE during the last decades.

Course and curriculum design are also closely connected to the above-mentioned theories of experiential learning. Crawley et al. (2014), while outlining the pedagogical foundation of the CDIO educational framework, lists six characteristics of experiential learning, referring to Kolb's work (1984):

- Learning is best conceived as a process, that is, concepts are derived from and continuously modified by experience.

- Learning is a continuous process grounded in experience, that is, learners enter the learning situation with more or less articulate ideas about the topic at hand, some of which may be misconceptions.

- The process of learning requires the resolution of conflicts between opposing modes of adaptation to the world, that is, the learner needs different abilities from concrete experience to abstract conceptualization, and from reflective observation to active experimentation.

- Learning is a holistic process of adaptation to the world, that is, learning is broader than what occurs in classrooms. 
- Learning involves transactions between the person and the real-world environment.

- Learning is a process of creating knowledge, that is, in the tradition of constructivist theories.

Moreover, as engineering domains are continuously becoming more complex, integrated, and cross-disciplinary, the concept of integrated curriculum is of interest for the EE community. On a curriculum level, aspects of interdisciplinarity are often represented by means of integrative measures that simultaneously provide curriculum content from different areas of engineering. In the literature, integrative learning is a key concept used to mirror the real-life situation of the practicing engineer:

[Integrative learning is] connecting skills and knowledge from multiple sources and experiences; applying theory to practice in various settings; utilizing diverse and even contradictory points of view; and understanding issues and positions contextually. [. . . ] [I]ntegrative experiences often occur as learners address real-world problems, unscripted and sufficiently broad to require multiple areas of knowledge and multiple modes of inquiry, offering multiple solutions and benefiting from multiple perspectives. (Huber et al., 2004)

There are examples where the whole curricula are subject of integrative measures such as changes in the undergraduate engineering programs at UCL (Mitchell et al., 2019, Tilley et al., 2015) based on the premise that "the modern engineer should understand the context of the problems they address, appreciating the ethical, societal and financial connotations of their design decisions" (Bains et al., 2015). Moreover, since its founding in 1997, the Olin College of Engineering has gained much attention for its organization and curriculum development processes. Classes at Olin emphasize context, interdisciplinarity, and emotional engagement. The curriculum is characterized by integrated course blocks that allow for exploration of relationships between main subject engineering calculus and physics (Goldberg et al., 2014) and "throughout the curriculum, students stay engaged by working on projects connected to real-world challenges. In their first year, students also begin to explore the arts, humanities and social sciences as well as entrepreneurship" (Olin College of Engineering, 2020). Integration is taken even further in the so-called New Model in Technology \& Engineering (NMiTE), a purpose-built teaching-only engineering and technology institution in Hereford, UK. The NMiTE initiative emphasizes "multidisciplinary teamwork, entrepreneurship, liberal arts and leadership, as well as science and math" (Grose, 2017). From the discussions regarding the NMiTE initiative and its strong orientation towards the role of engineers and engineering in relation to the surrounding society (Kozinski et al., 2017), one can observe that both context and identity are crucial to these types of educational settings.

Yet another apparently related reasoning is found in the work of Jamison et al. (2014) when referring to the concept of hybrid learning. Following an exploration of the contractiveness between market-driven and academic strategies of response to the challenges facing the engineering industrial and academic community, Jamison argues for an integrative approach to engineering education that "combines a scientific-technical problem-solving competence with an understanding of the problems that need to be solved" (2014). Jamison elaborates further that such an integrative approach would involve "a mixing of scientific education and practical training in technical skills with a cultivation of a broader cultural understanding of the implications of science and technology in general and reflections on one's own role as an engineer in particular" (2014). 
Course and curriculum development are a central subject of EER, and the literature offers substantial amount of contributions dealing with this subject. Notable works on this subject deal with curriculum development in relation to the so-called Bologna Process (Bolognadeklarationen, 2020). As an example, Heitmann (2005) discusses demands and challenges following the Bologna Process on the development of EE in a European context and provides examples of good practices that focus on components of innovative curricula that should guide curriculum development to satisfy various needs, including those of the Bologna Process. Moreover, Walkington (2002) identifies a process to provide curriculum leaders and policy-makers with a practical and flexible approach for designing and implementing engineering curricula.

A particularly relevant contribution given the aims and motives of this thesis is provided by Rompelman et al. (2006) who explicitly connects EE curriculum development with processes and practices of engineering. Rompelman et al. concludes that "engineers have a set of powerful tools at their disposal for designing robust and reliable technical systems" (2006) but that these tools are seldom applied in educational design.

Rompelman et al. takes on a systems engineering approach to describe educational development as a process that transforms the student into a graduate. Input and output quantities are defined as attributes in terms of knowledge, skills, understanding, etc. Rompelman et al. states that the "process" can be described as encompassing all the activities at the educational institution that has a pedagogical purpose, such as laboratory exercises and lectures. However, following a constructivist revision of this systems approach, teaching is defined as a separate facilitator aiding the learning process of the student - i.e., the knowledge is not transferred to the students but instead created by the students themselves (Figure 2-9).

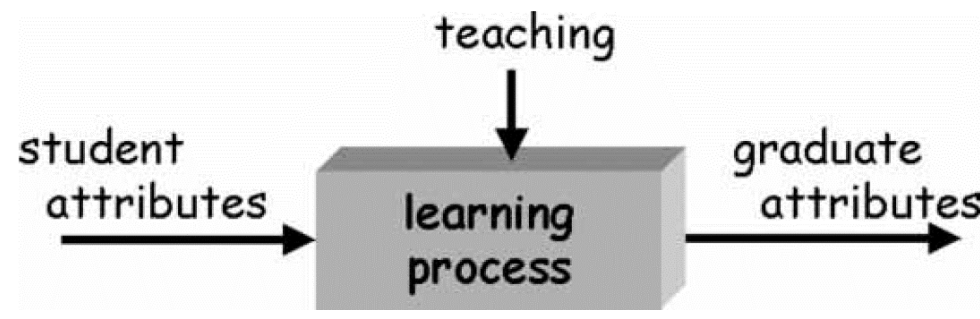

Figure 2-9 A systems engineering approach to educational development adopted from Rompelman et al. (2006).

Following the establishment of the model in Figure 2-9, Rompelman et al. raise three questions addressing its operation in the context of designing education.

1. How do we describe the input - i.e., what are the features of the student prior to the learning process?

2. How do we describe the output - i.e., what are the features of the student after the learning process?

3. How do we describe the learning process?

Rompelman et al. identify issues regarding both the first and second question in that descriptions of the input often focus on static information such as course descriptions, what course material is used, and literature and that 
[w]e only know something about the output, if we know what the student has done with the educational opportunities. The information on the output is based on a description of the input, an assumption of the student behavior and a, usually rather poor, verification. (Rompelman et al., 2006)

objectives:

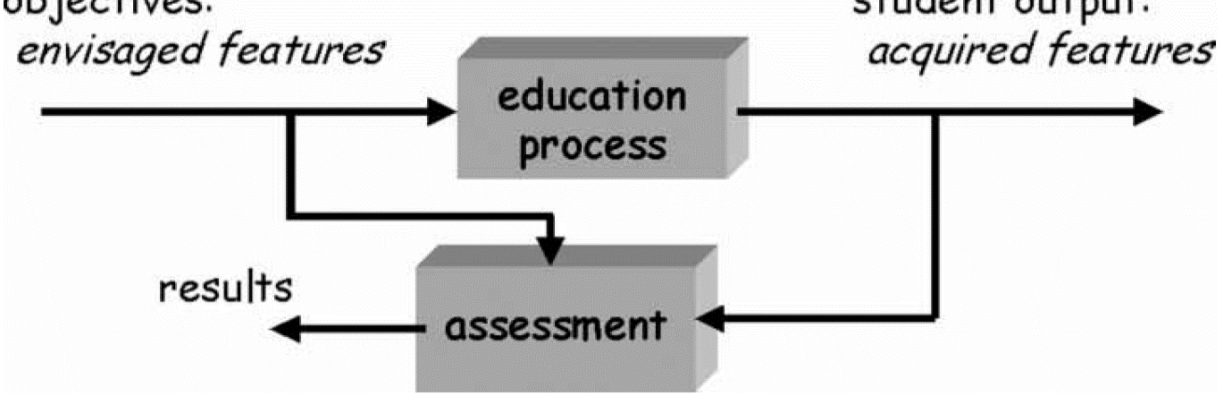

Figure 2-10 A control engineering approach to describe the educational process. The input of the educational process is defined as the envisaged features of the graduate and the output as the realized features. Feedback generally is constituted examination results. Rompelman et al. (2006).

Moreover, Rompelman et al. further elaborate on this by concluding that the model in Figure 2-9 lacks a "method of verifying whether the objectives (the envisaged learning outcomes) are indeed realized" (2006). Viewed from a systems engineering perspective, the model lacks a feedback loop. Consequently, the model in Figure 2-9 is updated by defining the input of the educational process as the "envisaged features of the graduate and the output as the actually realized features" (2006) (see Figure 2-10); Rompelman et al. continues to state, with reference to control engineering, that the "input is the 'set point' ('reference value') and the output the

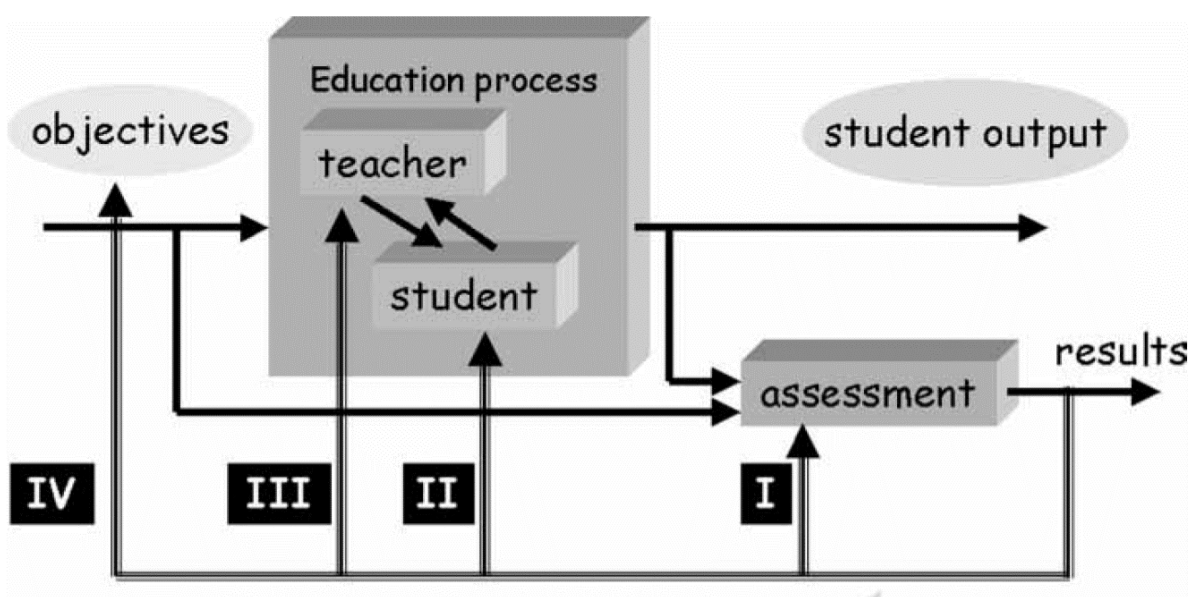

\section{Feed back}

Figure 2-11 Feedback pathways in order to extend the educational process into a controlled process; I: adjustment of assessment method, II: adjustment of students' activities, III: adjustment of teachers' activities, IV: adjustment of envisaged features. Rompelman et al. (2006). 
'controlled variable" (2006). However, Rompelman et al. conclude that "[i]n order to introduce feedback we need measurements" (2006).

From a control engineering perspective, the results from the assessment stage would have to be sent backwards, affecting input parameters or the process itself. Rompelman et al. suggest that the assessment results (feedback) would have to affect the system feedback information. Therefore, Rompelman et al. suggest "feedback pathways" extend the educational process into a controlled process: I: adjustment of assessment method; II: adjustment of students' activities; III: adjustment of teachers' activities; and IV: adjustment of envisaged features (Figure 2-11).

In addition to organizing a feasible path for students to accomplish, course and curriculum development imply that it has to meet the requirements from stakeholders other than students. For example, there are accreditation organizations that institutions depend on such as the Accreditation Board for Engineering and Technology in the US. In the Swedish context, a corresponding function is held by the Universitetskanslersämbetet (UKÄ), who "evaluates the quality of higher education and research, analyses the development, is responsible for official statistics about higher education and monitors compliance with laws and regulations among universities and university colleges" (UKÄ, 2020). Furthermore, at the time of writing, Swedish authorities have filed for membership to the European Association for Quality Assurance in Higher Education (ENQA), an organization that represents quality assurance and accreditation organizations from the European Higher Education Area (EHEA, 2020) and internationally.

\subsubsection{Engineering Educational Frameworks and Practices}

Some parts of EER address organizational aspects of higher EE. Two such aspects are of special interest for this thesis: the CDIO initiative and Problem-Based Learning (PBL).

\section{$C D / O$}

The CDIO initiative is an educational framework that advocates EE based on engineering fundamentals "set in the context of Conceiving - Designing -Implementing - Operating (CDIO) real-world systems and products" (CDIO Initiative, 2020). The cornerstone of the framework is the CDIO syllabus, which "offers rational, complete, universal and generalizable goals for undergraduate engineering education". Furthermore, the CDIO framework is expressed and communicated by a set of standards (Table 2-1). The standards are used "as a guideline for educational program reform and evaluation, create benchmarks and goals with worldwide application, and provide a framework for continuous improvement" (Crawley et al., 2011, Bennedsen et al., 2016). The CDIO initiative was introduced around the turn of the millennium (Berggren et al., 2003) and at the time of writing the framework has been adopted by more than 180 institutions worldwide. Linköping University is considered one of the cofounders of the CDIO Initiative, along with MIT, Chalmers, and KTH. 
Table 2-1 The twelve CDIO Standards (CDIO Standards 3.0, accessible form (http://www.cdio.org/content/cdio-standards-30)

\section{Standard}

1. The Context

\section{Learning Outcomes}

3. Integrated Curriculum

4. Introduction to Engineering

5. Design-Build Experiences

6. Engineering Learning Workspaces

7. Integrated Learning Experiences

\section{Active Learning}

9. Enhancement of Faculty Competence

\section{Enhancement of Faculty} Teaching Competence

11. Learning Assessment

\author{
Description \\ Adoption of the principle that sustainable product, process, system, and service \\ lifecycle development and deployment - Conceiving, Designing, \\ Implementing and Operating - are the context for engineering education
}

Specific, detailed learning outcomes for personal and interpersonal skills, and product, process, system, and service building skills, as well as disciplinary knowledge, consistent with program goals and validated by program stakeholders

A curriculum designed with mutually supporting disciplinary courses, with an explicit plan to integrate personal and interpersonal skills, and product, process, system, and service building skills.

An introductory course that provides the framework for engineering practice in product, process, system, and service building, and introduces essential personal and interpersonal skills and the rationale of sustainability in the context of engineering.

A curriculum that includes two or more design-implement experiences, including one at a basic level and one at an advanced level.

A physical learning environment that includes engineering workspaces and laboratories that support and encourage hands-on learning of product, process, system, and service building, disciplinary knowledge, and social learning, combined with a digital learning environment that includes on-line tools and spaces that support and enhance the quality of teaching and student learning.

Integrated learning experiences that lead to the acquisition of disciplinary knowledge, as well as personal and interpersonal skills, and product, process, system, and service building skills.

Teaching and learning based on active and experiential learning methods.

Actions that enhance faculty competence in personal and interpersonal skills, product, process, system, and service building skills, as well as disciplinary fundamentals.

Actions that enhance faculty competence in providing integrated learning experiences, in using active and experiential learning methods, and in assessing student learning.

Assessment of student learning in personal and interpersonal skills, and product, process, system, and service building skills, as well as in disciplinary knowledge.

A system that evaluates programs against these twelve standards and any optional standards adopted, and provides feedback to students, faculty, and other stakeholders for the purposes of continuous improvement.

The CDIO community advocates active leaning as a crucial component of any engineering curriculum (Malmqvist et al., 2006) and active learning is solely expressed by CDIO Standard 8. Furthermore, integration of knowledge domains is a central part of the CDIO approach to curriculum development and is explicitly expressed in Standard 3, Integrated Curriculum, and Standard 7, Integrated Learning Experience. This promotion of integration should, according to Edström, be "an effort to achieve a tighter coupling, with coordination between the programme and the courses, and horizontally between courses" (2017).

\section{PBL - Problem-Based Learning}

PBL centers learning around real-life situations. Most of the learning takes place during group work sessions where the students collect information that is discussed and reflected on with the 
support of a supervisor. A key principle within PBL is that the students have control and responsibility for their learning process. The fundamental idea of PBL is also to shift the focus from the teacher to the learner (Kolmos, 1996). Some of the recognized advantages from using $\mathrm{PBL}$ is that the knowledge acquisition becomes more grounded in reality than in traditional teaching because the learning is based on authentic cases and scenarios and students not only learn content and skills but also apply what they learn to new situations, which facilitates lifelong learning (Barrows et al., 1980). Furthermore, PBL work groups are trained to take responsibility and function socially in a group, which leads to the ability to work together to solve problems and therefore be better prepared for working life (Kek et al., 2016). There are, however, some disadvantages implementing PBL. For example, the model requires substantial resources and engagement from the faculty (Berkson, 1993, des Marchais, 1993 and Dym et al., 2005) and students often achieve less basic knowledge compared to those engage in traditional learning settings (Vernon et al., 1993). Students who are new to PBL and selfdirected learning may struggle with traditional assumptions that the teacher should be "the main disseminator of knowledge" and lack the ability to "simply wonder about something" (Donnelly et al., 2005 citing Reithlingshoefer, 1992 and Schmidt et al., 1992).

PBL has its origin in medical education in the 1960s (Barrows et al., 1980). There are also outspoken uses of PBL within EE. Following a declaration of the mechanism of PBL when used in different design education learning situations, Dym et al. (2005) conclude that the effectiveness of PBL is, from a pedagogical viewpoint, due to the students learning design by experiencing design as active participants.

Unlike CDIO, there is no unified model for implementing PBL as the standard model for teaching at an institution. However, Kolmos et al. (2009) speaks of common learning principles that cross PBL models and that can be captured in the following three approaches: learning, content, and social.

- The learning approach is organized around problems and will be carried out in projects. Kolmos states that this is a central principle for the development of motivation among the learners.

- The content approach especially concerns interdisciplinary learning, which may span across traditional subject-related boundaries and methods. It is practical in the sense that the learning outcome is an example of the overall objectives of the curriculum.

- The social approach is team-based learning. Team learning aspect underpin the learning process as a social act where learning takes place through dialogue and communication. Furthermore, the students are not only learning from each other but also sharing knowledge and organizing for themselves the process of collaborative learning.

Furthermore, based on the work of Savin-Baden (2000 and 2007), Kolmos presents five PBL models that cover different objectives of the PBL where the properties of each model are expressed as six dimensions: Knowledge, Learning, Problem scenario, Students, Facilitators, and Assessment (Table 2-2). 
Table 2-2. The five models of PBL, adopted from Kolmos et al. (2009).

\begin{tabular}{ll}
\hline Model I & Knowledge: Propositional knowledge Learning: use of propositional \\
Problem-based learning for & knowledge \\
epistemological competence & Problem scenario: limited problems with known solutions \\
& Students: are receivers of propositional knowledge \\
& Facilitators: guide to understand the correct knowledge \\
& Assessment: test of knowledge according to objectives \\
Kodel II & Knowledge: know-how Learning: skills for workplace \\
Problem-based & Problem scenario: real life \\
learningfor & Students: learning to solve real problems in order to undertake practical action \\
professional action & Facilitators: demonstrator of practical skills \\
& Assessment: test of skills for the workplace and supporting knowledge
\end{tabular}

Model III
Problem-based learning for
interdisciplinary
understanding

Model IV

Problem-based learning for trans-disciplinary learning
Knowledge: a cross between know-how and know-what Learning: knowledge and skills across discipline boundaries

Problem scenario: centered around knowledge with action

Students: integrators across boundaries

Facilitators: coordinator of skills and knowledge across boundaries

Assessment: skills and knowledge in a relevant context.

Knowledge: understanding existing boundaries

Learning: critical thinking and understanding discipline borders

Problem scenario: dilemmas

Students: independent thinkers with a critical stance

Facilitators: flexible

Assessment: opportunity to demonstrate integration across disciplines

Knowledge: contingent, contextual and constructed Learning: interrogation of frameworks

Problem scenario: multidimensional, offering alternative ways of understanding

Students: explorers of underlying structures and beliefs and developing new hypotheses and knowledge

Facilitators: commentator, challenger and decoder of cultures, disciplines and traditions

Assessment: open-ended and flexible

Edström et al. (2014), conducting a structured comparison between the CDIO framework and the models of PBL, made the following observation:

The fundamental idea of CDIO is the integrated curriculum, where discipline-led and problem/project-led learning are meaningfully combined. For existing programmes, it is often necessary to increase the share of PBL activities. But that is not sufficient; a curriculum is not integrated just because it contains both problem/project-led and discipline-led courses. The synergy comes from integrated learning experiences, where students simultaneously acquire disciplinary knowledge and professional engineering skills.

Thus, Edström acknowledges knowledge integration as key for the functioning of both CDIO and PBL, which also aligns with the motives for this thesis: as engineering domains continuously become more integrated, models of learning based on knowledge integration are, naturally, of high interest. 


\subsection{Learning Analytics}

The third area of knowledge that this thesis connects to is learning analytics (LA), mainly discussed in papers [V], [VI], and [VII]. LA combines expertise from different academic disciplines such as educational data mining and predictive modelling (Sclater, 2016). A recurring definition of the term learning analytics was first presented with the call for papers for the $1^{\text {st }}$ International Conference on Learning Analytics and Knowledge (February 27-March 1, 2011, Banff, Alberta):

Learning analytics is the measurement, collection, analysis and reporting of data about learners and their contexts, for purposes of understanding and optimizing learning and the environments in which it occurs. (Siemens et al., 2011)

Furthermore, Ferguson (2012) provides an overview of the field and its origins, stating that LA as a research field is, just like EER, relatively young. According to Ferguson, LA originates before the Internet and big data. Referring to an example from the late 1970s, Ferguson cites McIntosh (1979): "on ten years monitoring the progress of their many thousands of distance students, course by course, at several stages in the academic year". McIntosh speaks about a "Data Explosion" referring to information generated by "students, tutors, counsellors and academics both inside and outside the university" and that comes "through letters, phone calls, through analyses of assessment material and student performance, through observation, through questionnaires and interviews, and through information from the administrative system" (1979).

\subsubsection{Educational Data Mining}

Around the turn of the millennium, the advent of the second generation web (the read/write web) enabled for extensive collection of web-generated data, which in turn paved the way for data mining and therefore the automatic extraction of implicit and interesting patterns from large data collections (Klosgen \& Zytkow, 2002 and Clifton, 2010).

As an overlapping field with learning analytics, Educational Data Mining (EDM) uses algorithms based on statistics, machine learning, and data mining and applies them to different types of educational data. The main purpose is to analyze these types of data to resolve educational research issues (Romeo et al., 2010). The data that are subject for analysis could be everything from the obvious, such as student result data, and admission data to personal background data and environmental data. Romeo et al. also provide examples of expected outcomes from conducting EDM such as "discover new knowledge based on students' usage data in order to help to validate/evaluate educational systems, to potentially improve some aspects of the quality of education, and to lay the groundwork for a more effective learning process" (2010). Moreover, there is a wide range of stakeholders who are involved in EDM or benefit from it. Table 2-3 provides an overview adopted from Romeo et al. (2010). 
Table 2-3. Overview of EDM stakeholders. Table adopted from Romeo et al. (2010).

Users/Actors
Learners/Students/Pupils

Educators/ Teachers/
Instructors/ Tutors

Course Developers/

Educational Researchers

\section{Organizations/Learning \\ Providers/ \\ Universities/Private \\ Training Companies}

\section{Administrators/School District Administrators/ Network \\ Administrators/System Administrators}

\begin{abstract}
Objectives for using data mining
To personalize e-learning; to recommend activities to learners resources and learning tasks that could further improve their learning; to suggest interesting learning experiences to the students; to suggest path pruning and shortening or simply links to follow; to generate adaptive hints; to recommend courses, relevant discussions, etc.

To obtain objective feedback about instruction; to analyze students' learning and behavior; to detect which students require support; to predict student performance; to classify learners into groups; to find a learner's regular as well as irregular patterns; to find the most frequently made mistakes; to determine more effective activities; to improve the adaptation and customization of courses, etc. To evaluate and maintain courseware; to improve student learning; to evaluate the structure of course content and its effectiveness in the learning process; to automatically construct student models and tutor models; to compare data mining techniques in order to be able to recommend the most useful one for each task; to develop specific datamining tools for educational purposes, etc. To enhance the decision processes in higher learning institutions; to streamline efficiency in the decision-making process; to achieve specific objectives; to suggest certain courses that might be valuable for each class of learners; to find the most cost-effective way of improving retention and grades; to select the most qualified applicants for graduation; to help to admit students who will do well in university, etc.

To develop the best way to organize institutional resources (human and material) and their educational offer; to use available resources more effectively; to enhance educational program offers and determine the effectiveness of the distance learning approach; to evaluate teacher and curricula; to set parameters for improving web-site efficiency and adapting it to users (optimal server size, network traffic distribution, etc.).
\end{abstract}

There are numerous contributors in the field of EER that explicitly address EDM. Buniyamin et al. (2015) highlight the importance of using student data to drive improvement in education planning and present a tool that enables faculty members to identify, predict, and classify students based on academic performance using cumulative grade point averages. Pal (2012) uses a machine learning algorithm to not only predict engineering student dropout rates but also students in need of additional support, based on existing student dropout data.

Furthermore, Singer et al. (2020), evaluating how "learning disabilities in combination with accommodations, affect the performance of a decision tree to predict the stability of academic behavior of undergraduate engineering students", states that EDM helps students who face academic difficulties. Similarly, Khawaja et al. (2014) demonstrates adaptive tutorials capable of modifying student tasks based on previous responses, enabled by a web-based implementation of a virtual apparatus framework.

It should also be noted that the literature provides no clear distinction between LA and EDM. For example, according to Baker, the EDM and LA communities address many of the same research questions, using similar methods, where 
the core differences between the communities are in terms of emphasis: whether human analysis or automated analysis is central, whether phenomena are considered as systems or in terms of specific constructs and their interrelationships, and whether automated interventions or empowering instructors is the goal. (Baker et al., 2014).

Nevertheless, with reference to the motives stated in the introduction, both LA and EDM offer approaches, means, and concepts that serve the aims of this thesis. In particular the intention of approaching EE with engineering methods in search for improvements. Naturally, LA and EDM have a strong connection to research question 4 [RQ4]: What metrics could be defined to support curriculum development and to monitor student performance?

\subsubsection{Psychometric Measurement}

Paper [VII] deals with analysis of student performance in relation to the students' ability to manage their situation regarding aspects such as stress, view of life, challenges, motivation, and sense of meaningfulness and applies quantitative measurements to gain enhanced understanding of these aspects. Thus, there is a need to elaborate on the theoretical foundations connected to social cognitive theory and the psychometric means of investigating social cognitive properties of individuals. The overarching objective of paper [VII] is to investigate (from an engineering program management perspective) the usefulness of two so-called coping capability concepts - sense of coherence (SOC) and self-efficacy (SE).

Developed by Albert Bandura, SE is a widely used psychological model that assesses a person's optimistic self-belief regarding competence or the person's chances of successfully accomplishing a task and producing a favorable outcome (Bandura,1997). The theory of SE has its origins in social learning theory, which views human development in terms of children's tuition experiences based on their prime models within family, peer, gender, and culture groups. There is evidence that psychosocial influences of families and peers, such as parental goals and peer pressures, affect children's self-efficacy beliefs, aspirations, and levels of selfregulation. According to social learning theory, children's self-regulatory processes and beliefs affect their emotional, moral, and academic development (Zimmerman, 2001 and Yari et al., 2012).

Bandura defines four principal sources of SE: mastery experiences, vicarious experiences, verbal persuasion, and physiological states (Figure 2-12). Of these, mastery experiences are the most influential source of a person's development of SE, where personal accomplishments are based on authentic mastery experiences - i.e., success increases SE and failure decreases SE (Bandura,1997).

Vicarious, or secondary, experiences are another source of SE, where witnessing people similar to oneself succeed through sustained effort raises the observer's belief that she is also capable of mastering a comparable activity. On the other hand, observing other people's failures despite sustained effort diminishes the observer's judgment of her own efficacy. Furthermore, the impact on SE is strongly influenced by the perceived similarity from the observer's viewpoint, between herself and the observed person. Verbal persuasion is also a source of SE, where persuading a person to believe that she possesses a certain capability will increase her chances of reaching a goal. Finally, the physiological states also affect judgments about personal efficacy, with a positive mood enhancing SE and a melancholic mood diminishing SE (Bandura, 1997).

The literature distinguishes between general self-efficacy and domain- or discipline-specific SE (and sometimes even task-specific SE). Bandura actually emphasizes that SE should be seen as 


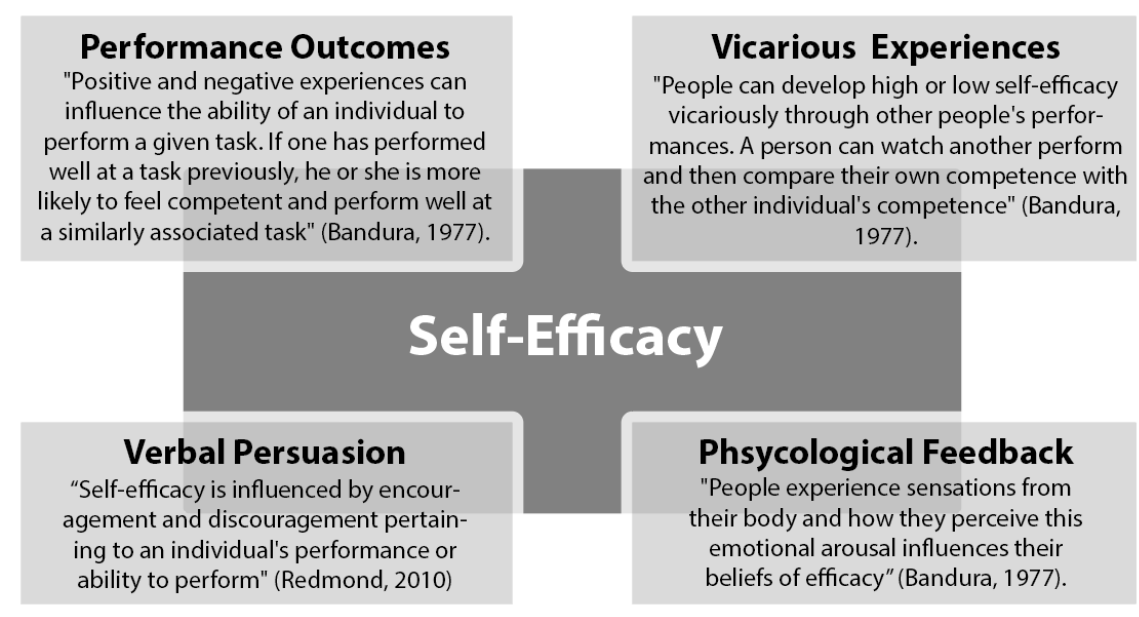

Figure 2-12 Overview of the four sources of information that individuals employ to judge their efficacy according to Bandura. Picture partly adopted from Redmond (2020).

a domain-specific capability that corresponds to different behaviors and situations. He also encourages development of domain-specific scales (Bandura, 1997).

The literature provides many examples of such domain-specific self-efficacy scales, including the engineering domain aimed at providing a measurement of engineering self-efficacy (ESE) (e.g., Carberry et al., 2010; Marra et al., 2009 and Baker et al., 2008). The ESE scale used for the study in paper [VII] was adopted from Mamaril et al. (2016). This scale was explicitly developed to measure "beliefs about engineering at both the general and skill-specific levels" (Mamaril et al., 2016). Mamaril et al. also aimed at a scale that "would pertain to students in a majority of engineering disciplines" (2016). The scale uses six items from Bong's (2001) SelfEfficacy for Academic Achievement Scale adapted to an engineering context for assessing general engineering self-efficacy. The following are examples of items from this scale: "I can master the content in the engineering-related courses I am taking this semester" and "I can learn the content taught in my engineering-related courses". An additional 19 items assess students' self-efficacy performing specific engineering skills, categorized as experimental, tinkering, and design and described by Mamaril et al. as "primary engineering skills" (2016). A few of examples of items from each skill category of the Mamaril et al. ESE scale are "I can analyze data resulting from experiments" and "I can solve problems using a computer" (Experimental self-efficacy), "I can work with tools and use them to build things", "I can manipulate components and devices" (Tinkering self-efficacy), "I can identify a design need", and "I can evaluate a design" (Design self-efficacy) (2016).

The second instrument that identifies coping capability measurement that is the subject for investigation in Paper [VII] - Sense of Coherence (SOC) - is part of the so-called salutogenic orientation developed by Aaron Antonovsky: 
A global orientation that expresses the extent to which one has a pervasive and enduring feeling of confidence in the predictability and explicability of stimuli deriving from internal and external environments (i.e. comprehensibility); that resources are available to meet the demands of the stimuli (i.e. manageability); and that those demands are challenges worthy of investment and engagement (i.e. meaningfulness). (Antonovsky, 1987)

The salutogenic model emphasizes investigating models focusing on the resources of an individual (Trap et al., 2015). Contrary to the traditional approach of pathogenesis, where the focus is on illness and disease, the salutogenic approach focuses on factors that support human health and well-being and does so by emphasizing health, stress, and coping. Furthermore, SOC is based on three dimensions of coping - comprehensibility, manageability, and meaningfulness. According to Antonovsky (1987), individuals with a high SOC have an increased ability to comprehend the surrounding world, to perceive manageability in whatever situation that arises, and to find meaning in their lives. SOC also reflects a person's view of life and capacity to respond to stressful situations (Lindström et al., 2005).

Each of the three SOC components - comprehensibility, manageability, and meaningfulness can be validated using a 29- or 13-item scale (Antonovsky, 1993). The SOC scale seems to be a reliable, valid, and cross-culturally applicable instrument to measure how people manage stressful situations and stay well (Eriksson et al., 2005). Assessing the 13-item SOC scale used for the current study, Pallant et al. (2002) conclude that people with higher SOC not only hold a more positive and optimistic outlook on life but also adopt different coping strategies when faced with stressful situations, compared with those with less SOC. For example, individuals with low SOC are drawn to more avoidant types of coping, whereas people of high SOC usually respond to a stressor with adaptive strategies, consequently "enhancing the likelihood of a positive outcome to the situation and reducing the chance of detrimental effects on health and well-being" (Pallant et al., 2002). Cohen et al. (2004) also concludes that people with strong SOC have lower levels of psychological distress and better physiological wellbeing.

A review of the literature suggests that $\mathrm{SOC}$ use is seemingly ignored by engineering educators. However, other studies involve SOC and college students. For example, Darling et al. (2007) investigated stress among freshman college students, how they cope with stress, and how the stress of renegotiating self and relationships influences their SOC. In addition, Darling et al., discussing the implications for educators, found that failure to "make an initial launch" (i.e., leave home and move to college) or failed attempts at doing so may be the result of a lack of SOC. Consequently, Darling et al. argues that awareness among students, educators, and program developers of the importance of the crucial nature of fostering SOC can help raise the likelihood that students will increase their SOC. Darling et al. also conclude that "educators can take the initiative to structure courses and course content to be sensitive to SOC and the management of stressor pile-up often experienced by college students" (2007).

Cohen et al. (2008), assessing SOC, coping strategies, and test anxiety as predictors of test performance in first-year undergraduates, found that SOC were negatively related to test anxiety, but the study also found that test anxiety is minimally associated with performance grades. Cohen et al., however, was unable to establish a relationship between SOC and student performance. Ying et al. (2001) had similar results examining the relationship between overall competence (operationalized by SOC) and grade point averages among undergraduates. However, Kristensson et al. (2005) found a relationship between SOC and performance in terms of grades (among upper secondary pupils), although inter-related with other variables as 
did Al-Yagon et al. (2004), who studied elementary school pupils. Thus, the literature remains inconclusive regarding the influence of SOC on performance.

From a general perspective and to summarize the bibliographic status of the salutogenic model and its core concept of SOC, Eriksson et al. (2006) serve as a suitable reference. Following a systematic integration of the contemporary knowledge base on the salutogenic research, Eriksson et al. conclude that "SOC is strongly related to perceived health, especially mental health. The stronger the SOC the better the perceived health in general, at least for those with an initial high SOC" (2006). It is also in the field of health we mainly find references to SOC and salutogenesis. A Web of Science category search query using the keyword "salutogenesis" reveals the distribution of records as being heavily oriented toward health sciences. Of the 330 records, 101 fall within the Public Environmental Occupational Health category, followed by Nursing (40), and Health Policy Services and Psychiatry (both 28 records). Queries were conducted in October 2020, spanning records between 1975 and 2020.

Moreover, SE is often used "to investigate student performance" in education settings in general and often are referred to in reports dealing with EE. Salutogenesis and SOC, however, is evidently unheard of within EE. Paper [VII] found a bibliometric review (Web of Science, 2020) of the presence of SOC/SE related keywords in seven of the most cited scientific journal publications connected to the field of engineering education (based on the $\mathrm{H}$ index of the SCImago Journal \& Country Rank) (Table 2-4). The timespan for the queries was set between 1975 and 2020, but none of the studied journals returned publications that included either the keyword "Sense of coherence" or "Salutogenesis". Free text search queries (through Google Scholar) using "sense of coherence" rendered a few hits but without relevance. Moreover, no combination of SOC keywords and keywords related to program development and management (e.g., "curriculum design", "curriculum development", and "program management") yielded any search results. Altogether, this indicates that the use of SOC instruments for curriculum development and program management are poorly investigated and therefore a research gap to be filled.

Table 2-4 Bibliometric overview of the presence of SOC/SE keywords in relevant scientific journal publications. Queries conducted October 2020, search interval years 1975-2020.

\begin{tabular}{|c|c|c|c|c|c|c|c|}
\hline \multirow[b]{3}{*}{ Publication Name } & \multirow[b]{3}{*}{ Country } & \multirow{3}{*}{\begin{tabular}{c|} 
SJR \\
H Index
\end{tabular}} & \multicolumn{5}{|c|}{ Web of Science } \\
\hline & & & \multirow[b]{2}{*}{$\begin{array}{l}\text { Impact } \\
\text { factor }\end{array}$} & \multirow[b]{2}{*}{ Records } & \multicolumn{3}{|c|}{ Keyword } \\
\hline & & & & & 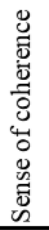 & 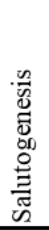 & 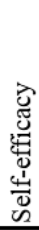 \\
\hline Journal of Engineering Education & United States & 101 & 2.63 & 610 & 0 & 0 & 13 \\
\hline IEEE Transactions on Education & United States & 65 & 1.85 & 2682 & 0 & 0 & 6 \\
\hline Journal of Science Education and Technology & Netherlands & 56 & 1.64 & 782 & 0 & 0 & 22 \\
\hline International Journal of Engineering Education & Ireland & 47 & 0.65 & 3246 & 0 & 0 & 24 \\
\hline European Journal of Engineering Education & United Kingdom & 41 & - & 393 & 0 & 0 & 10 \\
\hline International Journal of Technology and Design Education & Netherlands & 37 & 1.3 & 695 & 0 & 0 & 9 \\
\hline International Journal of STEM Education & Netherlands & 14 & 1.85 & 223 & 0 & 0 & 6 \\
\hline
\end{tabular}




\section{3 Contributions}

This thesis is based on research contributions targeting the three research areas product development, engineering education, and learning analytics as illustrated in Figure 1-1. This chapter starts by formulating the research contributions in relation to each of these areas where section 3.1 is directed more towards product development and the research conducted in paper [I] and [II], section 3.2 towards engineering education and papers [III] and [IV], and finally 3.3 to learning analytics based on the results from papers [V]-[VII]. Furthermore, a common and overarching contribution integrating the three domains could also be concluded, as is described in section 3.4 .

\subsection{Knowledge Creating and Learning Processes Supported by Physical Demonstrators}

Based on mainly paper [I] and paper [II], the licentiate thesis (Hallberg, 2013) introduces the concept of low-cost demonstrators (LCD) as opposed to conventional (and costly) demonstrators like the ones found in the aerospace industry (Figure 2-6). It is argued that LCDs allow for a more flexible and effective PD process that avoids expensive iterations of prototypes late in the process. The proposed purpose of a LCD is to act in parallel to the conventional PD process, allowing for maximized cost-effectiveness and flexibility. Papers [I] and [II] as well as papers [VIII], [IX], and [X] argue for different purposes of the LCD, such as physically validating parts of a digital prototype early on in the PD process or assessing viability of new technology. A more explicit capability of the LCD is to identify potential problem areas in the final product and subsequently conduct early requirement modelling identifying technical areas that have to be incorporated in a digital model and subjected to further analysis and development. The LCD is also framed as a remedy for the "devil in the details" if used to refine requirements on the product itself, since some requirements are not obvious until a physical manifestation of some kind has been realized. 


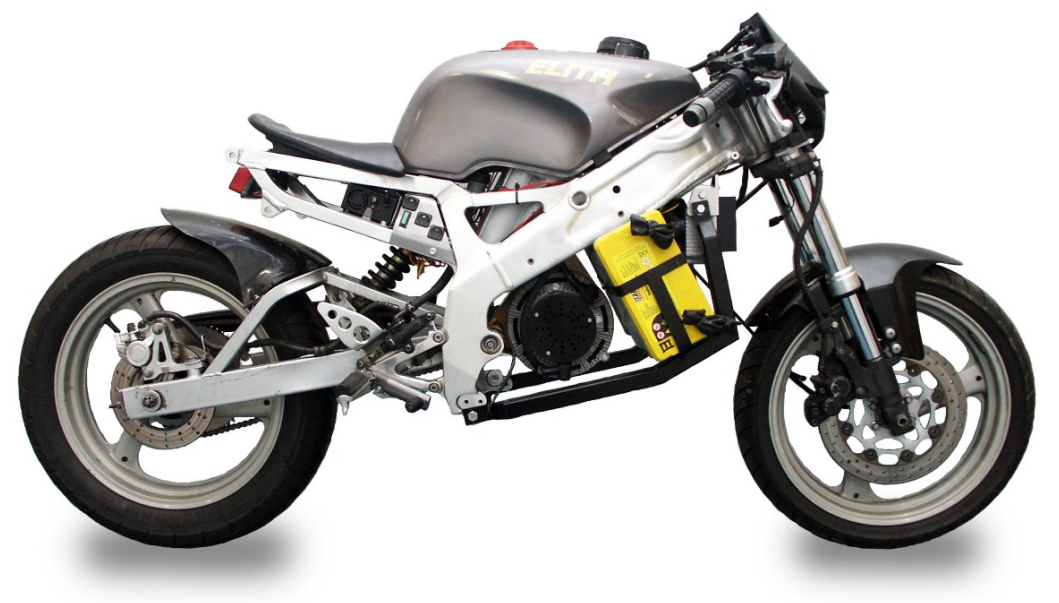

Figure 3-2 Example of a low-cost demonstrator. The pictured vehicle was an outcome from a final year project course on the mechanical engineering master program, involving costeffective exploration of an electric motorcycle concept by conversion of a conventional motorcycle.

Specifically, paper [I] as well as papers [VIII], [IX], and [X] examine LCDs by exploring requirements for transforming a product based on mature technology (internal combustion propelled two-wheel vehicles) into a product that uses a completely different domain of technology (electric propulsion). Figure 3-2 pictures one of these vehicles that was an outcome from a final year project course on the mechanical engineering master program. The project demonstrated exploration of an electric motorcycle concept by conversion of a conventional motorcycle. As the project sought for cost-effectiveness due to a restricted course budget, the design team used a scrapped vehicle and off-the-shelf components. Moreover, not only were the projects described in papers [I] and [VIII] - [X] constitute a methodological contribution regarding the use of LCDs in practice; today, the concept is ever so relevant given the current rapid transformation of many industry domains, away from fossil dependent technology to electrical substitutes. In addition, paper [II] picks up on several beneficial aspects of the LCD concept when reporting on a large CAD introductory course within an EE setting. The course is organized according to the CDIO initiative involving designing, building (implement), and
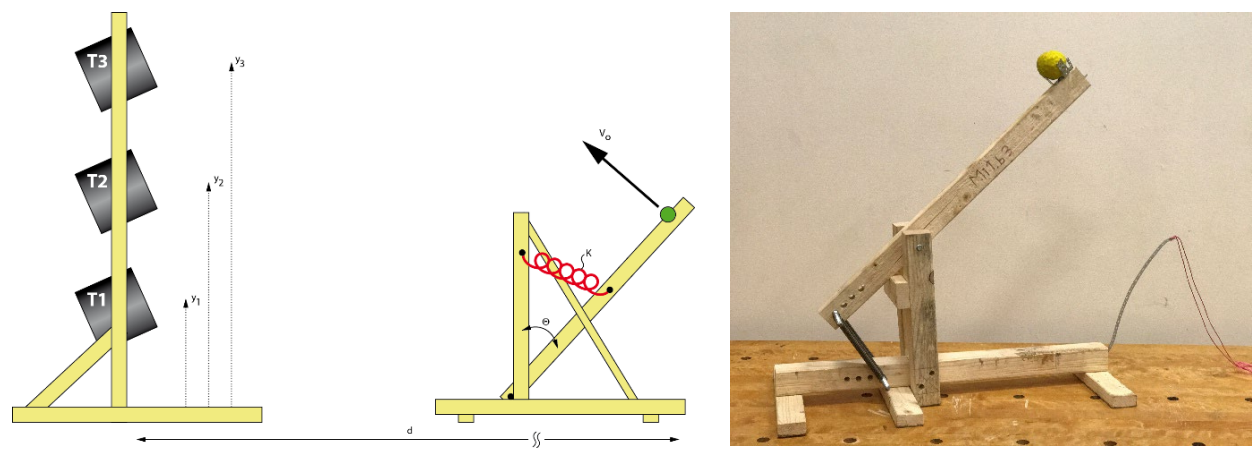

Figure 3-1 Illustration to support description of requirements, including the critical variables for a student project (left) involving designing, implementation and operation of a catapult (right). 
testing (operating) of a catapult that needs to hit a predetermined set of targets (Figure 3-1). To achieve this, the students are required to iteratively work with the physical representation of the digital (CAD model). As with the LCD motorcycle project, the student project described in paper [II] demonstrates a similar easy access, hands-on, and cost effective approach to realization of physical artifacts whose purpose is to support the design process.

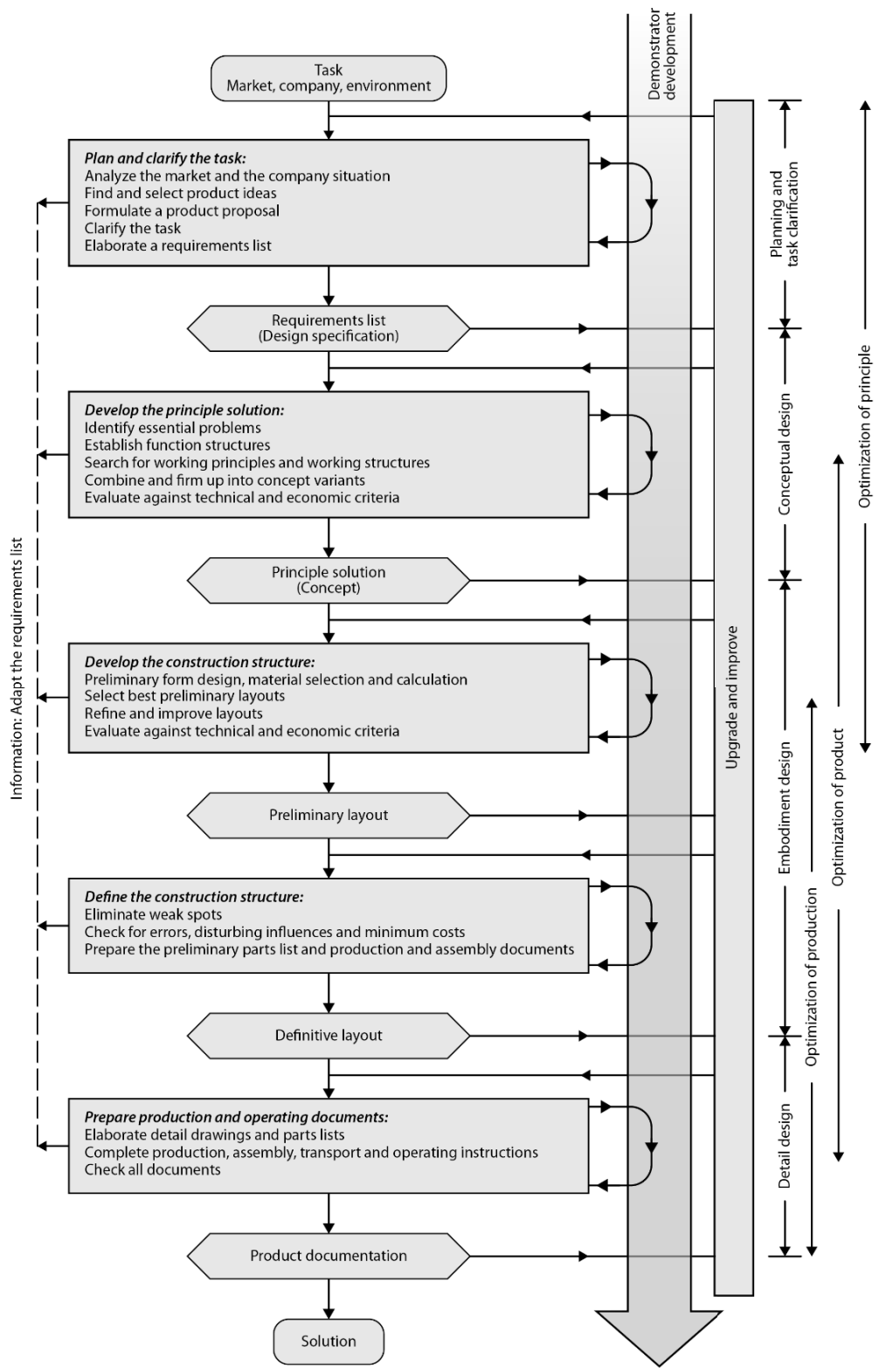

Figure 3-3 The Pahl and Beitz design process supplemented with a supportive demonstrator development process. (Hallberg, 2013) 
Moreover, papers [I] and [II] clearly focus on the presence of physical representations during knowledge creating processes, both from a PD perspective and a EE perspective. One of the joint messages of these two contributions is to emphasize and confirm the importance of deploying supportive attributes during knowledge creating processes, which also was the main take away from the licentiate thesis (Hallberg, 2013). Figure 3-3 (also from the licentiate thesis) illustrates this from a theoretical PD perspective and is an example of the PD process described by Pahl et al. (2012) and is continuously supported by demonstrator throughout the development process. The licentiate thesis (Hallberg, 2013) further elaborates on the role of a demonstrator relative to each of the stages of the process:

- Plan and clarify the task. The demonstrator is mainly used to support the requirement modeling process and planning for the forthcoming design process. If it is a matter of a new revision of an ongoing product life cycle, an already present demonstrator may be used to process information from the previous generation of the product, e.g., feedback from the market or the company's service organization or customer feedback.

- Develop the principle solution. This is perhaps the most obvious phase where the lowcost demonstrator would play a vital role. Being low-cost means that it (or several copies of it) would enable easily accessible concept exploration and evaluation. Customers could be brought in to assess whole concepts or small details without jeopardizing intellectual property. New and/or unfamiliar technology could also be evaluated using the demonstrator.

- Develop the construction structure. Here the main role of the demonstrator would be to back up the evolving digital models of the product being developed. For example, computer-intensive thermal analysis could be bypassed if performed on the demonstrator instead, consequently speeding up the product development process. Optimization studies could be performed in a hardware-in-the-loop manner.

- Define the construction structure. At this stage, the demonstrator could be used for continuous validation of the detailed solutions being made for the developing product. Refinement and optimization of subsystems are other possible tasks for the demonstrator.

- Prepare production and operating documents. At this stage, most likely a production prototype is being produced and naturally that prototype is part of the production planning process. However, by using the demonstrator, preparations for production could be begun much earlier thus gaining in time to market. 


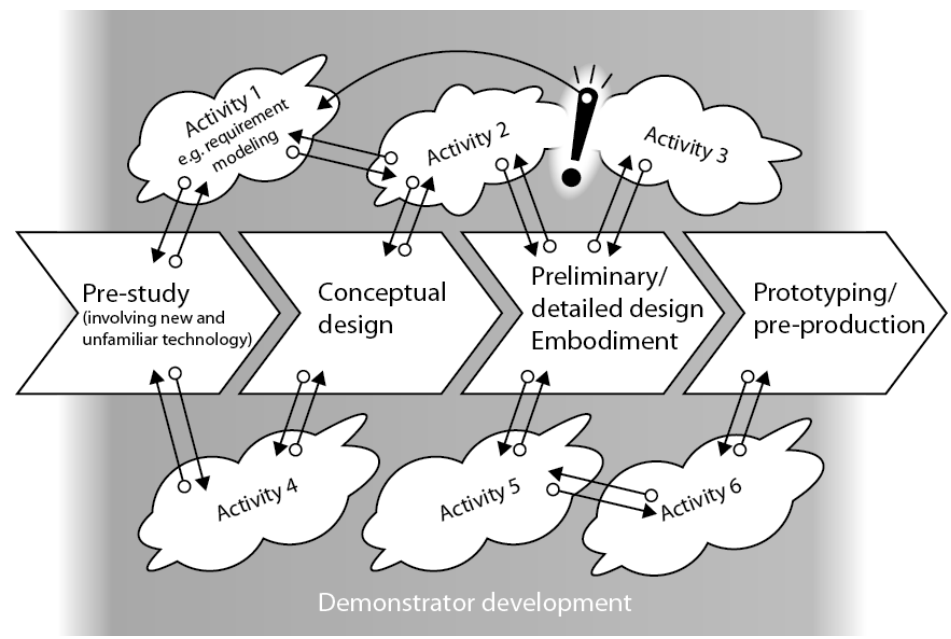

Figure 3-4 A conceptual depiction of a product development process supported by a parallel demonstrator being developed. (Paper [II])

Although the view on and concept of LCDs as "learning platforms" supporting the PD process was introduced in Paper [I], it was not until in Paper [II] a more detailed description of the function of a LCD in relation to a product development process took form. Figure 3-4 is adopted from Paper [II] and illustrates the demonstrator development process as activity parallel to a PD process. The paper elaborates this further:

The traditional product development process moves on, the low-costdemonstrator serves as a platform available for the design team to swiftly conduct studies in order to achieve vital information necessary for the development of the product. This 'platform-for-low-costdemonstration' should be available to all disciplines of expertise within the company or design team during all stages of the development process. For instance, the marketing department may use one part, or sub-system, of the demonstrator to conduct early customer studies, while the same sub-system is subjected to concept validation by the design department, where it may co-exist with other, less mature, sub-systems.

The nature of the contribution from this research area clearly has a practical aspect in the industrial context as well as from an EE perspective. For example, the introduction of a physical artifact in the CAD course described in paper [II] was not only beneficial for the students in terms of CAD skills but also how they "perceived" the course in more general terms, as shown in the course evaluations reported in the paper. Particularly interesting is the seeming ability of the physical hardware to clarify the task, which is reflected by the positive statements from the students regarding whether "the assessment was a good test of my understanding of the course content". The importance and benefits of involving physical artefacts in EE are well documented (Freeman et al., 2014), as these two papers confirm. However, the papers also show how the concept of active learning could be taken a step further by bridging product development from an industrial viewpoint and EE learning processes. 


\subsection{A Physical Platform Approach for Enabling and Implementing Educational Frameworks}

Whereas papers [I] and [II] speak of LCDs as a mean to connect product development and learning on the undergraduate level, papers [III] and [IV] adopt the principals of demonstrators as learnings platforms and suggest the concept of CDIO enabling platforms with reference to the CDIO educational framework presented in chapter 2.2.

The initiative to explore the concept of physical learning platforms emerged from the argument that an LCD allows for multiple design teams to work in parallel and simultaneously with the demonstrator. This results in an inevitable integration of the team members and their knowledge, with chances of new insights and otherwise overlooked phenomena. Paper [III] describes an attempt to use the integrative capabilities of a physical demonstrator to enhance and promote aspects of the implemented CDIO framework on a Mechanical Engineering bachelor program at Linköping University, in particular aspects related to CDIO Standard 7 (Integrated Learning Experiences) and CDIO Standard 8 (Active Learning). Here, the LCD took the form of an electric modular cargo bike to serve primarily as a physical reference model in a stretched-out computer engineering course. See the course TMKT73 in the semester overview displayed in Figure 3-5.

The bicycle was physically realized in the department workshop including associated welding fixtures. It was also deliberately half-finished and paired with a fictitious business case and product development scenario that allowed the students to approach a mandatory project assignment from different aspects and roles. More importantly, the bicycle was intentionally designed to allow for integration of tentative knowledge achievements from the four courses running in parallel with the course that hosted the bicycle. Figure 3-6 displays the complete setup including the so-called integrative interfaces that were introduced to the students for further exploration in the relation to the surrounding courses.

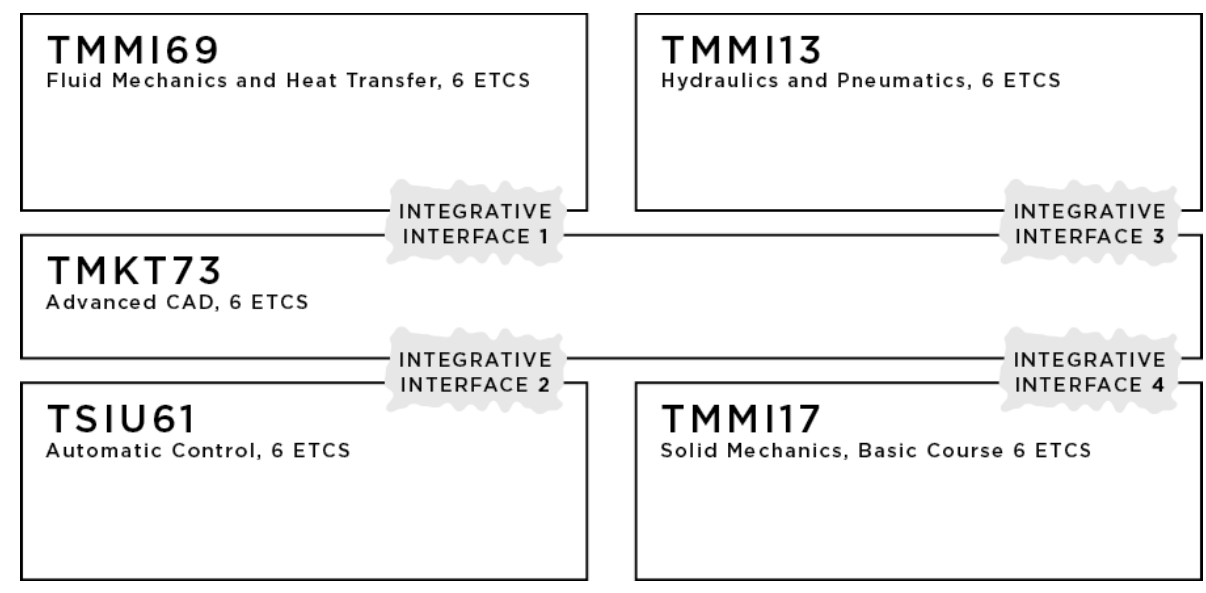

Figure 3-5 Outline of the 3rd semester of the Mechanical Engineering bachelor program at Linköping University. The course TMKT73 Advanced CAD was hosting the electric modular cargo bike as the enabling learning platform. 


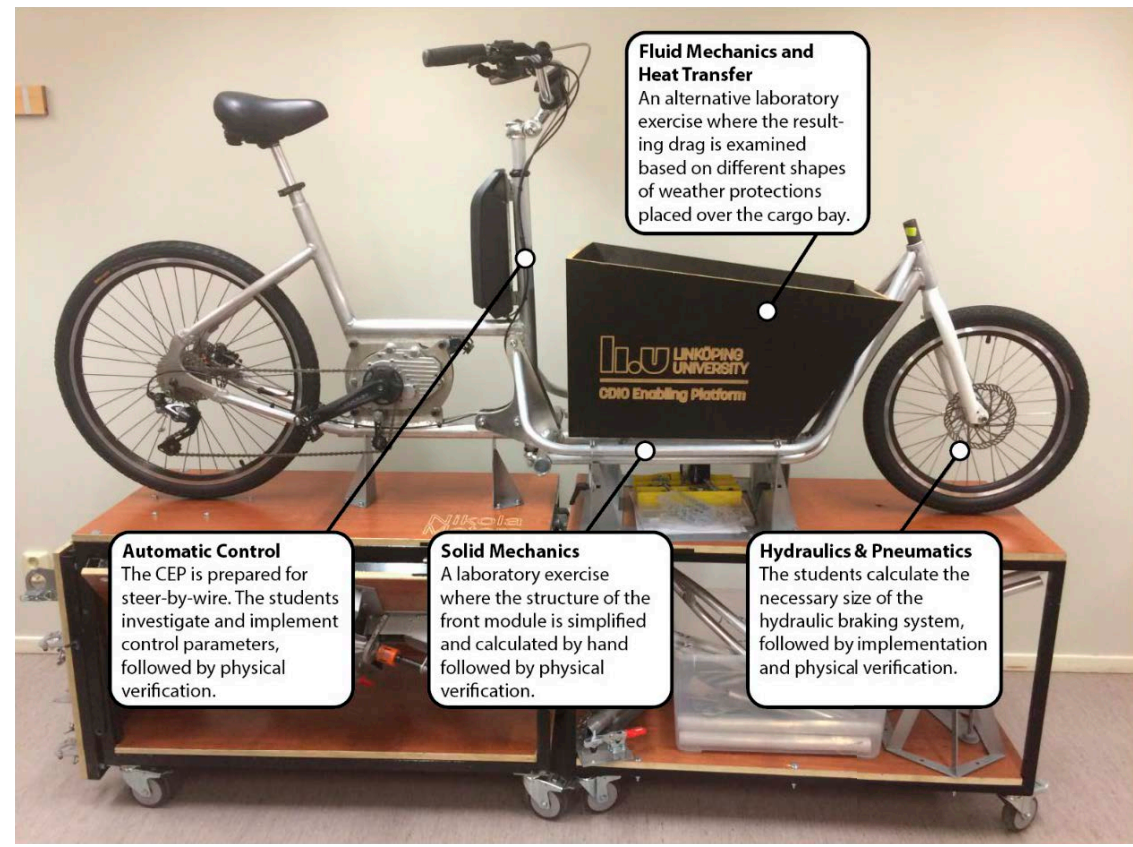

Figure 3-6 A physical representation of a CDIO Enabling Platform. Here exemplified with the rear and front module of an electric modular cargo bike, together with associated welding fixtures. The callouts show tentative integrative interfaces made available by the platform.

Following observation and analysis of the introduced bicycle and fixtures, the functioning of the actual integration with the surrounding courses, etc., the term CDIO Enabling Platform $(C E P)$ was coined. The term platform is justified both literally and metaphorically. Metaphorically, the platform is pictured in its wider meaning, more like an organizational unit that stakeholders on a particular semester gather around to create and process knowledge while executing the curriculum. Examiners and program planners could use the platform as a base to build and organize courses. Literally, the platform refers to the actual presence of the physical artefacts that resemble the platform - i.e., the assembly station with welding fixtures seen in Figure 3-6. For example, the station is equipped with wheels and therefore it can easily be moved between classrooms, workshops, labs, etc. In addition, the fact that the chosen product (the cargo bike) is modular opens up for developing different modules serving different purposes in parallel courses without ruining the overall scenario (or budget).

In addition to a more thorough description of the genesis of the CEP, paper [III] also argues for a its generalizability in terms of enabling and promoting the implementation of several CDIO standards. In addition to the already mentioned standards 7 and 8 , the concept as a whole naturally addresses the CDIO Standard 3, Integrated Curriculum, and indirectly the CDIO Standard 4, Introduction to Engineering. Furthermore, the platform may serve as a catalyst for discussion about the role of the engineer and places the learning activity, whatever it might be, in a context more similar to the industry, especially combined with a scenario. This clearly addresses CDIO Standard 6, Engineering Workspaces.

After all, many examiners active in mechanical engineering programs are either trained product developers or at least they have a view of where their discipline fits into the product development domain. However, many examiners are nevertheless comfortable as theorists or 
are forced to act as such while conducting their duties. In these cases, the introduction of a physical platform/scenario-based tool for learning could encourage examiners and teachers who would like to transform their teaching. Paper [III] states that the CEP could facilitate implementation of the CDIO framework as a whole, but it also specifically points towards CDIO Standard 9, Enhancement of Faculty Competence. For example, if the examiners are involved in the process of defining a platform, they will have to apply their domain of expertise onto the platform and at the same time adapt to the other examiners and their domains.

Paper [IV] pushed the concept of the CEP further by widening its area of action, elaborating on multiple roles, in particular with respect to the motives of this thesis as described in the introduction. Figure 3-7 illustrates some of the roles that paper [IV] argues that a CEP (or multiple) tentatively can play when active as an integrator between the academy and the industry. A quadrant-by-quadrant walk through of Figure 3-7 reads as follows:

- Academy/R\&D - the CEP acts as a platform for execution of joint industry/academy research projects. Moreover, existing (preferably physical) subjects of research projects may be used to develop undergraduate courses; if cleverly organized, simultaneously the CEP might support the very same research projects. In cases where the CEP resembles a physical product under development, activities of product development research are imaginable.

- Academy/EE - The CEP serves as a catalyst for curriculum development and maintenance as it fosters an overview for both students and faculty members. CEP has the potential to enable the implementation of CDIO standards, especially CDIO standards 3-8. Apart from being the backbone of a curriculum as a whole, there is also the possibility that CEP can serve as a subject for "stand-alone" lab exercises or thesis projects. Another plausible use is to let the CEP act as the collective subject upon which students from different programs collaborate.

- Industry/EE - If the CEP has a strong connection to the product development process within a collaborating company (which perhaps even took part in developing the CEP), it would be natural to formulate final year thesis projects for students close to exam. Consequently, such thesis projects would serve as a valuable recruitment reference for first employment. Also, as previously discussed, the CEP could be the connector regarding engineers in need of re-education due to effects of rapid transformation in the labor market.

- Industry/R\&D - Apart from being the corresponding industry/academy catalyst for collaboration, a CEP may also be represented in the form of a demonstrator perhaps as a part of research intensive product development projects. Examples of such demonstrators are common at technical universities but are rarely integrated with undergraduate activities.

Thus, Paper [IV] frames the CEP as a catalyst for integration between the stakeholders in the "eco-system" that consists of intersections between research/education and academy/industry environments. Moreover, paper [IV] argues for the CEP as contributing to and enhancing the cyclic aspects of this eco-system with reference to knowledge and information being created and the people who contribute. The central theme that addressed by this reasoning is the integration of knowledge creation activities illustrated by the overlapping field in Figure 3-7. Fundamentally, the prosperity of both industry and academy organizations depends on the success of their knowledge creation processes. However, these processes are connected with each 


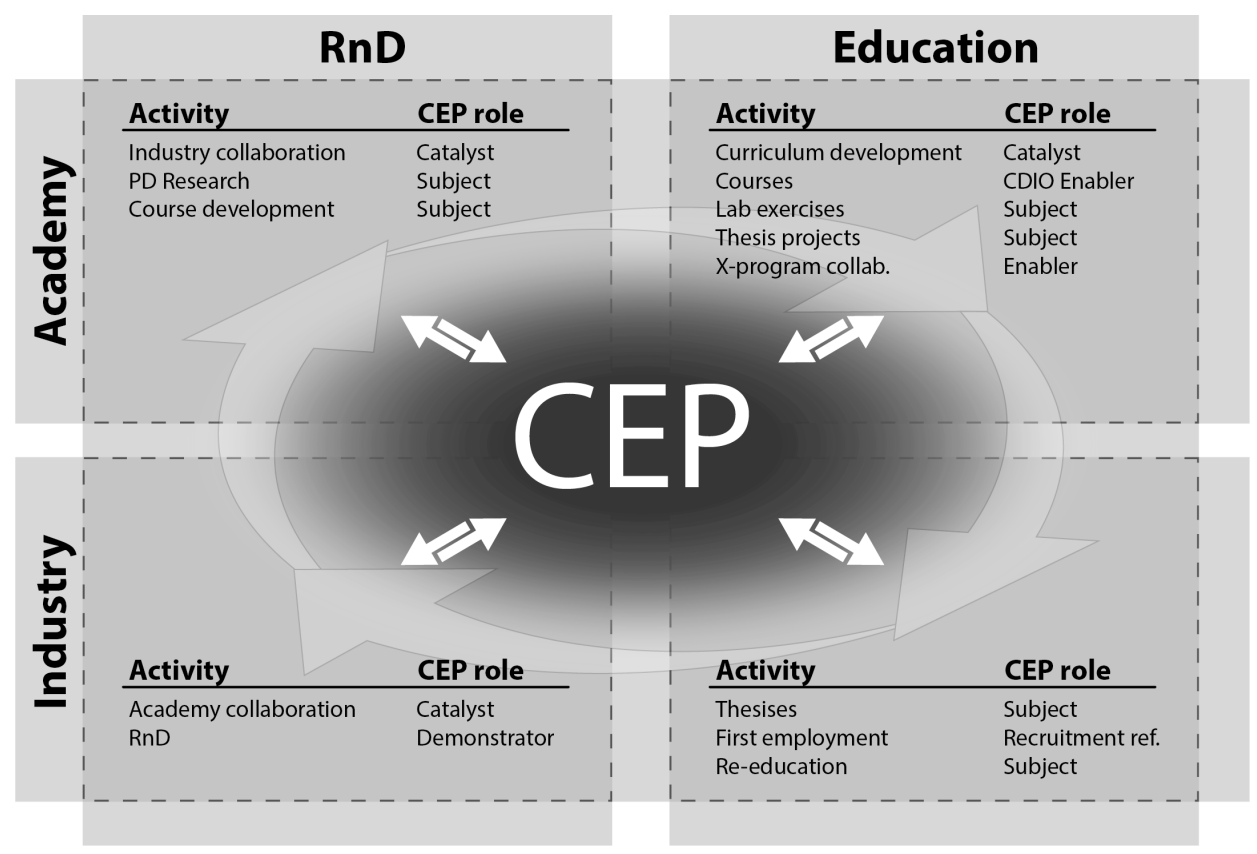

Figure 3-7 Schematic illustration of the CDIO Enabling Platform, showing examples of potential roles for different activities within the intersections of the academy and industry domains, and the research and education domains. The circling arrows indicates the intellectual properties, or people moving between domains. The illustration is adopted from paper [IV].

other via intellectual properties (possessed by scholars, graduates, or industry employees) flowing from one organization to another. The four-field matrix in Figure 3-7 schematically illustrates this flow as a cyclic loop (indicated by the circling arrows) where the CDIO Enabling Platform could work as a knowledge creation hub for many of the activities that take place within the industry and academy. Conducting higher engineering education is fundamentally an effort to integrate research with undergraduate education (through integration of state-ofthe-art knowledge into education) and students with the industry (via employment following graduation). Also, through joint research projects, the industry integrates with the academy, which in a sense closes a "loop of knowledge creation".

To further elaborate on the cyclicity of Figure 3-7, yet another feature aspect is actualized with the debate about so-called returning students, following shifts in competence demands as industries transform and adapt to new technologies and market conditions. Paper [IV] argues that the design of a CEP should consider the background of those returning students either by directly targeting their previous experience with the purpose of - and the CEP as a catalyst transferring their skills to the young students who are without industry experience or simply with the intention of adding specific skills to the returning students' toolbox. In any case, and this is also addressed in paper [IV], a CEP that is designed to meet the requirements and needs of returning students with industry experience provides an opportunity to transfer knowledge that almost exclusively comes from working in the industry. Paper [IV] explicitly points out tacit knowledge as such type of knowledge that institutions find very hard to teach. First coined in 1994 by Polanyi (Polanyi, 2009), tacit knowledge typically refers to skills acquired by someone who has been active in a profession for an extended period. In some cases, the only 
way of teaching such knowledge is to observe someone who possesses it while she or he actively makes use of their skills. Therefore, the arrangement of curriculums so that returning students and undergraduates cooperate on the same CEP with different (or the same) learning objectives would enable a transfer of knowledge otherwise hard to achieve. Also, much of the meaning of the term "employability" refers to tacit knowledge (or lack thereof) and other skills, heuristics, and behaviors that employers are looking for but are often absent in new graduates.

If read from a faculty perspective, all three of these papers provide important contributions regarding curriculum and course design using physical artifacts. This is especially the case when discussing implementation of active learning content in the curriculum. The cost-effective aspects of the LCD that are argued for from a PD/industry perspective can largely be translated into an academic setting. It is well-established that active learning is a catalyst for knowledge achievement (Prince, 2004), but implementing active learning modules in the curricula is equally known for requiring an extended budget. Lab equipment and other course material is expensive. The concept of LCDs for use in academic settings, as demonstrated in papers [I] and [II] (and the additional papers), should be seen as a tool for enabling active learning due to cost-reducing effects from sharing the LCDs between different modules, courses, and curricula.

But perhaps even more important, the reasonings about enabling platforms connect to organizational aspects of curriculum execution. The platform concept, exemplified as a CDIO Enabling Platform, offers solutions to some of the major challenges faced by curriculum developers, program managers, and other stakeholders. As noted in paper [III], the platform approach facilitates and ensures an educational framework implementation, such as the CDIO framework, and provides a more industry-like learning environment.

\subsection{Measures and Metrics for Supporting Development and Management of EE}

A fundamental part of the product development processes is to measure and predict the properties of the product being developed as well as to ensure an efficient process towards the finished product. These are also key motivations for the LCD concept as well as the CEP concept. During PD, there is a desire to efficiently and early-on obtain knowledge about, for example, "how much will the product cost?", "can it be produced?", and "will it meet customer expectations?". To obtain such information, developers may deploy different kinds of metrics and measures targeting both the development process and the product under development. Papers [V]-[VII] explore corresponding measures targeting the EE process (i.e., the engineering curriculum) and the "product" (i.e., the engineering student) with the purpose of improving both. The outline of this section essentially follows the numerical order of these papers.

\subsubsection{Overview}

Paper [V] serves as both an overview and a starting point for the exploration of measures and metrics for curriculum development and program management. The paper identifies the following four categories of "measurable" information as subjects of interest:

- Independent/Input data - This category represents official data that are more or less static and pre-determined such as type of programs, curriculum outlines, and syllabuses. Such information, although fully controlled by the faculty, tends to be characterized by rigidity and predictiveness, at least in shorter time frames. Students' personal and background data also belong to this category such as gender, enrollment age, and high 
school rank. If subject for statistical analysis, these data typically form independent variables.

- Dependent/output - Typically, these data are from students working according to the curricula. Not only passed (or failed) credits but also change of status, drop-outs, student throughput etc. belong to this category. Thus, these data may be viewed as dependent or output data that program planners can only indirectly affect by making changes to the curricula.

- Ambiguous data - These data cannot easily be categorized as either independent or dependent and include measurements of individual psychological or coping capabilities. Although measurement instruments are well established, it is often hard to find strong and clear connections between variables. Such data may also change as individuals develop, so the faculty has limited or no means available for influence.

- Real-time data - These data are continuously gathered during the actual learning process and may be both independent and dependent. Such information allows for continuous analysis and consequently more immediate responses from the teachers or the faculty. These data include patterns during classroom sessions and attendance but also data targeting specific issues that may be collected through on-the-fly questionnaires similar to customer satisfaction surveys frequently used within the marketing industry resulting in a so-called CSAT score (Farris et al., 2010).

Furthermore, paper [V] identifies three potential concepts of measures targeting curriculum development and program management. Each emphasizes different approaches to assessment of the EE learning environments as well as factors that might influence EE students' performance:

- Degree nativeness of curriculum content - A measure of the extent to which a particular element or type of curriculum content connects to the label of the degree the program entitles to. This forms a measurement that exposes the relation between curriculum characteristics and the performance of the students. Here the relevant data accessible for statistical analysis are characterized as independent and dependent input/output data.

- Measures of coping capabilities - Paper [V] suggests adopting psychometric measurements, some of which are previously unexplored within EE settings, with the purpose to evaluate the coping capabilities of first-year students. By doing so, it is possible to assess such measures as tools for elevated understanding of the behavior and performance among EE students. The relevant data are characterized as independent and dependent input/output data, but also ambiguous data.

- Real-time data gathering and Learning analytics - Paper [V] suggests collection of data in ways that allows for continuous monitoring and rapid response to changes in the EE environment. Data collection involves passively recorded environmental data and data originating from tracking real-time behaviors of students in their active learning process. Obviously, here the relevant data belong to the real-time data category. However, paper $[\mathrm{V}]$ points out the potentials of combining this data with data from other categories. 
The first two of these concepts - degree nativeness of curriculum content and measures of coping capabilities - are subjects of papers [VI] and [VII], respectively, and are discussed separately below. However, paper [V] elaborates on the initial findings following exploration of real-time measurement of both environmental data and student behavioral data. The paper reports of a project clearly targeting the emerging field of learning analytics, involving multiple means of data gathering allowing for analysis using interactive visualization tools (i.e., business intelligence tools such as Microsoft Power BI) (Power BI, 2020).

More specifically, the project declared for in paper [V] develops a help request and management application with the capability to store and visualize data generated from students and tutors using the application (Figure 3-8). The first prototype of the application consisted of a student desktop app (LiU-Help!) where the student can post a request for assistance from a tutor rather than raising hands. While registering the request, the student is required to provide details such as "which assignment", what type of problem, and location. The students' requests appear in the tutor's mobile application in the order they are posted allowing for a "fair" turn taking. The tutor's app also includes features to streamline the tutoring process such as monitoring where most of the students in need for help are located, producing a type of "heat-map". Through the app, the tutors can call for assistance from other tutors, minimizing the risk of leaving students without having been helped. Finally, a back-end application was set up to visualize all the data generated by both LiU-help! and the tutor's application.

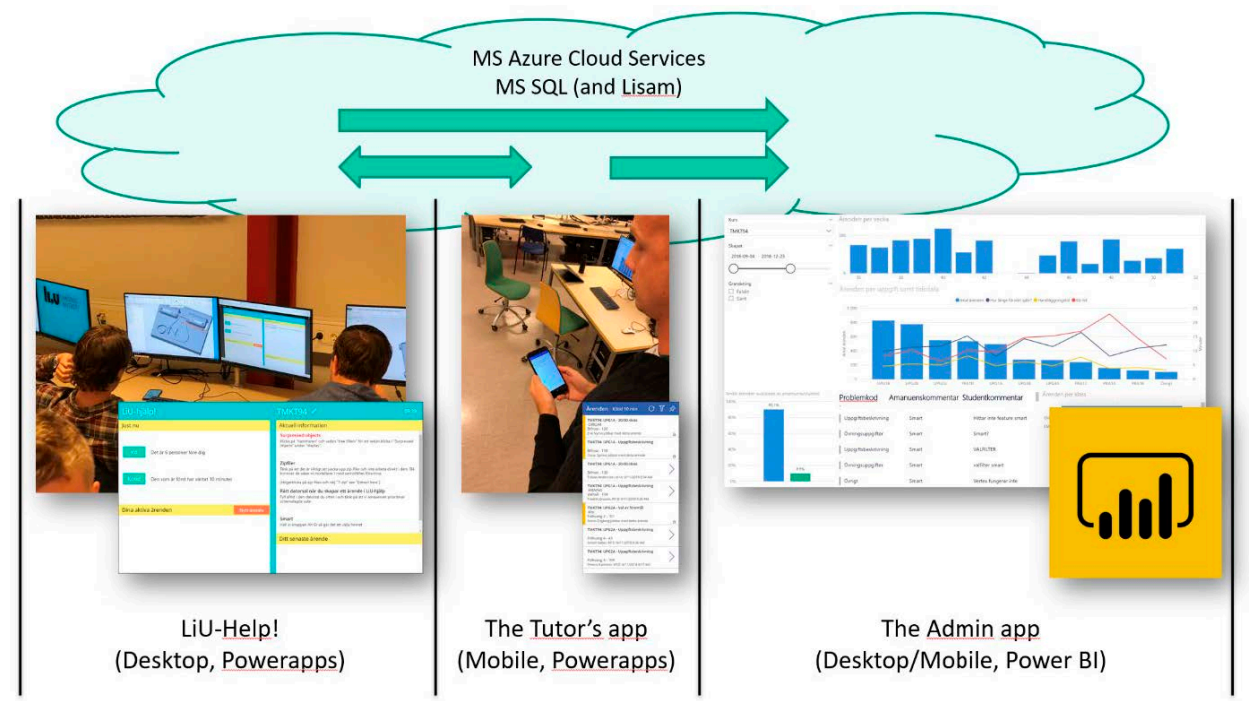

Figure 3-8 Overview of the student help request and management application.

The application described above and in paper [V] constitutes a typical instrument targeting LA (Learning Analytics) domain. As an example, the LiU-Help! application that was used by the students to request assistance is equipped with a kind of "frustration indicator" that, for example, allows students to estimate how long they tried solving a problem before posting the request. This indicator proved to correspond well to the previous experiences (from tutors) of which assignments are more or less demanding for the students. Thus, this approach potentially offers a quantitative real-time measure of student efforts during the learning process. Furthermore, of the three programs that the studied course is given for, one program is significantly different in terms of nativeness of the course subject (i.e., CAD). This 
circumstance can seemingly be visualized using the data, whereas the students "request pattern" differs from the students to which the subject is considered native. Other group level data point in the same direction (e.g., average handling time for tutors to help a student on different programs and the number of requests for help). Also, recorded data from previous semester proved useful for planning the next course, especially in terms of staffing and resource allocation.

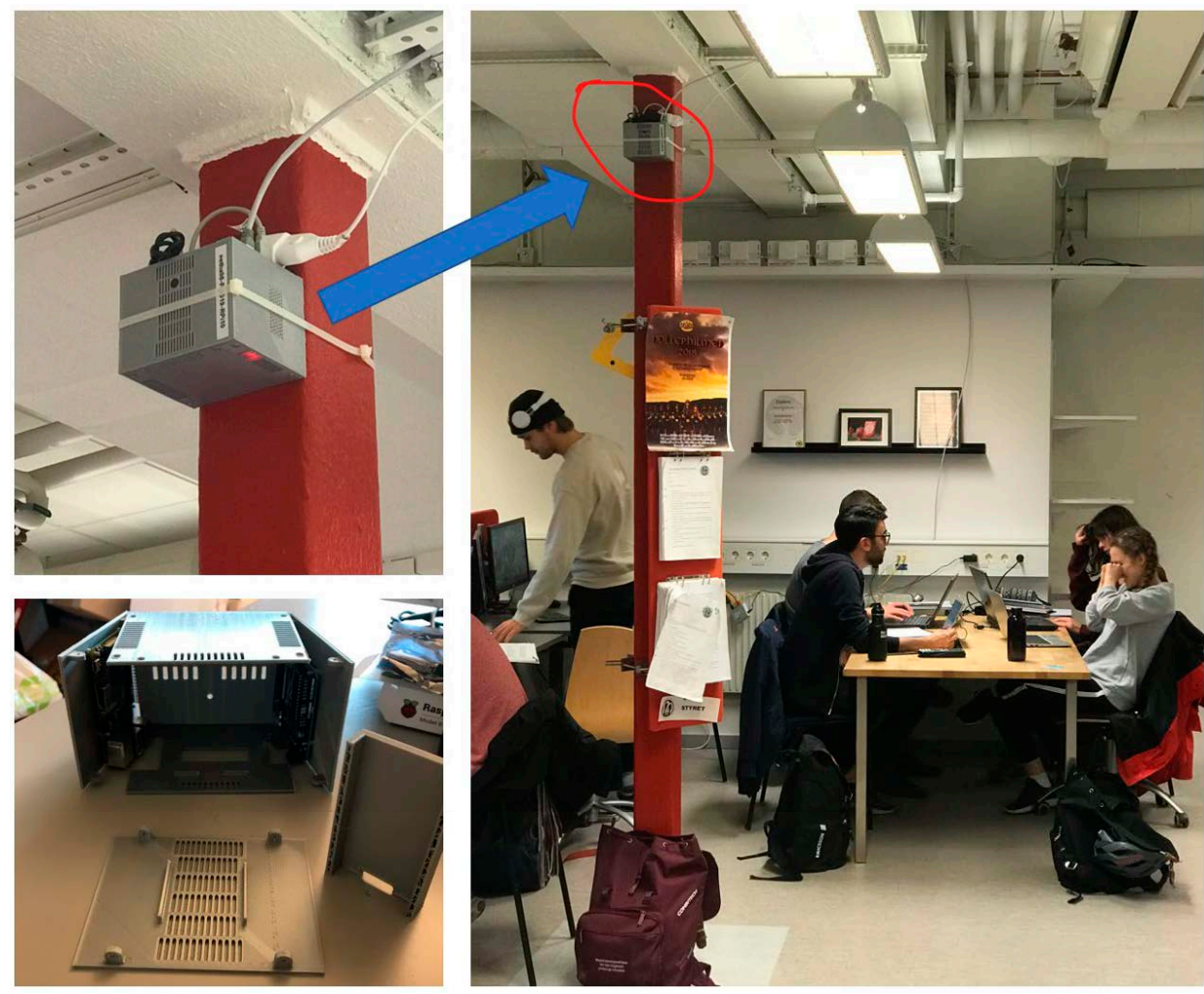

Figure 3-9 Pictures of the indoor climate measuring stations. The 3D-printed housing with Raspberry Pi and Arduino boards plus sensors (lower left) and an example of placement of station in a computer room (upper left and right).

Moreover, the project developed indoor climate measuring stations that were placed in the computer room used by the students during laboratory sessions (Figure 3-9). The stations passively record environmental properties in the computer rooms used for the sessions where supervision from tutors can be requested. The recorded data include $\mathrm{CO}_{2}$, volatile organic compounds (VOC), temperature, pressure, humidity, and noise levels. Thus, for each case posted by the students using the application, these environmental data are stored along with the data registered by the student and the tutor, so these data are available for additional analysis in relation with other types of data. For more details, see paper [V].

Altogether, the above described functionalities of the LA project that paper [V] reports concerns the multiple stakeholders listed in Table 2-3: 
- Students can, e.g., be presented with continuous feedback of their progress and achievement status with respect to the learning goals and examination requirements.

- Educators can monitor a group of students and their progress and make adjustments in course content accordingly.

- Program managers can, e.g., continuously monitor and compare group of students regarding progress, achievement, and attrition and compare data with previous cohorts of students.

\subsubsection{Novel measures of curriculum characteristics}

Paper [VI] adds two new expressions to the terminology of EE - native content and curriculum nativeness. Native content should be seen as the enabler of curriculum nativeness. The basis of these two terms is to what extent a curriculum is recognized and perceived as connected to the domain of technology and field of profession targeted by a specific engineering degree program. The paper uses preexisting classifications of courses at the studied institution (based on a set of main subjects, e.g., Mechanical Engineering, Computer Science, Mathematics, and Biology) to express curriculum nativeness in terms of a measurable variables suitable for statistical analysis. The measure Native Credit percentage (NC) is defined as the sum of all credits derived from courses classified within a main subject that clearly connect with the profession degree divided by the total number of credits (European Credit Transfer System, ETCS) for the studied period or program:

Table 3-1 Composition of studied programs during the first two semesters based on main subject occurrences for courses in the program. For each main subject, the number of occurrences of each program is specified. Gray cells indicate subjects that were judged to be native for the program, given its degree title. The total number of courses differ from the sum of all main subjects because a course might be classified with up to three main subjects.

\begin{tabular}{|c|c|c|c|c|c|c|c|c|c|c|c|c|c|c|c|c|c|c|c|c|c|c|}
\hline Degree title & 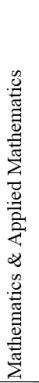 & 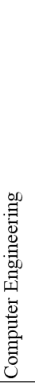 & 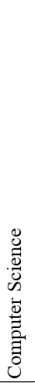 & 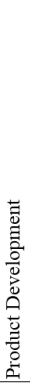 & 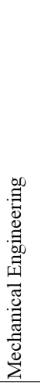 & 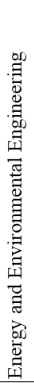 & 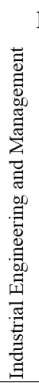 & $\begin{array}{c}\mathrm{Ma} \\
\\
\end{array}$ & & 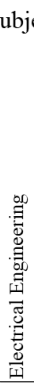 & & 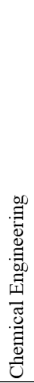 & & $\begin{array}{l}0 \\
0 \\
00 \\
0 \\
0 \\
0\end{array}$ & 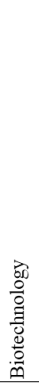 & 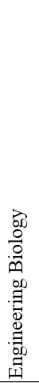 & & 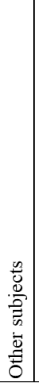 & 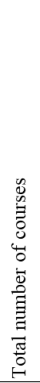 & 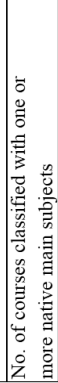 & 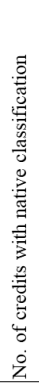 & $\underset{\mathrm{z}}{\stackrel{\mathrm{o}}{\mathrm{d}}}$ \\
\hline M.Sc. Computer Science and Engineering & 4 & 1 & 6 & & & & & & & 2 & & & & & & & 1 & 2 & 12 & 6 & 34 & 57 \\
\hline M.Sc. Design and Product Development & 4 & & 1 & 3 & 1 & & & & & & & & & & & & & & 9 & 3 & 24 & 40 \\
\hline M.Sc. Mechanical Engineering & 4 & & 1 & 2 & 4 & 1 & 1 & & & & & & & & & & & & 10 & 4 & 24 & 40 \\
\hline M.Sc. Applied Physics and Electrical Engineering & 5 & 1 & 1 & & & & & 2 & 3 & 2 & & & & & & & & & 10 & 4 & 18 & 30 \\
\hline M.Sc. Energy - Environment - Management & 4 & & 1 & 1 & 3 & 4 & 1 & & & & 1 & & & & & & & & 10 & 5 & 30 & 50 \\
\hline M.Sc. Industrial Engineering and Management & 6 & & 1 & & & & 2 & & & & & & & & & & & & 9 & 2 & 16 & 27 \\
\hline M.Sc. Engineering Biology & 3 & & & & & & & & & & 4 & 4 & 1 & 2 & 1 & 1 & & & 10 & 7 & 42 & 70 \\
\hline B.Sc. Computer Engineering & 2 & & 4 & & & & & & & 3 & & & & & & & & 1 & 9 & 6 & 40 & 67 \\
\hline B.Sc. Engineering Electronics & 2 & & 3 & & & & & & & 4 & & & & & & & & 1 & 9 & 6 & 40 & 67 \\
\hline B.Sc. Chemical Analysis Engineering & 2 & & & & & & & & & & 6 & 7 & 1 & & 1 & 1 & & & 9 & 7 & 42 & 70 \\
\hline B.Sc. Mechanical Engineering & 3 & & & 1 & 4 & & & & & 2 & & & & & & & & & 9 & 4 & 26 & 43 \\
\hline
\end{tabular}




$$
N C=\frac{\sum(\text { ECTS classified as native })}{\text { Total ECTS }}
$$

Table 3-1 illustrates how the NC percentage was calculated for each program. The NC measure was then used in correlation analyses and other dependency studies to assess performance of the students during their first year, including total grade point (GP) and attrition. The measure was also used to compare the programs that were covered by the case study. The results indicated that the level of native content in a curriculum influences student performance comparable to that of other learning types that are known to promote student achievement. In a similar manner as with the NC variable, the study developed a variable capable of reflecting the ratio of active learning elements for each course and curriculum and an Active Learning Credit (ALC) percentage variable was established that corresponds to the amount of active learning modules each student was "exposed" to as a result of their chosen program. Table 3-2 displays two regression analysis models for predicting total achieved GP based on age (High School/Enr. Delay), High School Rank, mathematical preparedness (Math Test), ALC percentage, and the Native Content percentage variable (NC).

Table 3-2 Regression analysis models for predicting GP based on age (High School/Enr. Delay), High School Rank, mathematical preparedness (Math Test) and the Active Learning Credit percentage, ALC (top table). The bottom model also includes the Native Content percentage variable (NC). The coefficient of multiple determination for these models are $R^{2}=0.187$ and $R^{2}=0.192$ respectively.

\begin{tabular}{|c|c|c|c|c|c|}
\hline & \multicolumn{2}{|c|}{$\begin{array}{c}\text { Unstandardized } \\
\text { Coefficients }\end{array}$} & \multirow{2}{*}{$\begin{array}{c}\text { Standardized } \\
\text { Coefficients }\end{array}$} & \multirow[b]{2}{*}{$\mathrm{t}$} & \multirow[b]{2}{*}{ Sig. } \\
\hline & B & Std. Error & & & \\
\hline (Constant) & $-0,195$ & 0,110 & & $-1,779$ & 0,076 \\
\hline High School/Enr. Delay & 0,354 & 0,093 & 0,159 & 3,796 & 0,000 \\
\hline High School Rank & 0,575 & 0,114 & 0,245 & 5,024 & 0,000 \\
\hline Math Test & 0,308 & 0,043 & 0,295 & 7,106 & 0,000 \\
\hline \multirow[t]{3}{*}{ ALC $(\%)$} & 0,236 & 0,045 & 0,208 & 5,216 & 0,000 \\
\hline & \multicolumn{2}{|c|}{$\begin{array}{l}\text { Unstandardized } \\
\text { Coefficients }\end{array}$} & $\begin{array}{l}\text { Standardized } \\
\text { Coefficients }\end{array}$ & & \\
\hline & B & Std. Error & Beta & $\mathrm{t}$ & Sig. \\
\hline (Constant) & $-0,264$ & 0,115 & & $-2,288$ & 0,022 \\
\hline High School/Enr. Delay & 0,354 & 0,093 & 0,159 & 3,805 & 0,000 \\
\hline High School Rank & 0,621 & 0,117 & 0,265 & 5,321 & 0,000 \\
\hline Math Test & 0,321 & 0,044 & 0,307 & 7,325 & 0,000 \\
\hline $\operatorname{ALC}(\%)$ & 0,171 & 0,057 & 0,151 & 3,013 & 0,003 \\
\hline $\mathrm{NC}(\%)$ & 0,106 & 0,056 & 0,099 & 1,893 & 0,059 \\
\hline
\end{tabular}


Other analysis of the study in paper [VI] indicated that native content credits were more frequently earned than non-native credits among the studied population of students. Furthermore, programs with a high degree of native content also seem to have a higher degree of active learning modules. The paper concludes that curriculum nativeness and levels of native content are perceived as a useful measure for comparing engineering curricula. However, the paper also concludes that further assessment of the proposed concepts and measures is necessary.

\subsubsection{Psychometrics and Student Performance}

Paper [VII] examines the development of another set of performance measurements of firstyear engineering students relative to their coping capability as represented by general and domain-specific self-efficacy beliefs as well as the salutogenesis concept of SOC.

A schematic overview of the study that paper [VII] is based on is illustrated in Figure 3-10. The study included approximately 900 students in 11 different engineering programs. Questionnaires were distributed on two occasions upon enrollment and during the final weeks of the first year. By extracting dependent data from a result database, student progress and academic achievement were continuously scanned during the first two semesters. The study also used other sources to collect independent data, such as the curricula and course databases and the admission and student registry.

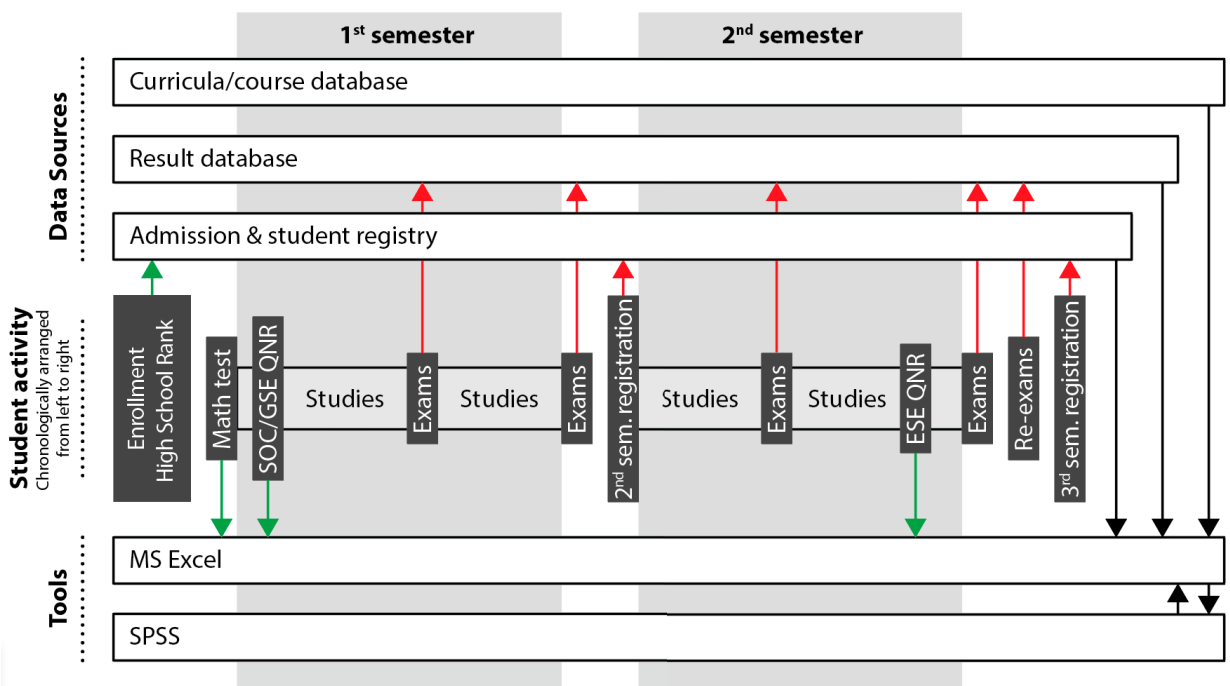

Figure 3-10 Schematic overview of the study describing data sources, dependent (red) and independent (green) information generating events (chronologically from left to right), and tools used for data processing and analysis.

The extensive statistical data analysis revealed that the measures regarding ability to predict performance showed a strong association with attrition and achievement. The dropout rate was two to three times higher among students with low coping capability compared to those with high coping capability (Table 3-3). In addition, paper [VII] demonstrated curricula comparison from a coping capability perspective, yielding examples where especially the meaningfulness dimension of SOC measurements shows large and significant differences between programs. 
Table 3-3 Performance measures - drop-out rate and normalized mean GP - by quartiles of different coping measures. Note, all measures are on the scale between 0 and 100 for ease of comparison.

\begin{tabular}{llcccc}
\hline & & \multicolumn{4}{c}{$\begin{array}{c}\text { Drop-out Rate \& Mean GP by } \\
\text { Quartiles of Coping Measure }\end{array}$} \\
\cline { 3 - 6 } & & Q1 & Q2 & Q3 & Q4 \\
\hline \multirow{2}{*}{ SOC } & Drop-out (\%) & 11,6 & 14,3 & 7,0 & 4,5 \\
& GP (Mean) & 64,2 & 64,8 & 69,1 & 70,9 \\
\hline \multirow{2}{*}{ SOC-C } & Drop-out (\%) & 14,1 & 6,2 & 14,3 & 3,3 \\
& GP (Mean) & 65,1 & 67,2 & 66,3 & 70,9 \\
\hline \multirow{2}{*}{ SOC-MA } & Drop-out (\%) & 10,9 & 12,8 & 6,5 & 6,3 \\
& GP (Mean) & 64,1 & 67,1 & 67,0 & 73,1 \\
\hline \multirow{2}{*}{ SOC-ME } & Drop-out (\%) & 15,9 & 9,6 & 5,0 & 6,4 \\
& GP (Mean) & 60,6 & 68,2 & 69,9 & 71,0 \\
\hline \multirow{2}{*}{ GSE } & Drop-out (\%) & 11,5 & 13,6 & 3,7 & 7,1 \\
& GP (Mean) & 66,1 & 66,1 & 71,0 & 66,1 \\
\hline
\end{tabular}

The study also confirmed an association between the applied global coping measures of SOC and self-efficacy.

Paper [VII] also included measurements for assessing students' engineering self-efficacy regarding performing specific engineering skills (ESE), categorized as experimental (ESE-E), tinkering (ESE-T), design (ESE-D), and general engineering tasks (ESE-G). Although limited dependencies regarding performance (in terms of achievements) could be seen, this domainspecific measure correlated to a number of independent variables, with gender being the most significant. Following correlation analysis, all ESE variables show a clear inverse association with being female, with the exception of the ESE-G subcomponent. In particular, the tinkering component ( $\rho$ ESE-T,Gender $=-0.525$; significant at the $p=0.01$ level) and the accumulated ESE score $\left(\rho_{\mathrm{ESE}, \mathrm{Gender}}=-0.500\right)$ stood out. This is also confirmed by the comparison in Table 3-4, where males are shown to score almost $40 \%$ higher on the ESE-T score, a finding that suggests male and female first-year engineering students have significantly different self-efficacy regarding characteristic engineering activities and behaviors, such as tinkering. However, given that the concept of self-efficacy is understood as an individual's optimistic self-belief regarding competence and chances of successfully accomplishing a task and producing a favorable outcome (Bandura,1997), this finding should not be interpreted as women being less confident in performing engineering tasks. On the contrary, the result can just as easily be interpreted as men, more than women, over-estimate their capabilities. In fact, studies have shown that male individuals are significantly more likely to over-estimate their performance compared to females (Cooper et al., 2018, Pazicni et al., 2013).

Paper [VII] provides additional gender-related findings (Table 3-4). For example, the drop-out rate for the males is much higher, almost $60 \%$ more frequent compared to the females. On the other hand, the female cohort of the studied population is shown to possess a slightly better general relative standing upon enrollment compared to the males (in terms of High School Rank, 4.7\%), whereas the males show a slightly better mathematical preparedness $(5.2 \%$ higher). 
Table 3-4 Dependent and independent variables broken down by gender, all on a scale of 0 to 100.

\begin{tabular}{|c|c|c|c|c|c|c|c|c|c|c|c|}
\hline & \multicolumn{11}{|c|}{ Gender } \\
\hline & \multicolumn{3}{|c|}{$\mathrm{F}(24 \%)$} & \multicolumn{3}{|c|}{$\mathrm{M}(76 \%)$} & \multicolumn{5}{|c|}{ Total } \\
\hline & \multirow[b]{2}{*}{$\stackrel{\Xi}{\Xi}$} & \multirow[b]{2}{*}{ SD } & \multirow{2}{*}{$\begin{array}{l}Z \\
\frac{\Xi}{*} \\
\geq\end{array}$} & \multirow[b]{2}{*}{$\stackrel{\Xi}{\Xi}$} & \multirow[b]{2}{*}{ SD } & \multirow{2}{*}{$\begin{array}{l}Z \\
. \bar{J} \\
\geq\end{array}$} & \multicolumn{2}{|c|}{ Diff. } & \multirow[b]{2}{*}{$\stackrel{\Xi}{\Xi}$} & \multirow[b]{2}{*}{ SD } & \multirow{2}{*}{ 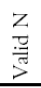 } \\
\hline & & & & & & & $\dot{0} \dot{0}$ & $\%$ & & & \\
\hline SOC & 65,3 & 13,0 & 108 & 68,5 & 11,8 & 334 & M & 4,9 & 67,7 & 12,2 & 442 \\
\hline SOC-C & 59,0 & 16,1 & 108 & 63,4 & 14,5 & 334 & M & 7,5 & 62,3 & 15,0 & 442 \\
\hline SOC-MA & 63,7 & 15,4 & 108 & 72,6 & 13,5 & 334 & M & 13,9 & 70,4 & 14,5 & 442 \\
\hline SOC-ME & 74,7 & 13,7 & 108 & 70,6 & 14,7 & 334 & $\mathrm{~F}$ & 5,7 & 71,6 & 14,6 & 442 \\
\hline GSE & 74,5 & 10,4 & 108 & 77,2 & 11,4 & 334 & $M$ & 3,6 & 76,6 & 11,2 & 442 \\
\hline ESE & 67,8 & 11,1 & 38 & 80,7 & 9,0 & 127 & M & 19,0 & 77,8 & 10,9 & 165 \\
\hline ESE-G & 82,2 & 16,0 & 38 & 84,9 & 11,8 & 127 & M & 3,3 & 84,3 & 12,9 & 165 \\
\hline ESE-D & 61,7 & 13,8 & 38 & 76,8 & 12,5 & 127 & M & 24,4 & 73,3 & 14,3 & 165 \\
\hline ESE-T & 55,6 & 15,6 & 38 & 76,9 & 14,3 & 127 & M & 38,2 & 72,0 & 17,1 & 165 \\
\hline ESE-E & 78,6 & 14,1 & 38 & 86,5 & 10,1 & 127 & M & 10,1 & 84,7 & 11,6 & 165 \\
\hline ECTS & 79,5 & 21,9 & 108 & 78,6 & 25,1 & 334 & $\mathrm{~F}$ & 1,1 & 78,8 & 24,3 & 442 \\
\hline GP & 66,7 & 19,0 & 108 & 67,5 & 22,0 & 334 & M & 1,2 & 67,3 & 21,3 & 442 \\
\hline Drop-out (\%) & 6,5 & - & 108 & 10,2 & - & 334 & M & 57,1 & 9,3 & - & 442 \\
\hline High School Rank & 87,4 & 7,3 & 86 & 83,5 & 9,5 & 294 & $\mathrm{~F}$ & 4,7 & 84,4 & 9,2 & 380 \\
\hline Math Test & 52,5 & 21,9 & 97 & 55,2 & 20,4 & 308 & $M$ & 5,2 & 54,5 & 20,8 & 405 \\
\hline
\end{tabular}

Given the results of the study and the discussion regarding the usability of the studied instruments, paper [VII] concludes that multiple stakeholders could benefit from using coping measures such as SOC and self-efficacy, in particular members of the faculty responsible for program management. From this viewpoint, one can point to some of the findings of the paper that are related to curriculum observations. For example, the meaningfulness dimension of the SOC measure (SOC-ME) proved (mathematically) significantly different between programs and one may assume the program attracts students driven by diverse motives and attitudes regarding their choice of studies. The contributions of paper [VII] also point towards a framework that enables measurement of coping capabilities of engineering students to enhance general performance and reduce attrition.

To conclude, Table 3-5 summarizes the findings from papers [V], [VI], and [VII]. Viewed separately or in combinations, curriculum nativeness, coping capabilities, and real-time monitoring demonstrate the large range and variety of data sources available for analysis that will help program planners, teachers, and students better understand what factors influence the progress of students. 
Table 3-5. Summarizing overview findings from papers [V], [VI], and [VII].

\begin{tabular}{|c|c|c|}
\hline Mean & Data collection & Main finding \\
\hline Curriculum nativeness & Existing databases & $\begin{array}{l}\text { Credits from native content courses are more frequently earned. } \\
\text { Seemingly influencing the profile of students attracted to a } \\
\text { program. } \\
\text { Highlights issues regarding the way math is being taught and } \\
\text { implemented in the curriculum }\end{array}$ \\
\hline Coping capability & $\begin{array}{l}\text { Existing databases } \\
\text { Surveys }\end{array}$ & $\begin{array}{l}\text { Coping capability has limited influence in terms of passed } \\
\text { courses. } \\
\text { Coping capability influences attrition in term of drop-out rate. } \\
\text { Gender differences can be observed regarding domain specific } \\
\text { self-efficacy beliefs. } \\
\text { Program-level observations point to significant differences in } \\
\text { meaningfulness dimension of SOC. }\end{array}$ \\
\hline $\begin{array}{l}\text { Real-time environmental } \\
\text { data gathering }\end{array}$ & $\begin{array}{l}\text { Existing databases } \\
\text { Surveys } \\
\text { Sensors }\end{array}$ & $\begin{array}{l}\text { Demonstration of real-time measurements of student activity } \\
\text { during classroom teaching, such as request patterns, and } \\
\text { "frustration monitoring". } \\
\text { Useful information for both teachers (course planning) as well } \\
\text { as program managers, but the results are also subject for further } \\
\text { analysis. }\end{array}$ \\
\hline
\end{tabular}

\subsection{Overarching Contribution}

With the more specific contributions from each appended paper declared for in sections 3.1 to 3.3 as a backdrop, more overarching contributions will be discussed in this section.

\subsubsection{Alignments of Theories of Knowledge Creation and Learning}

The theoretical foundations of papers [II] and [III] emphasize the relationship between the knowledge-creating processes described by product development theory and the cognitive processes described by general learning theory. This is illustrated in Figure 3-11 where the phases of Cross' (2009) generic product development model - initial exploration, iterative generation, and evaluation, and eventual communication (Figure 2-1) - align with Kolb's (2014) fundamental cognitive model of learning (Figure 2-7). Of the four stages of Kolb's learning cycle, the first and second are arguably connected with product development activities dealing exploration and evaluation. Most prescriptive PD models include stages or elements of judgement and decisions that are either explicitly or implicitly based on feeling and reviewing from the people engaged in the process. For example, Pahl et al. (2013), when elaborating on characteristics of good problem solvers, speaks of essential elements required for "decision making behavior" - e.g., recognizing dependencies and estimating importance and urgency. Moreover, according to Pahl et al., information processing (in a problem-solving context) is an iterative process involving reception and processing (and transmission) of information. Pahl et al. also emphasize the importance of decisions based on objective evaluations: "without decisions and experiencing their consequences there can be no progress" (2013). More concretely, one can point to the labeling of activities in the PD phases most related to intense generation of information (and therefore eligible as processes of knowledge creation) such as the concept development phase (Phase 2) (Ulrich et al., 2015) illustrated in Figure 2-2. According to Ulrich 


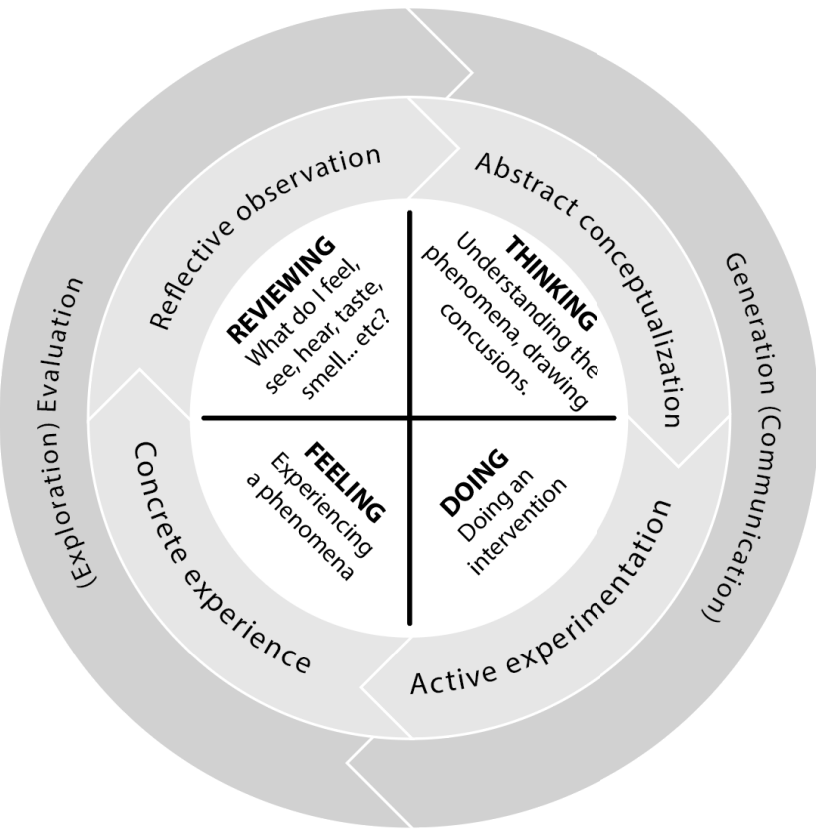

Figure 3-11 Schematic illustration of the alignments between elements of Cross' (2008) meta-described PD process (outmost circle) and the elements of the learning cycle of Kolb (2014) (inner circle).

et al., this phase is comprised of activities such as identify lead users and competitive products, investigate feasibility of product, estimate manufacturing costs, and assess production feasibility, activities that relate to cognitive processes of both concrete experiences and reflective observations.

Accordingly, we find similar connections between product development activities dealing with generation and communication (referring Cross' (2009) model), and the other two cognitive processes described by Kolb - i.e., abstract conceptualization and active experimentation. The part of Kolb's learning cycle that deals with abstract conceptualization could more loosely be described as thinking for the purpose of understanding a phenomenon and drawing conclusions. From the perspectives of PD theory, there are many means and attributes that aim at understanding the development of products such as CAD tools and CAE tools and other visualization digital tools. Other PD methods are developed to explicitly support the thoughtprocess of understanding a problem, for example, the function-means tree approach for functional decomposition and concept generation (originally proposed by Andreasen, 1980). Finally, PD theory comprises a range of activities and means that both figuratively and literally relate to active experimentation (i.e., actively doing and intervention following previous understandings). Part of this thesis clearly addresses means of PD that target this element of the learning process (i.e., prototyping in this case represented by the LCD and CEP concepts). However, one can also point to less concrete examples such as (outcomes of) creative methods, brainstorming sessions, and sketching techniques. 


\subsubsection{Physical Representations for Bridging PD and EE}

This section extends the reasoning regarding the contribution of the concept of low-cost demonstrators and the CDIO Enabling Platform (described in 3.1 and 3.2 respectively). Fundamentally, the general conception of standard elements of product development processes - i.e., pre-study, conceptual design, detailed design, and prototyping (Figure 3-3) - also form the basis of the founding principles of the engineering educational framework that this thesis partly addresses - i.e., the CDIO Initiative. In fact, Crawley et al. (2014) frame the CDIO framework as a "model of the engineering lifecycle" by connecting each of the abbreviated verbs Conceive - Design - Implement - Operate to activities of PD (Table 3-6).

Table 3-6. The principles of CDIO educational framework framed as "activities of the engineering lifecycle" (Crawley et al., 2014).

\begin{tabular}{ll}
\hline Conceive & $\begin{array}{l}\text { Defining customer needs, considering technology, enterprise strategy and } \\
\text { regulations, and developing conceptual, technical, and business plans. }\end{array}$ \\
Design & $\begin{array}{l}\text { Creating the detailed information description of the design; the plans, } \\
\text { drawings, and algorithms that describe the system to be implemented. }\end{array}$ \\
Implement & $\begin{array}{l}\text { Transforming the design into the product, process, or system, including } \\
\text { hardware manufacturing, software coding, testing, and validation. }\end{array}$ \\
Operate & $\begin{array}{l}\text { Using the implemented product, process, or system to deliver the } \\
\text { intended value, including maintaining, evolving, recycling, and retiring } \\
\text { the system. }\end{array}$
\end{tabular}

As seen in Table 3-6, the first three stages align well with the described functioning of the LCD from both a PD and EE perspective. However, the activities of the final stage of the CDIO sequence (i.e., operate) that for most part are referenced by activities associated with postdevelopment stages are in need of slight re-interpretation to have this stage align with the reasonings about the purposes and functionalities of the LCD. As stated in sections 3.1 and 3.2, neither the concept of LCD nor the CEP platform support perceptions of "finished" or "deliverable" products. However, they should be considered part of something "under development". Therefore, it is reasonable to align the CDIO "model of learning" with the LCD "model of knowledge creation" (pictured in Figure 3-4) to emphasize the joint contribution of both the LCD and the CEP platform concept. This alignment, described in Figure 3-12, illustrates the commonality regarding integrative capabilities of both concepts. On the one hand, there are beneficial aspects of the LCD supporting multidisciplinary projects (as discussed in 3.1); on the other hand, LCD can be compared with the cross-course/cross-curricula purposes of implementing a CDIO Enabling Platform, as discussed in section 3.2. 


\section{CDIO Enabling Platform development}

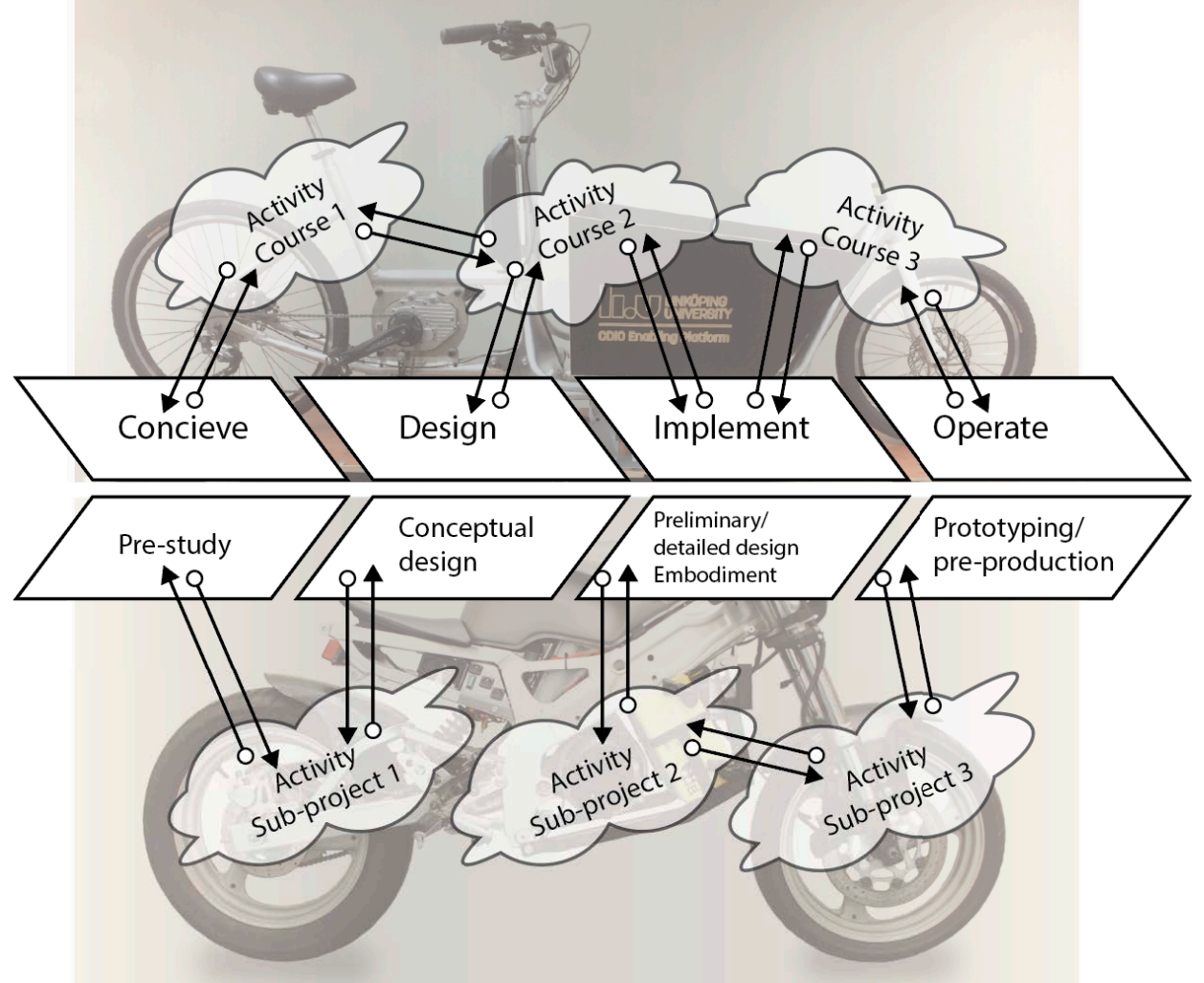

\section{Low-Cost Demonstrator development}

Figure 3-12 Schematic side-by-side alignment between the CDIO learning process and a general PD process, supported by a CDIO Enabling platform and a Low-Cost demonstrator respectively.

\subsubsection{An Engineering Approach to EE Development}

The previous reasoning about the alignment between models of cognitive learning processes and the fundamental process of product development, as illustrated in Figure 3-11, is in itself an expression of approaching processes of learning and knowledge creation from an engineering perspective. With reference to section 2.2.2 and Rompelman et al.'s attempt of approaching course and curriculum development from a systems engineering perspective, it is evident that contributions from many of the appended papers provide some of the answers to the questions that followed from Figure 2-9 and Figure 2-10: What are the "features" of the student prior and after the learning process and what happens in between? By supplementing the findings of papers [V], [VI], and [VII] to Rompelman et al.'s "control engineering" model approach to EE 
development, a new expanded model can be established that encompasses and rationalizes many aspects of this dissertation (Figure 3-13). Where Rompelman et al. speak of "teaching as a facilitating condition" for the educational process, the new model suggests that the CEP be a supplement facilitator for teaching and knowledge creation among the engineering students (as described in papers [III] and [IV]). Adding to Rompelman et al.'s reasoning about feedback pathways (Figure 2-11), the new model proposes three feedback loops: 1) relevant information from the assessment stage is passed to potentially adjust the envisaged features such as curriculum composition; 2) information is fed back to adjust elements of the education process such as teachers and students and their activities and learnings styles etc. as well as facilitating elements such as a CEP, if present; and 3) as proposed by Rompelman et al., self-evaluation of assessment methods should be implemented.

Moreover, the first and second feedback loop are maintained by data collected prior, after, and during the education process. Prior data typically means student properties, such as high school grades and coping capabilities (paper [VII]), but also data related to the envisaged features, such as curriculum characteristics that may be quantitatively expressed by metrics such as NC (paper [VI]) or requirements expressed by the industry. During the education process, real-time data of student progress can be collected as described in section 3.3.1 and in paper [V]. After the education process, data on the acquired features, such as examination results and survey data as well as work life data from practicing engineers and their employers can be gathered. The assessment stage, or control stage in terms of control engineering, in Figure 3-13 clearly connects to the knowledge area of LA described in section 2.3 and 3.3.1 as well as the metrics proposed in paper [V].

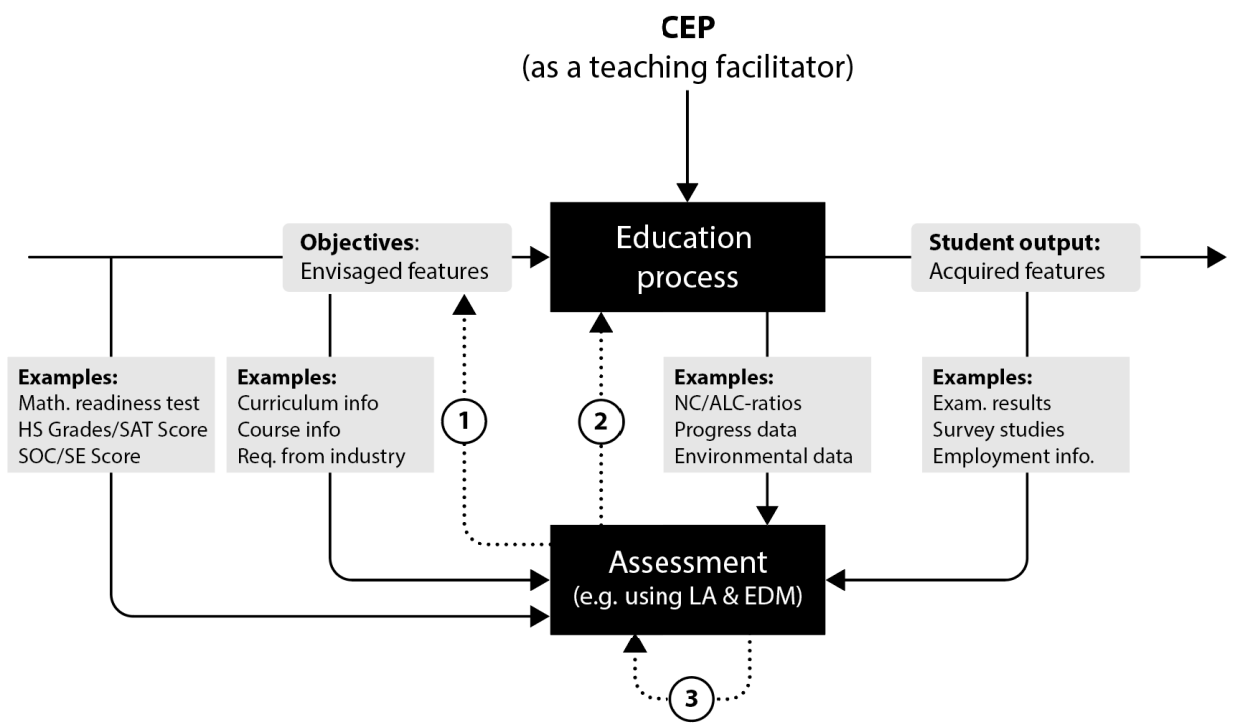

Figure 3-13 An expanded and supplemented feedback model of the educational process of Rompelman et al. (2006). The CEP concept (paper [III] and [IV]) acts as a supplementing facilitator for teaching during the education process. The dotted lines represent feedback pathways to adjust 1) the envisaged features, 2) elements of the education process and 3) the assessment methods. The figure also provides examples of input data to the assessment stage that are represented in paper[V], [VI] and [VII]. 


\subsubsection{Aspects of Curriculum Nativeness and Engineering Identity}

The concept of curriculum nativeness should not be seen as an isolated and unique contribution of paper [VI]. Thoughts on engineering identity run through all the appended papers. Papers [I] and [II] both stress the benefits of implementing hardware in the courses to strengthen knowledge acquisition through active learning, which paper [VI] concludes to be a parts of fostering engineering identity among students. The CEP concept, which is the basis of papers [III] and [IV], is also a subject for consideration as several reasonings point towards a use that strengthens engineering identity of the learning setting. Moreover, some of the main findings of the psychometric case study in paper [VII] clearly addressed the relevance of incorporating aspects of engineering identity into processes of curriculum development and program management, particularly following the findings regarding ESE and findings related to the differences between the genders. Hence, the conducted research stresses the importance of incorporating aspects of engineering identity in the process of curriculum development. Many of the concepts developed and elaborated on in the appended papers - e.g., the CDIO Enabling Platform, the construct of curriculum nativeness, ratios of native, and active learning - provide effective ways to develop curricula that address engineering identity. 


\section{4}

\section{Discussion}

This chapter discusses topics related to the contributions presented in the previous chapters. Starting with an elaboration on purpose, motivation, and usefulness, the following sections deal with the overarching take-away from this work: approaching engineering education from an engineering perspective. This is followed by answers to the research questions that were formulated in 1.2. A final subsection comments on the applied methodology and validity of this work.

\subsection{Purpose, Motivation, and Usefulness}

One overarching purpose of this thesis is found in the introduction: as fields of engineering are rapidly evolving, schools of engineering must follow. In addition, many aspects of how current $\mathrm{EE}$ is organized (at least from a Swedish perspective) originated in an era (mid-twentieth century) that was significantly different from today's circumstances. From this standpoint, it is easy to argue for the usefulness of this research as EE still has a strong need for improvement. An obvious value for society is that there are strong economic reasons for ensuring that new engineers are being equipped with "the right" set of knowledge and skills upon graduation to tackle current and future technical challenges. This thesis provides some suggestions on tools and methods that target the "the right tools" and metrics that could be applied to measure the effect of curriculum development. For example, it is reasonable to have curricula that help returning students develop new skills, a feature of the CEP concept presented here. Given that industry needs are and will be shifting more rapidly, it is reasonable to process how this should be handled, especially concerning design and development of engineering curricula.

To approach the justification and usefulness of this thesis from an engineering education perspective, one of the overarching contributions stated in 3.4 is that faculty organizations could use the findings from this study to enhance and streamline the processes under which knowledge acquisition happens among engineering students. This permeates, to varying degrees, all the appended papers of this thesis. Papers [I] and [II] are of interest to the curriculum developer searching to foster knowledge acquisition through active learning. In 
addition to promoting active learning, papers [III] and [IV] address the organizational aspect of implementing the CEP concept, where paper [IV] particularly emphasizes the platform considering the role of $\mathrm{EE}$ in a wider context, incorporating both industrial and academic research and development.

Paper [V] specifically argues for extended exploration of program management by identifying different categories of information available for program planners to consider when assessing and fostering student persistence. Papers [VI] and [VII] provide examples of using data to establish new tools that may increase the understanding of the EE setting from a program manager perspective. In paper [VII], this becomes particularly evident following from two notable observations:

1) Differences between the genders are substantial and significant for important clusters of metrics targeting the self-perceived capability of "doing engineering" represented by measurements of engineering self-efficacy (ESE).

2) On the group level, significant differences exist regarding the meaningfulness dimension of sense of coherence (SOC-ME).

Both of these findings serve as arguments for further exploration of the demonstrated psychometrics as tools for curriculum development and management.

\subsection{Engineering Education}

One can argue for the reasonableness of applying engineering thinking and methods to the development of engineering education. Traditionally, in Swedish EE settings, developing and updating a curriculum is a joint venture that involves the personnel active in the program such as lecturers and examiners, representatives from industry, as well as students. The large majority of these individuals have gone through undergraduate engineering training before further academic qualifications. Therefore, it can be assumed that there are low thresholds for these individuals to absorb the proposed approach to curriculum development.

With reference to the three research areas in this thesis (PD, EE, and LA) as well as the research aims, this should also be considered as one of the overarching contributions from this thesis. That is, the thesis explores and manifests a concept of engineering EE. The engineering behaviors and tools that follow from PD and LA theory are engineering approaches to problem solving. Papers [V], [VI] and [VII] fundamentally address methods familiar to most engineers - i.e., measuring, data processing, and statistical analysis.

By connecting PD theory (through the use of physical demonstrators/platforms, i.e., the LCD concept) and educational frameworks (such as the CDIO initiative through development of the CEP concept), this thesis contributes to the discussion on how to apply the taught PD methods and ways of thinking about the actual EE environment, including its learning processes - i.e., "product development", knowledge, skills, and attitudes among the engineering students as well as the learning processes required to achieve these skills. A clear example of the latter are the measurement tools described in paper [VI] - i.e., NC/NCA and ALC. These serve as a demonstration of how engineering methods can be applied and used to develop and manage curriculum. Similarly, paper [VII] provides an example where measurements (of learning and coping) are used to gain better understanding of the performance of the students and the functioning of the curricula. Altogether, these papers should be seen as additional tools for engineering curriculum management and development. 


\subsection{Answers to Research Questions}

The following sections answer the previously posed research questions and end with an outlook on suggested future research directions.

\section{[RQ1]: What are the relations between product development processes and learning processes in higher engineering education?}

Several parts of this thesis contribute to answering this question. In fact, all the appended papers show examples of different relations between PD and EE. In 3.4.1, Figure 3-11 presents a relationship between generic knowledge-creating processes described by product development theory and the cognitive process described by general learning theory. The model includes the cognitive prosses associated with experiential learning (i.e., the work of Kolb, 2014), which forms the basis of contemporary engineering education settings. To support this reasoning, Crawley et al. (2014), for example, explicitly refer to characteristics of experiential learning while outlining the pedagogical foundation of the CDIO educational framework (see 2.2.2). A corresponding observation, illustrated in Figure 3-12, points at the commonalities of the CDIO learning process and a basic product development process supported by a CDIO Enabling platform (described in 3.2 and depicted in Figure 3-6) and a Low-Cost demonstrator (described in 3.1), respectively. Moreover, the CDIO educational framework, which advocates experiential learning through active learning as essential for successful EE, in itself serves as an answer to this question as it builds on the fundamental principles of product development processes (see 3.4.2).

Furthermore, both the CDIO Enabling Platform concept as well as the "engineering EE" approach put forward in 3.4 .3 could be seen as implicit answers to this research question. Based on Rompelman et al. (2006), the expanded feedback model described in Figure 3-13 details how elements of product development can be applied to managing the learning processes in engineering education. Moreover, CEP is a facilitator for the education process stage in the model illustrated in Figure 3-13 and capable of mirroring real-life PD scenarios as described in 3.2 (also see papers [III] and [IV]).

\section{[RQ2]: How can physical representations and artifacts support the creation of new knowledge in both an educational and product development setting?}

Even in eras of digitalization, the use of physical artifacts such as prototypes and demonstrators can help advance the development process. Physical products are, after all, physical regardless of the circumstances under which they are being developed, fictitiously in an EE setting or in a business governed by the laws of a competitive market. From this perspective, the concept of Low-Cost Demonstrator presented in 3.1 and its EE counterpart, the CDIO Enabling Platform described in 3.2, serve as answers to [RQ2]. Both of these concepts point out the rationale of using physical artifacts to support knowledge creation and learning processes.

Regarding the LCD concept, the additional supporting aspects (with reference to the wording of the RQ) are mainly represented by the presence of the LCD during parts of the PD process where the developers would otherwise rely on other (usually non-physical) means for try-out, evaluation, decision making, etc. This argument is exemplified and illustrated in Figure 3-4, where a continuous LCD "development process" is placed alongside the traditional chain of events of a PD process. From this perspective, the LCD concept extends the literature on 
product development prototyping by explicitly advocating a low-cost approach that ultimately allows for more extensive use of physical artifacts during product development.

Corresponding supporting aspects of the CEP concept is mainly constituted by its catalytic properties regarding elements of engineering education. In addition to presenting the obvious capability to provide a platform for experiential and active learning, 3.2 also specifically emphasizes the function of the CEP as allowing for integration between courses and therefore between different domains of knowledge. Cost aspects are also referred to when promoting implementation of the CEP as the concept advocates concurrent use within courses running in parallel and therefore share costs. Moreover, as described in 3.2, the CEP concept bridges academia and industry, enabling proposed activities that support knowledge-creating processes for both parties.

Furthermore, there are also less tangible aspects of knowledge creation within engineering educational settings that nevertheless contribute to answering this RQ. For example, as pointed out in 3.4.4, the CEP concept forms the basis of several reasonings pointing towards a use that strengthens engineering identity of the learning setting. Altogether, the parts of the thesis dealing with the CEP concept extend the existing literature base that advocates use of physical artifacts for improving aspects of engineering education.

\section{[RQ3]: How can a physical platform be formalized to support the development of knowledge-creating processes and engineering curriculum execution in a CDIO setting?}

The CDIO Enabling Platform concept in itself serves as an answer to this question. In section 3.2, the functions of a CEP are argued to support implementation of several of the CDIO Standards, most prominent Standard 3 (Integrated Curriculum), Standard 7 (Integrated Learning Experience), and Standard 8 (Active Learning). Furthermore, if combined with a scenario and implemented with enough possibilities of interaction, the CEP meets many the beneficial aspects of problem-based learning described in the literature. Some of these aspects are highlighted in 2.2 .3 (e.g., knowledge acquisition becomes more grounded in reality than in traditional teaching because the learning is based on authentic cases and scenarios) (Barrows et al., 1980). Moreover, according to the literature, the fundamental idea of Problem-based Learning also shifts the focus from the teacher to the learner (Kolmos, 1996) and therefore CEP should be seen as an enabler of learning. By allowing the students to actively engage and interact with a CEP, the platform acts as the main focus of the learning process rather than the teachers who can take on the role of facilitators during different models of PBL (Table 2-2 and Kolmos, 2009).

Moreover, the implementation of the CEP as described in paper [III] (and also in 3.2) demonstrates a pathway of integrating courses that are already in place by designing the CEP according to needs. This supplements the literature dealing with implementation of educational frameworks such as the CDIO initiative.

Furthermore, if placed in a broader context, a CEP may also function as a hub supporting other aspects of a technical institution involved in EE - namely, research and industry collaborations. These aspects, which were mainly put forward in 3.2 and in paper [IV], are implicitly connected to the CDIO approach to EE. 
[RQ4]: What metrics could be defined to support curriculum development and to monitor student performance?

The attempts of this thesis to approach engineering education from a product development perspective (e.g., as described in 3.4) has yielded several proposed metrics that support the development of engineering curricula. Specifically, the Native Credit (NC) measure of curriculum nativeness, described in Table 3-1 (3.3.2), constitutes a novel approach to describe curriculum characteristics, extending the literature on engineering curriculum development. This also includes the approach of using existing classification systems available at an institution. For example, the case study that dealt with the NC measurement (paper [VI]) also yielded other measures of curriculum characteristic - i.e., the Active Learning Credit (ALC) measure for measuring the amount of active learning modules of a curriculum.

Moreover, the coping measure described in 3.3.3 - Sense of Coherence - introduces a concept used in other domains into engineering education. In particular, the described studies emphasize SOC's usefulness for analyzing differences between programs and groups of students. Also, the apparent differences between the genders regarding engineering self-efficacy, as described in 3.3.3, serves as an example where types of coping measures could provide increased understanding of whole cohorts of students.

The thesis also identifies potential uses in metrics based on gathering of real-time data in the educational environment. For example, 3.3.1 describes how continuous collection of data on progress and other behaviors could be used to detect and verify differences between groups of students. Such information could potentially be used for more swift response in terms of adjustments of the education process. Moreover, the type of data management described in 3.3.1 clearly aligns with the potentials of learning analytics and so-called educational data mining described in the literature. For example, as described in 2.3.1, Romeo et al. (2010) states that such data could be used to discover "new knowledge based on students' usage data in order to help to validate/evaluate educational systems, to potentially improve some aspects of the quality of education, and to lay the groundwork for a more effective learning process". Also, as seen in Table 2-3, the literature points out a number of stakeholders connected to this research question, and this implicitly tells us what type of data are yet to be explored using the means and methods described in 3.3.1 (and paper [V]) - e.g., data for personalizing student elearning experiences or for automatic detection of students in need of support.

Altogether, the measures and instruments described in this thesis - NC, SOC, ESE, real-time data, etc. - help program managers gain better understanding of the functioning of the curriculum as well as the teachers and students involved in its execution.

\subsection{Limitations and Validity}

As always, every piece of research should be discussed in the light of the circumstances under which the research has been conducted. As part of the outcomes of this dissertation are based on activities and observations at Linköping University, it is reasonable to raise the question of generalizability and reproducibility. Considering the Swedish context, to start with, one can argue that most of the adopted approaches are applicable to other Swedish EE institutions as they are relatively homogeneous in comparison and they are subject to the same governmental regulations. In addition, multiple national organizations, communities, and networks work together not only to ensure progress and quality but also to promote homogeneity among EE institutions in Sweden. That is, the way curricula are organized, composed, and executed are also comparable between Swedish institutions offering engineering degree programs. This 
includes the type of introductory first-year and final year courses referred to in papers [I] and [II] as described by Gustafsson et al. (2002) and Evertsson et al. (2007). These types of courses are also seen internationally (see Jones et al. (2013), Vallim et al. (2006), and Deslauriers et al. (2011) as described in paper [VI]) and therefore the knowledge gain should be generalizable outside the Swedish context. Furthermore, the fact that the CEP concept builds on the principles of the widespread CDIO Initiative also speaks in favor of generalizability and reproducibility.

Moreover, regarding the development of the metrics in papers [VI] and [VII], most of the independent data can be collected in a similar manner from Swedish publicly available databases. This also applies for the main subject course classification system that forms the basis of the NC measurement in paper [VI], which is represented by comparable systems at Swedish institutions. However, in an international context, there is reason for concern regarding the absence of a comparable classification system, which also points towards future work that looks for alternative means of operationalization of the NC measurement.

Methodologically, the adoption and modification of the industry-as-a-laboratory method described in 1.3.1 is considered a suitable way to describe the overarching course of actions. Furthermore, the chosen research methods must be discussed in relation to the extended period during which the research has taken place. Consequently, there have been periods where research activities have been relatively disconnected from the overarching aims that were eventually formulated in this thesis.

\subsubsection{Considerations of Research Validity}

Here, I turn to the literature in search for an existing validation framework applicable for the research represented by this thesis. In part, Pedersen et al. (2000), which is further developed by Seepersad et al. (2006), serves the purpose. The so-called "Validation Square" (depicted in Figure 4-1) originally targets the engineering design domain. However, it is judged as applicable given the overarching approach of this thesis to apply engineering methods for research on aspects of engineering education. Pedersen et al. claim generality for their approach to validate research methods and state that "the purpose of going through the Validation Square is to present 'circumstantial' evidence to facilitate a leap of faith, i.e., to produce belief in a general usefulness of the method with respect to an articulated purpose" (2000).

Pedersen et al. present the model following an assertion that research validation is a process of building confidence in its usefulness with respect to a purpose. The model is based on evaluation of effectiveness and efficiency of an applied design method based on qualitative and quantitative measures, respectively. The process of validation is synthesized by the four-field matrix in Figure 4-1. Depending on whether effectiveness (the two leftmost squares) or efficiency (the two rightmost squares) of the examined method is assessed, this synthesis is based on the criteria elements of each square. The separate squares in Figure 4-1 (including their criteria) are referred to as theoretical structural validation (TSV), theoretical performance validity (TPV), empirical structural validity (ESV), and empirical performance validity (EPV).

Before moving forward, one can conclude that for TSV, ESV, and EPV it is possible to provide arguments for validity based on the content of the presented thesis and the appended papers and therefore tentatively attain acceptance. However, the second criterion of TSV is considered less applicable for this research as it more specifically refers to assessment of the type of engineering design methodologies that the validation process originally was intended (see Pedersen et al., 2000 and Seepersad et al., 2006). Moreover, to meet the sixth criteria of the 


\section{STRUCTURAL PERFORMANCE}

\begin{tabular}{|c|c|}
\hline $\begin{array}{l}\text { 1. Accepting the constructs validity: } \\
\text { The method is valid given that it is } \\
\text { based on accepted constructs } \\
\text { (theories, concepts, structures, } \\
\text { strategies, or approaches). } \\
\text { 2. Accepting internal consistency: } \\
\text { The method proposes an adequate } \\
\text { flow of information. }\end{array}$ & $\begin{array}{l}\text { 6. Accepting usefulness of the } \\
\text { method beyond examples: } \\
\text { The method is useful and valid in } \\
\text { general for problems adequate to its } \\
\text { application. }\end{array}$ \\
\hline $\begin{array}{l}\text { ESV } \\
\text { 3. Accepting the example problems: } \\
\text { The method is validated using a set } \\
\text { of example problems that are } \\
\text { adequate to be used with the } \\
\text { method. }\end{array}$ & $\begin{array}{l}\text { EPV } \\
\text { 4. Accepting usefulness of the } \\
\text { method for the example } \\
\text { problem(s): } \\
\text { The method shows to be useful when } \\
\text { applied to the example problems. } \\
\text { 5. Accepting the usefulness is } \\
\text { linked to the method: } \\
\text { The useful results of the conducted } \\
\text { process are related to the application } \\
\text { of the method. }\end{array}$ \\
\hline
\end{tabular}

Figure 4-1 The "Validation Square" of Pedersen et al. (2000) and Seepersad et al. (2006). The model is based on evaluation of effectiveness (the two leftmost squares) and efficiency (the two rightmost squares) based on qualitative and quantitative measures respectively. Each square contains criterion elements (numbered 1-6) for assessment of theoretical structural validation (TSV), theoretical performance validity (TPV), empirical structural validity (ESV), and empirical performance validity (EPV) respectively.

TPV square would require claiming general usefulness and validity beyond the presented examples, which may have been proved valid. Pedersen et al. refer to this as a "Leap of Faith" because it ultimately requires believing in the validity of the method under tentative future circumstances.

For assessment of the qualitative/structural elements of this thesis, one may approach issues of validity by asking questions such as "Does it make sense?" and "Can I trust it?", adhering to criteria 1 and 3 of the TSV and ESV squares in Figure 4-1. In this work, the answers to such questions lie in the reasoning connected to the relevant contributions. Generally, the research represented by the appended papers has been based on constructs, theories, and approaches founded in the scientific literature. Moreover, the contributions of papers [I]-[VII] (as well as papers $[\mathrm{VIII}]-[\mathrm{X}]$ ), when brought forward in journals and at conferences, workshops, seminars, etc., have been met by sound and constructive criticism together with positive feedback pushing toward further development. The fact that this criticism and feedback for the most part have been trusted speaks in favor regarding validity in these parts of the conducted research. Altogether, these responses speak in favor of the third criterion of the ESV square as well - i.e., that the concepts brought forward are adequate representations of the proposed methods and concepts. All proposed concepts have proven useful when applied in realistic EE settings. Nevertheless, particularly relevant when discussing qualitative research, there are concerns 
regarding aspects of bias that that could affect validity. Although bias has been a monitored throughout the research process, it cannot be ruled out. In future work, the research could be further strengthened when applied in other settings outside the author's home institution. Moreover, the absence of implementation and validation of a LCD in an industrial context constitutes a weakness of the thesis when elaborating on this subject.

To provide arguments regarding validity connected to quantitative/performance elements of this thesis, the focus is on aspects of usefulness adhering to the fourth and fifth criterion of the EPV square in Figure 4-1. For accepting usefulness of the applied methods, Pedersen et al. specifically refer to the industrial perspective and purposes of the research that are "linked to reducing cost and/or time and/or improving quality" (2000). As such purposes are one of the main drivers for developing the LCD, they also speak to its validity. However, there is a significant weakness in LCD concept as it does not address industrial applications. On the other hand, the CEP concept provides an array of arguments of usefulness that also have been verified following implementation in the target context. However, a strengthened validity would follow successful implementation at additional engineering education institutions, which is an area for future research. Similar reasoning applies for the measures and metrics declared in 3.3. Moreover, regarding usefulness from a scholarly perspective, Pedersen et al. state that purpose of the research should be "augmented to include addition of scientific knowledge that can help produce more scientific knowledge" (2000). With reference to this statement, it should be noted that both the contributions represented by papers [VI] and [VII] explicitly claim to extend the literature on the addressed subjects.

Furthermore, more general argument on validity regarding the statistical studies mainly represented in papers $[\mathrm{VI}]$ and $[\mathrm{VII}]$ are thoroughly dealt with within the separate papers. To highlight some of these, paper [VI] elaborates on validity issues by discussing face validity regarding the operationalization of the $\mathrm{NC}$ measurement given that it is based on a classification system that initially had different purposes (e.g., legislative). The study in paper [VI] also had to deal with validity issues related a potentially biased process under which the main subjects (whose combinations form the NC measure) were selected. Moreover, paper [VII], which is partly based on survey data, raises questions about validity given that it tries to measure insubstantial phenomena without a direct basis in the physical world.

The tools and methods proposed in this thesis have shown promise to improve quality in engineering education. However, there has been no discussion regarding the cost benefits of the proposed concept: Are the potential gains of the proposed methods worth the additional efforts and costs required for implementation? In addition, implementation and acceptance by the broader faculty have not been considered. Naturally, these are all very important aspects that to a great extent are left for future research. However, the methods developed are all based on concepts familiar to most engineers, so the threshold of applying them in a broader setting should be rather low. Moreover, because inertia against change is evident in any organization, it is important to identify faculty members who could lead the way as early adopters of the proposed methods. These early adopters will also be able to evaluate the concepts and develop the methods further. The literature has specifically pointed out such aspects as subjects of concern when dealing with EE development. For example, Edström (2018) speaks of strategies to overcome an "organizational gravity" when discussing a theoretical model that connects the educational program with the organizational characteristics of the organization in which it is situated. Finally, the individual teachers and examiners have a very large impact on the actual learning activities in $\mathrm{EE}$, so continuous pedagogical education development is important for the success of any higher education institution. This thesis could be a small piece in the puzzle to further strengthen the faculty members in their work. 


\section{5 \\ Conclusions}

In this thesis, development of products and related theories are identified as processes of knowledge creation that align with learning processes of the engineering academia. This in turn has allowed for development of two separate yet related concepts or platforms of knowledge creation and learning: Low-Cost Demonstrators (LCD), targeting the product developing industry, and the CDIO Enabling Platform (CEP), targeting engineering education settings. Each of these platforms possess similar mechanisms of knowledge creation, and each align with theories of product development, but adapted to their target context.

In practice, the LCD concept has been shown to foster early-on, continuous, and cost-effective support for a number of elements of the product development process - e.g., supporting the requirement modeling process, enabling easily accessible concept exploration and evaluation, back-up evolving digital models of the developing product, and continuous validation of the detailed solutions being made for the product. The thesis also elaborated on the catalytic properties of an LCD regarding innovation and integration between domains of technologies.

The CEP concept has been shown to foster the implementation of several aspects of the CDIO educational framework - i.e., the so-called CDIO Standards, in particular Standard 7 (Integrated Learning Experiences) and Standard 8 (Active Learning). However, the concept as a whole naturally addresses Standard 3 (Integrated Curriculum) and indirectly Standard 4 (Introduction to Engineering). Furthermore, the platform is framed as a catalyst for discussion about the role of the engineer and places the learning activities in a context more similar to the industry, which clearly addresses CDIO Standard 6 (Engineering Workspaces). Moreover, the thesis has argued for additional roles of the CEP concept that further widens its area of action. This includes acting as an integrator between the academy and the industry that fosters activities of mutual interest - i.e., execution of joint industry/academy research projects, acting as a catalyst for joint development of curricula based on competence needs of the industry and capabilities of the academia and facilitating efficient management of and use by returning students who seek to upgrade their skills. 
An additional outcome of the research represented by this thesis is a set of tools that can be used to enhance development and management process of an engineering education environment. These tools target both the engineering curriculum itself and the teachers and students who are involved in its execution - e.g., The Native Credit (NC) measurement reflects the extent to which a particular element or type of curriculum content connects to the degree program, psychometric measurements (of which some previously unexplored within EE settings) with the purpose of predetermine the coping capabilities of first-year students, and collection of real-time data that allow for continuous monitoring and rapid response to changes in the EE environment.

Moreover, seen as platforms of knowledge creation and learning, the LCD and CEP constitute an approach to engineering education from a product development perspective and vice versa. This also reflects a general theme of this thesis: using an engineering perspective to develop engineering education. The thesis picks up on previous attempts where the engineering educational process is approached using system engineering principles. Individual findings of the research in this thesis have been shown to supplement and extend the literature by placing theory into context - i.e., engineering education settings.

Finally, the properties of the platforms of LCD and CEP as well as the aforementioned engineering approach to engineering education has proved relevant for curriculum development and program management at engineering institutions. This thesis points out several aspects and circumstances where this approach could be beneficial for many involved stakeholders such as students, educators, researchers, and industry.

\subsection{Future Work}

Further development of the CEP concept should be prioritized and could be done in collaboration with an industrial partner that concurrently explores the LCD concept, which currently lacks industrial verification. Also, the integration of the CEP and LCD concepts could be key facilitators for returning students (i.e., engineers active in industry but currently pursuing life-long learning activities). To further explore this opportunity is considered a valuable area for future research.

Moreover, the CEP has proven a useful approach to gain enhancements of EE learning environments as it has been evaluated at the bachelor program of mechanical engineering (see 3.2). However, a reasonable path forward is to try out the concept on other programs at other institutions and to widen the definition of the term "enabling platform". As elaborated in paper [IV], the CEP is proposed to take on other roles that are not explicitly addressed by the CDIO educational framework such as collaboration between academia and industry as well as the proposed platform for integration, management, and use of returning students described in 3.2. Both these aspects of the CEP call for more research. In addition, further work on the CEP concept should formalize the development process of a CEP. Such a process should proposedly be based on a standardized requirements and stakeholders and should ultimately serve as a guide for how a CEP should be implemented in practice.

Furthermore, the concepts developed within this thesis have been implemented at LiU, and a natural continuation is to investigate their applicability in other settings both in Sweden and internationally. As the work relies on generic acceptable theories (SOC, SE, etc.) that are globally accepted, there is no reason it should not be applicable elsewhere. The same holds for some of the underlying approaches that have been required for conducting the research described in this dissertation. For example, the case studies that formed the basis of papers [VI] 
and [VII] required capturing of the necessary data. The process of gathering this data could be seen as generic and therefore applicable for other institutions. Hence, further investigations and verification from others of the proposed metrics or variants would be regarded with anticipation.

Moreover, an extended exploration of the concept of curriculum nativeness should be conducted, and verification of reproducibility at other institutions would be highly anticipated. However, such studies would have to be preceded by a generalizable operationalization of the $\mathrm{NC}$ metric. In any case, papers [VI] and [VII] call for follow-up studies as the first-year students who were the subject of these studies were approaching graduation at the time of writing. One could also imagine formulation of additional research questions that takes advantage of the extended time frame required for completion of the programs that were included in the studies (i.e., three-year bachelor and five-year master programs).

Finally, insights gained following the investigations of the coping measures in paper [VII] (i.e., Sense of Coherence and Self-Efficacy) point towards further discussions regarding how they should and could be applied. In addition to more concrete and empirical research on their use from a program management perspective, the nature of these measurements leaves us with a substantial amount of ethical questions and considerations. Consequently, these questions constitute a particularly adequate field that is subject for research before moving forward. 



\section{References}

1st International Conference on Learning Analytics and Knowledge, Banff, Alberta, February 27-March 1, 2011, as cited in George Siemens and Phil Long, "Penetrating the Fog: Analytics in Learning and Education," EDUCAUSE Review, vol. 46, no. 5 (September/October 2011).

Al-Yagon, M., \& Mikulincer, M. (2004). Socioemotional and academic adjustment among children with learning disorders: The mediational role of attachment-based factors. The Journal of Special Education, 38(2), 111-123.

American Society for Engineering Education. (2006). The Research Agenda for the New Discipline of Engineering Education. Journal of Engineering Education, 95(4), 259_ 261. doi:10.1002/j.2168-9830.2006.tb00900.x

Andreasen, M. M. \& Hein, L. (1986). Integrert produktutvikling. Oslo: Universitetsforl.

Andreasen, M. M. (1980). Syntesemetoder på systemgrundlag-bidrag til en konstruktionsteori (Doctoral dissertation, Lunds tekniska högskola).

Antonovsky, A. (1987). Unraveling the mystery of health: How people manage stress and stay well. Jossey-bass.

Antonovsky, A. (1993). The structure and properties of the sense of coherence scale. Social Science \& Medicine, 36(6), 725-733.

Asimow, M. (1962). Introduction to design. Englewood Cliffs, NJ, Prentice-Hall.

Bains, S., Mitchell, J. E., Nyamapfene, A., \& Tilley, E. (2015, March). Work in progress: Multi-disciplinary curriculum review of engineering education. UCL's integrated engineering programme. In 2015 IEEE Global Engineering Education Conference (EDUCON) (pp. 844-846). IEEE.

Baker, D., Krause, S., \& Purzer, S. Y. (2008, January). Developing an instrument to measure tinkering and technical self-efficacy in engineering. In ASEE Annual Conference and Exposition, Conference Proceedings.

Baker, R. S., \& Inventado, P. S. (2014). Educational data mining and learning analytics. Learning analytics, 61-75.

Bandura, A. (1977). Self-efficacy: Toward a unifying theory of behavioral change. Psychological Review, 84(2), 191-215.

Bandura, A. (1997). Self-efficacy: The exercise of control. W H Freeman/Times Books/ Henry Holt \& Co.Barrows, H. S., \& Tamblyn, R. M. (1980). Problem-based learning: An approach to medical education.

Bennedsen, J., Georgsson, F., \& Kontio, J. (2016). Updated Rubric for Self-evaluation (v. 2.1). In The 12th International CDIO Conference (p. 140). 
Berggren, K. F., Brodeur, D., Crawley, E. F., Ingemarsson, I., Litant, W. T., Malmqvist, J., \& Östlund, S. (2003). CDIO: An international initiative for reforming engineering education. World Transactions on Engineering and Technology Education, 2(1), 4952.

Berkson, L. (1993). Problem-based learning: have the expectations been met?. Academic medicine.

Beuren, F. H., Ferreira, M. G. G., \& Miguel, P. A. C. (2013). Product-service systems: a literature review on integrated products and services. Journal of cleaner production, 47, 222-231.

Biggs, J. (1996). Enhancing teaching through constructive alignment. Higher education, 32(3), 347-364.

Bolognadeklarationen. (2020). Retrieved 1 December 2020, from https://web.archive.org/web/20050215021343/http://www.abo.fi/fa/stuby/bologna/b ologna.htm

Bong, M. (2001). Role of self-efficacy and task-value in predicting college students' course performance and future enrollment intentions. Contemporary Educational Psychology, 26(4), 553-570.

Bonwell, C. C., \& Eison, J. A. (1991). Active Learning: Creating Excitement in the Classroom. 1991 ASHE-ERIC Higher Education Reports. ERIC Clearinghouse on Higher Education, The George Washington University, One Dupont Circle, Suite 630, Washington, DC 20036-1183.

Borrego, M., \& Bernhard, J. (2011). The emergence of engineering education research as an internationally connected field of inquiry. Journal of Engineering Education, 100(1), $14-47$.

Borrego, M., Douglas, E. P., \& Amelink, C. T. (2009). Quantitative, qualitative, and mixed research methods in engineering education. Journal of Engineering education, 98(1), 53-66.

Buniyamin, N., bin Mat, U., \& Arshad, P. M. (2015). Educational data mining for prediction and classification of engineering students achievement. In 2015 IEEE 7th International Conference on Engineering Education (ICEED) (pp. 49-53). IEEE.

BYU Faculty Center. (2003). Activities to enhance student learning based on Kolb's learning dimensions. Focus on Faculty, 14(1), 3.

Cagiltay, N. E. (2008). Using learning styles theory in engineering education. European journal of engineering education, 33(4), 415-424.

Cambridge English Dictionary. (2020). Prescriptive, meaning. Retrieved 1 December 2020, from https://dictionary.cambridge.org/dictionary/english/prescriptive 
Carberry, A. R., Lee, H. S., \& Ohland, M. W. (2010). Measuring engineering design selfefficacy. Journal of Engineering Education, 99(1), 71-79.

Carr, W., \& Kemmis, S. (2003). Becoming critical: education knowledge and action research. Routledge.

CDIO Initiative. (2020). Worldwide CDIO Initiative Homepage. Retrieved 18 November 2020, from http://www.cdio.org/about

Chan, C. K. Y. (2012). Exploring an experiential learning project through Kolb's Learning Theory using a qualitative research method. European Journal of Engineering Education, 37(4), 405-415.

Clifton, C. (2010). "Encyclopædia Britannica: Definition of Data Mining". Retrieved 202009-21.

Cohen, Louis, et al. (2017). Research Methods in Education, Taylor \& Francis Group. ProQuest Ebook Central, http://ebookcentral.proquest.com/lib/linkopingebooks/detail.action?docID=5103697.

Cohen, M., \& Kanter, Y. (2004). Relation between sense of coherence and glycemic control in type 1 and type 2 diabetes. Behavioral Medicine, 29(4), 175-185.

Cohen, M., Ben-Zur, H., \& Rosenfeld, M. J. (2008). Sense of coherence, coping strategies, and test anxiety as predictors of test performance among college students. International Journal of Stress Management, 15(3), 289.

Cooper, K. M., Krieg, A., \& Brownell, S. E. (2018). Who perceives they are smarter? Exploring the influence of student characteristics on student academic self-concept in physiology. Advances in physiology education, 42(2), 200-208.

Crawley, F., Malmqvist, J., Östlund S., Brodeur, D. R., Edström K. (2014). Rethinking Engineering Education: The CDIO Approach: Vol. Second edition. Springer.

Creswell, J. W., \& Clark, V. L. P. (2017). Designing and conducting mixed methods research.

Cross, N., (2008). Engineering design methods: strategies for product design. John Wiley \& Sons Inc.

Darling, C. A., McWey, L. M., Howard, S. N., \& Olmstead, S. B. (2007). College student stress: The influence of interpersonal relationships on sense of coherence. Stress and Health: Journal of the International Society for the Investigation of Stress, 23(4), 215229.

de Graaff, E. (2016). Developments in engineering education and engineering education research in Europe. In Advances in Engineering Education in the Middle East and North Africa (pp. 11-33). Springer, Cham.

Des Marchais, J. E. (1993). A student-centered, problem-based curriculum: 5 years' experience. CMAJ: Canadian Medical Association Journal, 148(9), 1567. 
Deslauriers, L., Schelew, E., \& Wieman, C. (2011). Improved learning in a large-enrollment physics class. science, 332(6031), 862-864.

Donnelly, R., \& Fitzmaurice, M. (2005). Collaborative project-based learning and problembased learning in higher education: A consideration of tutor and student roles in learner-focused strategies. Emerging issues in the practice of university learning and teaching, 87-98.

Dym, C. L., Agogino, A. M., Eris, O., Frey, D. D., \& Leifer, L. J. (2005). Engineering design thinking, teaching, and learning. Journal of engineering education, 94(1), 103120.

Edström, K. (2017). Exploring the dual nature of engineering education: Opportunities and challenges in integrating the academic and professional aspects in the curriculum $(\mathrm{PhD}$ dissertation). Stockholm. Retrieved from http://urn.kb.se/resolve?urn=urn:nbn:se:kth:diva-217315

Edström, K. (2017). Exploring the dual nature of engineering education: Opportunities and challenges in integrating the academic and professional aspects in the curriculum. Doctoral Thesis, KTH Royal Institute of Technology, Stockholm, Sweden.

Edström, K., \& Kolmos, A. (2014). PBL and CDIO: complementary models for engineering education development. European Journal of Engineering Education, 39(5), 539-555.

EHEA. (2020). European Higher Education Area and Bologna Process. Retrieved 7 December 2020, from http://www.ehea.info/page-full_members

ENQA. (2020). European Association for Quality Assurance in Higher Education. Retrieved 7 December 2020, from https://enqa.eu/

Eriksson, M., \& Lindström, B. (2005). Validity of Antonovsky's sense of coherence scale: a systematic review. Journal of Epidemiology \& Community Health, 59(6), 460-466.

Eriksson, M., \& Lindström, B. (2006). Antonovsky's sense of coherence scale and the relation with health: a systematic review. Journal of Epidemiology \& Community Health, 60(5), 376-381.

Evertsson, M., Bankel, J., Enelund, M., Eriksson, A., Lindstedt, P., \& Räisänen, C. (2007). Design-implement experience from the 2nd year capstone course "Integrated design and manufacturing”. 3rd International CDIO Conference2007: MIT, Cambridge, Massachusetts. Biographical Information Tom Steiner has been an engineering educator for, 25.

Farris, P. W., Bendle, N., Pfeifer, P. E., \& Reibstein, D. (2010). Marketing metrics: The definitive guide to measuring marketing performance. Pearson Education.

Ferguson, R. (2012). Learning analytics: drivers, developments and challenges. International Journal of Technology Enhanced Learning, 4(5-6), 304-317. 
Freeman, S., Eddy, S. L., McDonough, M., Smith, M. K., Okoroafor, N., Jordt, H., \& Wenderoth, M. P. (2014). Active learning increases student performance in science, engineering, and mathematics. Proceedings of the National Academy of Sciences, 111(23), 8410-8415.

Goldberg, D. E., \& Somerville, M. (2014). A whole new engineer. ThreeJoy Associates, Inc..

Grose, T. (2017). Engineering School Disrupter. ASEE Prism, 27(1), 18-18. Retrieved November 15, 2020, from www.jstor.org/stable/90015162

Gürel, E., \& Tat, M. (2017). SWOT analysis: a theoretical review. Journal of International Social Research, 10(51).

Gustafsson, G., Newman, D. J., Stafström, S., \& Wallin, H. P. (2002). First-year introductory courses as a means to develop conceive-design-implement-operate skills in engineering education programmes. SEFIrenze 2002, Florence, Italy, 8-11 September 2002.

Hallberg, P. (2013). Low-Cost Demonstrators: Enhancing Product Development with the Use of Physical Representations (Licentiate dissertation). Linköping University Electronic Press, Linköping. Retrieved from http://urn.kb.se/resolve?urn=urn:nbn:se:liu:diva-86668

Hammond, M., \& Wellington, J. (2012). Research methods: The key concepts. ProQuest Ebook Central https://ebookcentral.proquest.com

Heitmann, G. (2005). Challenges of engineering education and curriculum development in the context of the Bologna process. European journal of engineering education, 30(4), 447-458.

Huber, M. T., \& Hutchings, P. (2004). Integrative Learning: Mapping the Terrain. The Academy in Transition. Association of American Colleges and Universities.

Hubka, V., \& Eder, W. E. (1992) Engineering Design: General Procedural Model of Engineering Design. Edition Heurista, Zurich.

Jamison, A., Kolmos, A., \& Holgaard, J. E. (2014). Hybrid learning: An integrative approach to engineering education. Journal of Engineering Education, 103(2), 253-273.

Jesiek, B. K., Newswander, L. K., \& Borrego, M. (2009). Engineering education research: Discipline, community, or field?. Journal of Engineering Education, 98(1), 39-52.

Jones, B. D., Epler, C. M., Mokri, P., Bryant, L. H., \& Paretti, M. C. (2013). The effects of a collaborative problem-based learning experience on students' motivation in engineering capstone courses. Interdisciplinary Journal of Problem-based Learning, $7(2), 2$.

Jørgensen, F., \& Busk Kofoed, L. (2007). Integrating the development of continuous improvement and innovation capabilities into engineering education. European Journal of engineering education, 32(2), 181-191. 
Jørgensen, U. (2007). Historical accounts of engineering education. In Rethinking engineering education (pp. 216-240). Springer, Boston, MA.

Jouannet, C., Berry, P., Melin, T., Amadori, K., Lundström, D., \& Staack, I. (2012). Subscale flight testing used in conceptual design. Aircraft Engineering and Aerospace Technology.

Kek, M. Y. C. A., \& Huijser, H. (2016). Problem-based learning into the future: Imagining an agile PBL ecology for learning. Springer.

Khawaja, M. A., Prusty, G. B., Ford, R. A., Marcus, N., \& Russell, C. (2013). Can more become less? Effects of an intensive assessment environment on students' learning performance. European Journal of Engineering Education, 38(6), 631-651.

Klösgen, W., \& Zytkow, J. M. (Eds.). (2002). Handbook of data mining and knowledge discovery. Oxford University Press, Inc..

Kolb, D. A. (1984). Experiential Learning.

Kolb, D. A. (2014). Experiential learning: Experience as the source of learning and development.

Kolmos, A. (1996). Reflections on project work and problem-based learning. European journal of engineering education, 21(2), 141-148.

Kolmos, A., De Graaff, E., \& Du, X. (2009). Diversity of PBL-PBL learning principles and models. In Research on PBL practice in engineering education (pp. 9-21). Brill Sense.

Kothari, C.R. (2008). Research Methodology: Methods and Techniques. New Age International.

Kozinski, J. A., Evans, E., Usher, K., \& Sheppard, D. (2017, November). A Humanist Engineer by Design. In 2017 7th World Engineering Education Forum (WEEF) (pp. 792-797). IEEE.

Kristensson, P., \& Öhlund, L. S. (2005). Swedish upper secondary school pupils' sense of coherence, coping resources and aggressiveness in relation to educational track and performance. Scandinavian Journal of Caring Sciences, 19(1), 77-84.

Lindström, B., \& Eriksson, M. (2005). Salutogenesis. Journal of Epidemiology \& Community Health, 59(6), 440-442.

Mack, C. A. (2011). Fifty years of Moore's law. IEEE Transactions on semiconductor manufacturing, 24(2), 202-207.

Malmqvist, J., Edstrom, K., Gunnarsson, S., \& Ostlund, S. (2006). The application of CDIO Standards in the evaluation of Swedish engineering degree programs. World Transactions on Engineering and Technology Education, 5(2), 361. 
Mamaril, N. A., Usher, E. L., Li, C. R., Economy, D. R., \& Kennedy, M. S. (2016). Measuring undergraduate students' engineering self-efficacy: A validation study. Journal of Engineering Education, 105(2), 366-395.

Marra, R. M., Rodgers, K. A., Shen, D., \& Bogue, B. (2009). Women engineering students and self-efficacy: A multi-year, multi-institution study of women engineering student self-efficacy. Journal of Engineering Education, 98(1), 27-38.

McIntosh, N. E. (1979). Barriers to implementing research in higher education. Studies in Higher Education, 4(1), 77-86.

Mills, G. E., \& Gay, L. R. (2019). Educational research: Competencies for analysis and applications. Pearson. One Lake Street, Upper Saddle River, New Jersey 07458.

Mitchell, J. E., Nyamapfene, A., Roach, K., \& Tilley, E. (2019). Faculty wide curriculum reform: the integrated engineering programme. European Journal of Engineering Education, 1-19.

Muller, G. (2011). Industry-as-laboratory applied in practice: The boderc project.

National Science Board (US). Task Committee on Undergraduate Science, \& Engineering Education. (1987). Undergraduate Science, Mathematics and Engineering Education: Source materials (Vol. 2). National Science Board, Task Committee on Undergraduate Science and Engineering Education.

nEUROn, the European combat drone demonstrator: Introduction. (2020). Retrieved 8 September 2020, from https://www.dassaultaviation.com/en/defense/neuron/introduction/

Olin College of Engineering. (2020). Retrieved 15 November 2020, from http://www.olin.edu/academics/curriculum/

Pahl, G., \& Beitz, W. (2013). Engineering design: a systematic approach. Springer Science \& Business Media.

Pal, S. (2012). Mining educational data to reduce dropout rates of engineering students. International Journal of Information Engineering and Electronic Business, 4(2), 1.

Pallant, J. F., \& Lae, L. (2002). Sense of coherence, well-being, coping and personality factors: further evaluation of the sense of coherence scale. Personality and Individual Differences, 33(1), 39-48.

Pazicni, S., \& Bauer, C. F. (2014). Characterizing illusions of competence in introductory chemistry students. Chemistry Education Research and Practice, 15(1), 24-34.

Pedersen, K., Emblemsvag, J., Bailey, R., Allen, J. K., \& Mistree, F. (2000). Validating design methods and research: the validation square. In ASME Design Engineering Technical Conferences (pp. 1-12).

Polanyi, M. (2009). The tacit dimension. University of Chicago press. 
Potts, C. (1993). Software-engineering research revisited. IEEE software, 10(5), 19-28.

Power BI | Interactive Data Visualization BI Tools. (2019). Powerbi.microsoft.com. Retrieved 23 September 2019, from https://powerbi.microsoft.com/en-us/

Prince, M. (2004). Does active learning work? A review of the research. Journal of engineering education, 93(3), 223-231.

Pugh, S. (1990). Integrated methods for successful product engineering. Addison-Wesley.

Putman, V. L., \& Paulus, P. B. (2009). Brainstorming, brainstorming rules and decision making. The Journal of creative behavior, 43(1), 29-40.

Redmond, B. F. (2010). Self-efficacy theory: Do I think that I can succeed in my work? Work attitudes and motivation. The Pennsylvania State University, World Campus.

Redmond, B. F. (2020). Self-Efficacy and Social Cognitive Theories - PSYCH 484: Work Attitudes and Job Motivation - Confluence. Retrieved 24 September 2020, from https://wikispaces.psu.edu/display/PSYCH484/7.+SelfEfficacy+and+Social+Cognitive+Theories

Reithlingshoefer, S. J. (1992). The future of nontraditional/interdisciplinary programs: Margin or mainstream. In Virginia Beach, VA. Selected Papers from the Tenth Annual Conference on Nontraditional and Interdisciplinary Programs.

Romero, C., \& Ventura, S. (2010). Educational data mining: a review of the state of the art. IEEE Transactions on Systems, Man, and Cybernetics, Part C (Applications and Reviews), 40(6), 601-618.

Rompelman, O., \& De Graaff, E. (2006). The engineering of engineering education: curriculum development from a designer's point of view. European journal of engineering education, 31(2), 215-226.

Roozenburg, N. F., \& Eekels, J. (1995). Product design: fundamentals and methods.

Säljö, R. (2013). Lärande i praktiken. Ett sociokulturellt perspektiv.

Sandberg, A. (2013). An overview of models of technological singularity. The Transhumanist Reader: Classical and Contemporary Essays on the Science, Technology, and Philosophy of the Human Future, 376-394.

Savin-Baden, M. (2000). Problem-based learning in higher education: Untold stories: Untold stories. McGraw-Hill Education (UK).

Savin-Baden, M. (2007). Challenging models and perspectives of problem-based learning. In Management of change (pp. 9-29). Brill Sense.

Schmidt, H., Boshuizen, H., \& de Vries, M. (1992). Comparing problem-based with conventional education: A review of the University of Limburg medical school experiment. Age and Ageing, 5, 193-198.

Schrage, M. (1999). Serious play: How the world's best companies simulate to innovate. 
Sclater, N., Peasgood, A., \& Mullan, J. (2016). Learning analytics in higher education. London: Jisc. Accessed February, 8(2017), 176.

Seepersad, C. C., Pedersen, K., Emblemsvåg, J., Bailey, R., Allen, J. K., \& Mistree, F. (2006). The validation square: how does one verify and validate a design method. Decision making in engineering design, 303-314.

SEFI - European Society for Engineering Education. (2020). Retrieved 15 September 2020, from https://www.sefi.be/

Short, B. (2009). Imhotep and the origins of ancient Egyptian military medicine. ADF Health, 10(1), 48-50.

Siemens, G., \& Long, P. (2011). Penetrating the fog: Analytics in learning and education. EDUCAUSE review, 46(5), 30.

Singer, G., Golan, M., Rabin, N., \& Kleper, D. (2020). Evaluation of the effect of learning disabilities and accommodations on the prediction of the stability of academic behaviour of undergraduate engineering students using decision trees. European Journal of Engineering Education, 45(4), 614-630.

Smith, R. J. (2020). Engineering | Definition, History, Functions, \& Facts. Retrieved 22 October 2020, from https:/www.britannica.com/technology/engineering\#ref64713

Swedish Foundation for Strategic Research. (2014). Vartannat jobb automatiseras. Retrieved 1 October 2020, from https://strategiska.se/vartannat-jobb-automatiseras/

Taba, H. (1962). Curriculum development: Theory and practice. New York: Harcourt, Brace $\&$ World.

Tao, F., Cheng, J., Qi, Q., Zhang, M., Zhang, H., \& Sui, F. (2018). Digital twin-driven product design, manufacturing and service with big data. The International Journal of Advanced Manufacturing Technology, 94(9-12), 3563-3576.

Terninko, J., Zusman, A., \& Zlotin, B. (1998). Systematic innovation: an introduction to TRIZ (theory of inventive problem solving). CRC press.

Tilley, E., \& Mitchell, J. E. (2015, March). Sense of achievement: Initial evaluation of an Integrated Engineering design cornerstone module. In 2015 IEEE Integrated STEM Education Conference (pp. 114-120). IEEE.

Trap, R., Rejkjær, L., \& Hansen, E. H. (2015). Empirical relations between sense of coherence and self-efficacy, National Danish Survey. Health Promotion International, 31(3), 635-643.

UKÄ. (2020). Swedish Higher Education Authority. Retrieved 1 December 2020, from https://english.uka.se/

Ullman, D. G. (2017). The Mechanical Design Process, 6th edn. 480 p. David Ullman LLC. 
Ulrich, K. \& Eppinger, S., (2015). Product design and development. McGraw-Hill Higher Education.

Vallim, M. B., Farines, J. M., \& Cury, J. E. (2006). Practicing engineering in a freshman introductory course. IEEE Transactions on Education, 49(1), 74-79.

Van den Akker, J. (2007). Curriculum design research. An introduction to educational design research, 37.

Vernon, D. T., \& Blake, R. L. (1993). Does problem-based learning work? A meta-analysis of evaluative research. Academic medicine.

Vygotsky, L. S. (1997). The collected works of LS Vygotsky: Problems of the theory and history of psychology.

Walkington, J. (2002). A process for curriculum change in engineering education. European Journal of Engineering Education, 27(2), 133-148.

Wallin, P. (2015). From Tissue Engineering to Engineering Education Research: Designing in vitro cell microenvironments and undergraduate research experiences. Chalmers University of Technology.

Web of Science (2020). Web of Science Core Collection Advanced Search. Retrieved 6 October 2020, from https://apps.webofknowledge.com/WOS_AdvancedSearch_input.do?SID=D2zDblq6 pBQhaAnRVtw\&product=WOS\&search_mode=AdvancedSearch

World Bank Education Overview : Higher Education (English). (2020) World Bank Education Overview Washington, D.C. : World Bank Group. Retrieved 23 October 2020, from http://documents.worldbank.org/curated/en/610121541079963484/World-BankEducation-Overview-Higher-Education

Yari, S., \& Bakht, T. G. (2012). The relationship between self-efficacy and self-perception with anxiety of examination in high school students. International Journal on New Trends in Education \& their Implications (IJONTE), 3(4).

Yin, R. K. (2014). Case study research: Design and methods. Fifth Edition. Sage publications.

Ying, Y. W., Lee, P. A., Tsai, J. L., Hung, Y., Lin, M., \& Wan, C. T. (2001). Asian American college students as model minorities: An examination of their overall competence. Cultural Diversity and Ethnic Minority Psychology, 7(1), 59.

Zimmerman, B.J. (2001). Social learning, cognition, and personality development. In International Encyclopedia of the Social \& Behavioral Sciences. 
APPENDED PAPERS 



\section{Papers}

The papers associated with this thesis have been removed for copyright reasons. For more details about these see:

http://urn.kb.se/resolve?urn=urn:nbn:se:liu:diva-172681 



\section{FACULTY OF SCIENCE AND ENGINEERING}

Linköping Studies in Science and Technology, Dissertation No. 2121, 2021

Department of Management and Engineering

Linköping University

SE-581 83 Linköping, Sweden

www.liu.se

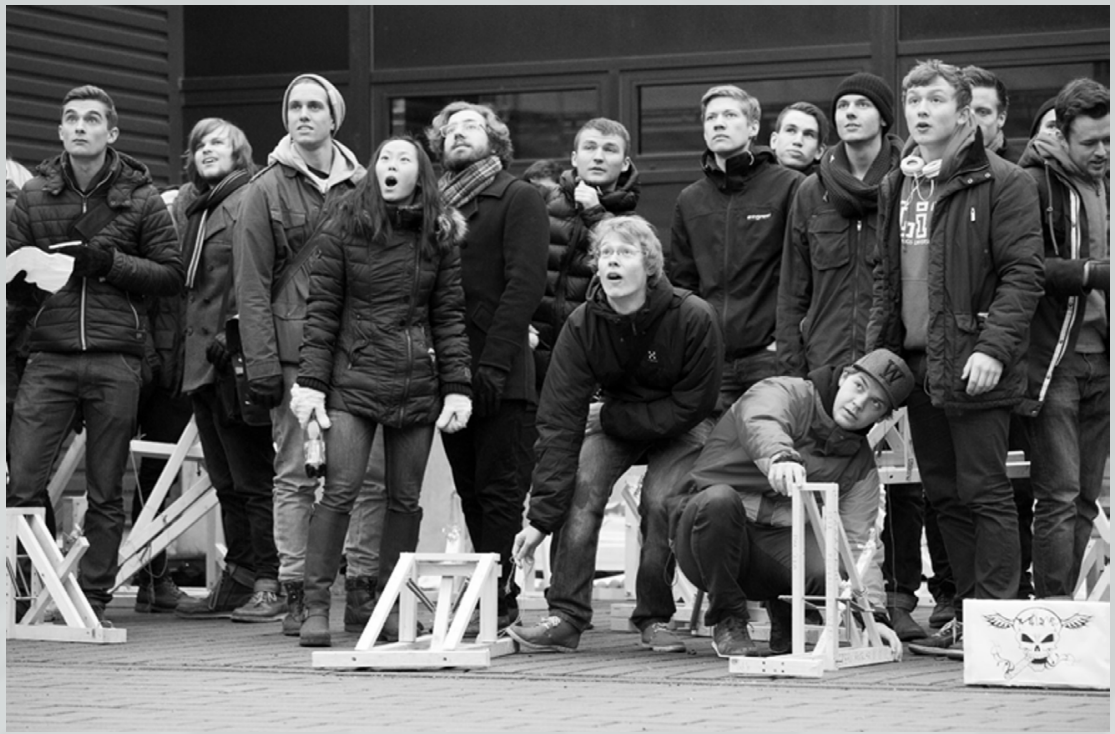

